\title{
Interface Design for Offline Learning
}

\author{
Antero Gandra
}

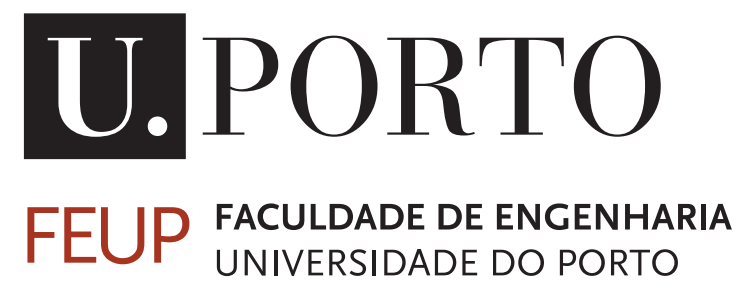

Mestrado Integrado em Engenharia Informática e Computação

Supervisor: Teresa Galvão Dias

July 30,2021 



\title{
Interface Design for Offline Learning
}

\author{
Antero Gandra \\ Mestrado Integrado em Engenharia Informática e Computação
}





\section{Abstract}

Education is a basic need for a society to develop and evolve. Any failure in this field and the future of each citizen and future generations is at risk. Thus, educational systems are continuously studied, analyzed, and adapted to bring more efficient solutions and plans to populations worldwide. With the COVID-19 pandemic, those educational systems were questioned and challenged if proper education could be offered to everyone outside schools, universities, and other educational institutions. As a result, a big part of the world closed their educational institutions, and most students had to stay at home and rely mostly only on technological solutions. For that, education moved from inside the classroom to the student's and teacher's residences.

Various tools and solutions were provided and employed for distance learning, such as video calling applications, like Zoom, Skype, or Google Meets, or other learning platforms with the ability to share files and other educational content, such as Moodle, Microsoft Teams, or Google Classroom. However, these solutions are not yet well adapted for locations and scenarios where access to the internet is limited. In many locations, students do not have access to the internet at home or even at school, contributing to students quitting their studies more quickly. According to Unicef, by November 2020, two-thirds of the world's school-age children have no internet access at home.

Among those different solutions, we can find some offline alternatives, but they are not well adapted to the classroom environment. This work proposes an application focused on providing an autonomous experience aimed at students who, even though they or their parents might own mobile devices, do not have easy access to the internet or the accompaniment of a teacher or tutor in the learning process. Another important objective is the design of a working tool for teachers and educators, where the process of creating class content is as intuitive and straightforward as possible.

The application intends to motivate the students to keep a study routine and to encourage the learning experience. Allowing multiple content formats but providing at the same time a solid and joyful activity is one of the principles behind this solution. This solution covers the gaps left by other educational platforms by working offline and on mobile devices with low specs, with content well-formatted and adapted to a healthy and reliable classroom environment. The solution is divided into two parts: the content creation module, aimed to be used by teachers and educators, and the learning module, designed and focused on the students.

The approach to reach teachers and students of locations with poor internet access or even none relied upon communication done with none or the minor use of the internet: telephone calls, emails, and Whatsapp messages. The user testing of the prototypes was performed remotely, applying the suitable user-testing methods within what was possible to do. As challenging as it could be, the contacts made regarded this solution as beneficial and impactful.

Keywords: Human-Computer Interaction, User Experience, Interface Design, Education, App 


\section{Acknowledgements}

To my family, for all the support they provided during the last 6 years:

My mother, Graça Gandra, for the energy and strength to not quit my goals.

My father, Antero Gandra, for his patience and encouraging me to be creative.

My sister, Graça Gandra, for being such an inspiration for me and showing me that there are not enough barriers when we are chasing our dreams.

My grandparents, for being so supportive all these years.

My cousins, for making me unwind and relax more, with a special shoutout to my cousin Pedro Campos for the best carpool rides to Porto.

To my friends, for all the company provided:

My friends from Póvoa, especially André Cruz, Laura Ivaškevičiūte, and Tiago Mariz, for reminding me that great friendships survive the passage of time.

My friends from FEUP, for not letting me feel alone through all this effort.

My friend João Damas, for supporting me and accompanying me through all my crazy ideas.

To my supervisor, Teresa Galvão, for all the helpful guidance and for accepting my dissertation proposal. Thanks for making this happen.

To all the teachers involved in this process: Maria do Céu, Carlos Incanha, Sica Sanha, Jbraima Sissé, Salvador Beifa, Sabastiana Lopes, Samoel Djy, Maria Gomes, Aladji Fati, Marcelino Gomes, Euclides, Muscuta Quebe, António Nacia, Daniel Sanha, Djelma Fati, Joia Ja, Francisca de Barros, Isolina Ramos, Porfiria Monteiro and Zulmira Duúsine.

To Mustafa Fati, for helping me reach almost all these contacts.

To teacher Maria do Céu's pupils, for being such great validators.

I hope someday this solution or a similar one can help you break more barriers and obstacles in education. This was all for you.

Antero Gandra 
"Educating the mind without educating the heart is no education at all."

Aristotle 


\section{Contents}

1 Introduction 1

1.1 Context ......................... 1

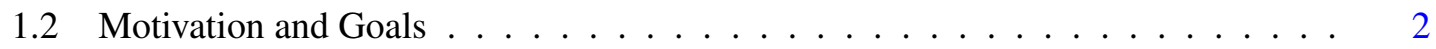

1.3 Document Structure . . . . . . . . . . . . . . . . . . . . 2

2 State of the Art 3

2.1 Mobile Learning . . . . . . . . . . . . . . . . . . 3

2.1.1 Design Principles . . . . . . . . . . . . . . . . . 4

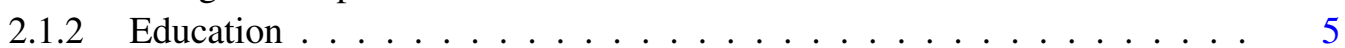

2.2 Challenges, Issues and Opportunities . . . . . . . . . . . . . . . 6

2.2.1 Challenges and Issues . . . . . . . . . . . . . . . . . . . 6

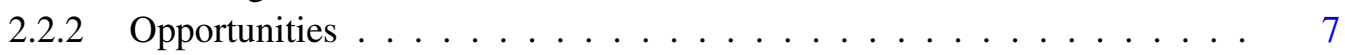

2.3 Methodologies and Frameworks . . . . . . . . . . . . . . . 8

2.3.1 Interaction Design and Human-Centered Design _ . . . . . . . . . 8

2.3.2 Fundamental Principles of Interaction . . . . . . . . . . . . . . . 9

2.3.3 Lifecycle Models . . . . . . . . . . . . . . . . . . . . . . . . . 10

2.3 .4 FRAME Model . . . . . . . . . . . . . . . . . . . . . . . . . . . . 14

2.3.5 Experimental Design . . . . . . . . . . . . . . . . . . . . . . 19

2.4 Related Work . . . . . . . . . . . . . . . . . . . . . . 22

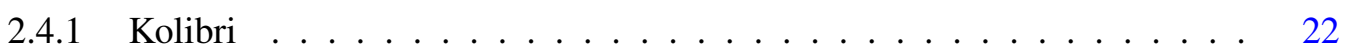

2.4 .2 Rumie . . . . . . . . . . . . . . . . . . . . 23

2.4 .3 Ustad Mobile . . . . . . . . . . . . . . . . . . . . . . . 23

2.4.4 Summary and App Comparison . . . . . . . . . . . . . . . 24

3 Problem and Proposed Solution $\quad 25$

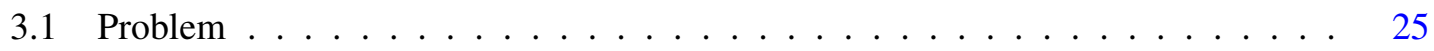

3.2 Proposed Solution . . . . . . . . . . . . . . . . . . . 26

3.2.1 Conceptual Model . . . . . . . . . . . . . . . . . . . . . 26

3.2 .2 System Architecture . . . . . . . . . . . . . . . . . . . . . 26

3.2 .3 Methodologies . . . . . . . . . . . . . . . . . . . 27

3.2 .4 Prototyping Tools . . . . . . . . . . . . . . . . . . . . 28

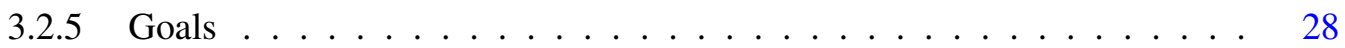

4 Requirements $\quad 29$

4.1 Students App . . . . . . . . . . . . . . . . . . . . . . . . . . . . 29

$4.1 .1 \quad$ FRAME Model . . . . . . . . . . . . . . . . . . . . . . . . . . . . 29

4.1 .2 Requirements . . . . . . . . . . . . . . . . . . . . 34

4.2 Teachers App . . . . . . . . . . . . . . . . . . . 34 


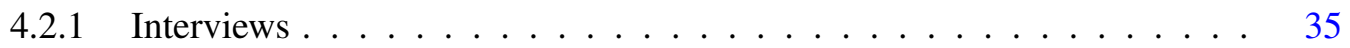

4.2 .2 Results . . . . . . . . . . . . . . . . . 35

4.2 .3 Requirements . . . . . . . . . . . . . . . . . 38

4.3 Use Cases Diagram . . . . . . . . . . . . . . . . . . . . . . . 38

5 Design 41

5.1 Personas .................................... 41

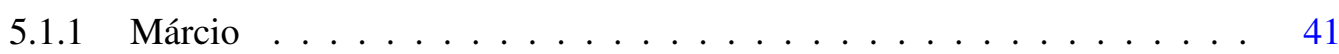

$5.1 .2 \quad$ Luzia . . . . . . . . . . . . . . . . . . . 42

5.1 .3 Adesh . . . . . . . . . . . . . . . . . 42

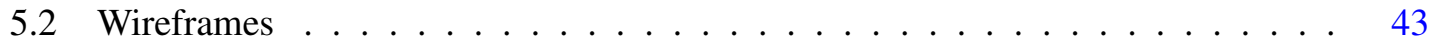

5.2 .1 Student Main Screens _ . . . . . . . . . . . . . . . . . . 43

5.2 .2 Settings Screens . . . . . . . . . . . . . . . . . . 46

5.2 .3 Lessons Screens . . . . . . . . . . . . . . . . . . . . 46

5.2 .4 Teachers Main Screens _. . . . . . . . . . . . . . . . . . . 47

5.2.5 Content Creation Screens . . . . . . . . . . . . . . . . . . 48

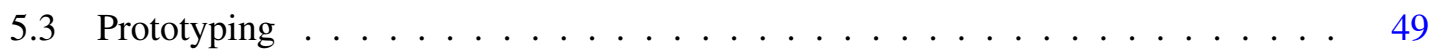

5.3 .1 Teachers App . . . . . . . . . . . . . . . . . . . . . . 49

$5.3 .2 \quad$ Students App . . . . . . . . . . . . . . . . . . . . . . . . 49

6 Evaluation

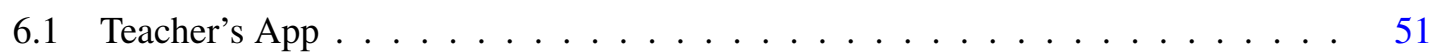

6.1 .1 Methodology ..................... 51

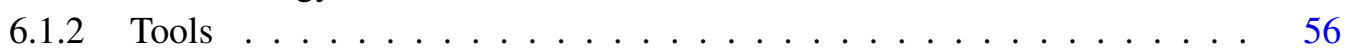

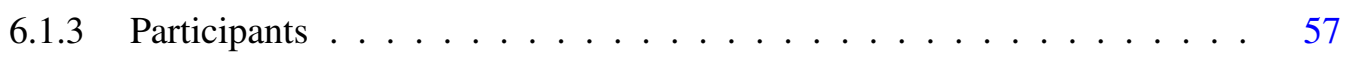

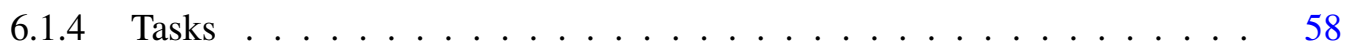

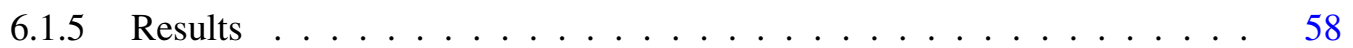

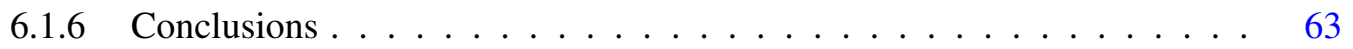

6.2 Student's App . . . . . . . . . . . . . . . . . . . . . . . . 64

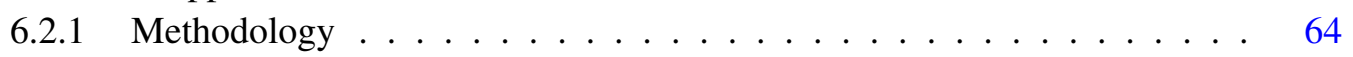

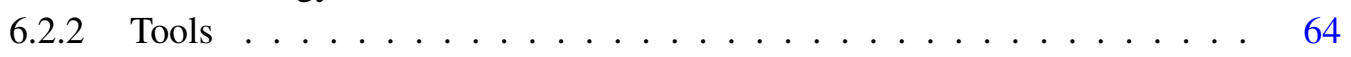

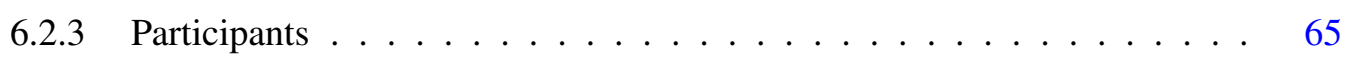

6.2 .4 Tasks ............................ 65

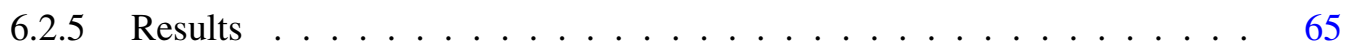

6.2 .6 Feedback . . . . . . . . . . . . . . . . . . . . 69

6.2 .7 Conclusions . . . . . . . . . . . . . . . . . . . . . . . 69

7 Conclusions and Future Work $\quad 71$

7.1 Main Results . . . . . . . . . . . . . . . . . . . . . 71

7.2 Future Goals . . . . . . . . . . . . . . . . . . . . 72

$\begin{array}{ll}\text { A Personas } & 73\end{array}$

B Intreview Script 77

B.1 English Version . . . . . . . . . . . . . . . . . . . . . . . . 77

B.2 Portuguese Version . . . . . . . . . . . . . . . . 78

$\begin{array}{ll}\text { C Lesson Content Wireframes } & 79\end{array}$ 
D Teachers App Designs $\quad 81$

D.1 Homepage . . . . . . . . . . . . . . . . . . . . . 81

D.2 Lesson Screens . . . . . . . . . . . . . . . . . . . . . . . . . . . 82

D.3 Profile Screens . . . . . . . . . . . . . . . . . . . . . . . . . 82

D.4 Share Screens . . . . . . . . . . . . . . . . . . . . . . . . 83

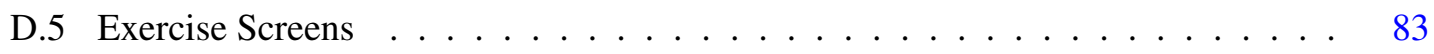

D.6 Solution Selection Screens $\ldots \ldots \ldots$. . . . . . . . . . . . . . . . 84

E Students App Designs $\quad 85$

E.1 Main Screens . . . . . . . . . . . . . . . . . . . . . . . . . 85

E.2 Library Screens . . . . . . . . . . . . . . . . . . . . . . 86

E.3 Lesson Screens . . . . . . . . . . . . . . . . . . . . . . . . . . 86

$\begin{array}{lr}\text { References } & 87\end{array}$ 


\section{List of Figures}

2.1 The Seven Stages of Action . . . . . . . . . . . . . . . . . . . . 10

2.2 Star Lifecycle . . . . . . . . . . . . . . . . . . . . . . . . . . . . 11

2.3 Usability Engineering Lifecycle . . . . . . . . . . . . . . . . . . . . . . 12

2.4 The FRAME Model . . . . . . . . . . . . . . . . . . . . . . . . . . . . . . . . . . 14

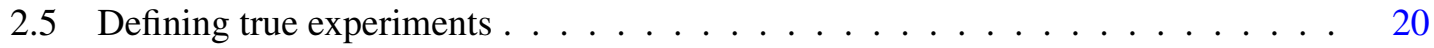

2.6 Experiment Structures _. . . . . . . . . . . . . . . . . . . . . 21

2.7 Kolibri Channels . . . . . . . . . . . . . . . . . . . . . . . . . 22

2.8 Rumie on Browser . . . . . . . . . . . . . . . . . . . . . . . 23

2.9 Ustad Mobile; On the left: Learner Screen; On the right: Educator Screen . . . . 24

3.1 Conceptual Model . . . . . . . . . . . . . . . . . . . . . . . . . . 26

3.2 Architecture Model . . . . . . . . . . . . . . . . . . . . . . 27

4.1 Age and Gender Distribution . . . . . . . . . . . . . . . . . . . . . . 36

4.2 Smartphone and Internet Access . . . . . . . . . . . . . . . . . . 36

4.3 Carreer years distribution and Education Levels . . . . . . . . . . . . . . . . . . . . 37

4.4 Technology Usage in the workplace . . . . . . . . . . . . . . . . 37

4.5 Use Cases Diagram . . . . . . . . . . . . . . . . . . . . . . . . . . . . . . . . 39

5.1 Students Homepage . . . . . . . . . . . . . . . . . . . . . . . . 44

$5.2 \quad$ Students Personal Page $\ldots \ldots \ldots \ldots \ldots$. . . . . . . . . . . . . . . . 45

5.3 Students Sharing Page . . . . . . . . . . . . . . . . . . . 45

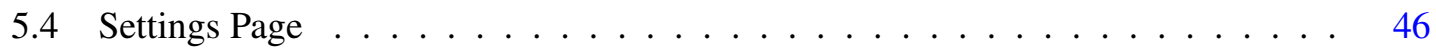

5.5 Students Lesson Screens _ . . . . . . . . . . . . . . . . . . . . . . . . 47

5.6 Teacher Main Screens . . . . . . . . . . . . . . . . . . . . . . . . . . . . 48

5.7 Content Creation Screens . . . . . . . . . . . . . . . . . . . . . . . . 48

5.8 Teachers Screens with instructions . . . . . . . . . . . . . . . . . . . 49

5.9 Students Main Screens _ . . . . . . . . . . . . . . . . . . . . . 50

6.1 Contacts Shared . . . . . . . . . . . . . . . . . . . . 52

6.2 Methodology Scheme . . . . . . . . . . . . . . . . . . 53

6.3 Interaction with the contacts $\ldots \ldots \ldots \ldots \ldots$

6.4 Task 1 Direct Path Heatmap $\ldots \ldots \ldots$. . . . . . . . . . . . . . . . . 59

6.5 Task 2 Direct Path Heatmap . . . . . . . . . . . . . . . . . . . . . . . 59

6.6 Task 3 Direct Path Heatmap ．.. . . . . . . . . . . . . . . . . . . . . . . 60

6.7 Task 4 Direct Path Heatmap $\ldots \ldots \ldots$. . . . . . . . . . . . . . 61

6.8 Task 5 Direct Path Heatmap . . . . . . . . . . . . . . . . . . . . . 61

6.9 Task 6 Direct Path Heatmap $\ldots \ldots \ldots$. . . . . . . . . . . . . . 62

6.10 Task 7 Direct Path Heatmap $\ldots \ldots \ldots$. . . . . . . . . . . . . 63 
6.11 Task 1 Direct Path Heatmap _ . . . . . . . . . . . . . . . . . . . . 66

6.12 Task 2 Direct Path Heatmap _ . . . . . . . . . . . . . . . . . . . . . 67

6.13 Task 3 Direct Path Heatmap . . . . . . . . . . . . . . . . . . . . . . 67

6.14 Task 4 Direct Path Heatmap $\ldots \ldots$. . . . . . . . . . . . . . . . 68

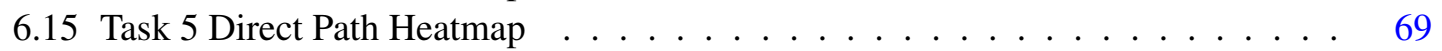




\section{List of Tables}

2.1 Distance Learning Generations . . . . . . . . . . . . . . . . . . . . . . . . . . . 4

2.2 Lifecycle Comparison . . . . . . . . . . . . . . . . . . . . 14

2.3 Device Aspects . . . . . . . . . . . . . . . . . . . . . . . . . . . . . . . . . . . . . . . . . .

2.4 Learner Aspects . . . . . . . . . . . . . . . . . . . . 16

2.5 Social Aspects . . . . . . . . . . . . . . . . . . . . . 17

2.6 Device Usability Intersection . . . . . . . . . . . . . . . . . . . 17

2.7 Social Technology Intersection . . . . . . . . . . . . . . . . . . . . 18

2.8 Interaction Learning Intersection . . . . . . . . . . . . . . . . . . . . . . 19

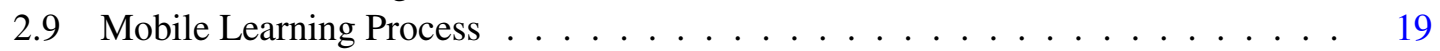

2.10 Type Of Experiment Designs . . . . . . . . . . . . . . . . . . . . 21

2.11 Offline App Comparison . . . . . . . . . . . . . . . . . . 24

3.1 Prototype Tools Comparison . . . . . . . . . . . . . . . . . . 28

4.1 Students App Key Requirements . . . . . . . . . . . . . . . . . . . . . . . . . . . . . . 34

4.2 Teachers App Key Requirements . . . . . . . . . . . . . . . . . . . . . 38

6.1 Teachers App Results Overview . . . . . . . . . . . . . . . . . . . 64

6.2 Students App Results Overview . . . . . . . . . . . . . . . . . 70 


\section{Abbreviations}

COLL Contextual Lifelong Learning

FRAME Framework for the Rational Analysis of Mobile Education

PC Personal Computer

PDA Personal Digital Assistant

SMS Short Message Service

UI User Interface

UID User Interface Design

UNESCO United Nations Educational, Scientific and Cultural Organization 



\section{Chapter 1}

\section{Introduction}

The learning process is continuous throughout life, but there needs to be a solid foundation in education in order for a population to progress. Thus, it is an essential pillar in society's development, and it is necessary to provide quality education. There is a constant study in the existing educational systems to make the teaching process as efficient and evolved as possible.

With the rise of digital technologies, new teaching methods were developed to bring more practical and advanced education materials to the learners' hands and more straightforward tools for the teachers. These tools are put to the test when educational activities change forcibly in case of a catastrophe. With the latest pandemic, governments were forced to adopt new methodologies so students could continue to learn without risking their health.

Most of the solutions were possible with the use of video calling between students and their teachers. In cases where distance learning is inexistent or even impossible, the students are left alone. This situation is recurrent in developing countries, where the majority of the educational activity is presential, and the learning activity is entirely dependent on the teacher.

With new technologies, the educational activity can adapt to bring school to the students' homes and make the learning activity as autonomous as possible if the students cannot meet their teachers.

\subsection{Context}

Mobile learning can be interpreted as educational outlines where the dominant technologies are handheld devices from a techno-centric perspective [19], as an extension of e-learning, as learning outside the classroom or even on the mobility of the learner [21].

This dissertation focuses on bringing a mobile learning solution that can work in developing countries, where education is needed for a societal pathway towards economic growth and gender equity [11]. 


\subsection{Motivation and Goals}

The motivation to choose and propose this theme was to think about the number of students, especially children in developing countries, where the worst teaching conditions are already found, who were left without access to schools and contact with their teachers and educators.

With this, the idea of creating interfaces to prototype a mobile application arose, which tries to solve these issues, being able to work offline, on any mobile device, to provide equitable and non-discriminatory teaching

The work to be conducted will aim to:

- Realize a previous study, where it will be evaluated the different types of computer interaction and current applications;

- Analyze the success and failure cases of the implementation of applications in teaching and other solutions;

- Select the use cases to implement in distance education applications;

- Develop and evaluate prototypes that aim to implement the solutions to this problem.

\subsection{Document Structure}

This dissertation plan includes six more chapters besides the introduction. Chapter 2 defined state of the art concerning the methodologies, challenges, issues, opportunities, and related work with this thesis. Chapter 3 focuses on the problem and the suggested solution to solve it, reviewing the previous chapter's topics. Chapter 4 describes the requirements phase, where the apps' requirements were identified and listed. Then, in chapter 5, the design process is described, from requirements to wireframes to high fidelity prototypes. Finally, chapter 6 is destined for the evaluation of the prototypes designed, describing the evaluation process and the results from it. To conclude, chapter 7 points to the conclusions of this dissertation, including the future steps to be taken. 


\section{Chapter 2}

\section{State of the Art}

In this chapter, we describe the various conclusions taken from multiple studies and applications with similar nature. We can see the numerous possibilities of methodologies to approach this dissertation, its pros and cons, and how they were already applied in projects that aimed for the same impact in our world.

\subsection{Mobile Learning}

Mobile learning is part of the last generations of distance learning due to the new realities of the modern world's technologies. The five generations of distance learning, based on the delivery technologies [5], are represented in table 2.1

\begin{tabular}{|l|l|l|}
\hline Generation & Model & Delivery Technologies \\
\hline First Generation & The Correspondence Model & Print \\
\hline Second Generation & The Multi-Media Model & $\begin{array}{l}\text { Print, Audio tapes, Video } \\
\text { Tapes, Computer Based } \\
\text { learning, Interactive Video }\end{array}$ \\
\hline Third Generation & The Tele-Learning Model & $\begin{array}{l}\text { Audio teleconferencing, } \\
\text { videoconferencing, } \\
\text { audio-graphic } \\
\text { communication, broadcast } \\
\text { TV/Radio }\end{array}$ \\
\hline Fourth Generation & The Flexible Learning Model & $\begin{array}{l}\text { Interactive Multimedia } \\
\text { Online, Internet based access } \\
\text { to www resources, Computer } \\
\text { Mediated Communications }\end{array}$ \\
\hline
\end{tabular}




\begin{tabular}{|l|l|l|}
\hline Generation & Model & Delivery Technologies \\
\hline Fifth Generation & $\begin{array}{l}\text { The Intelligent Flexible } \\
\text { Learning Model }\end{array}$ & $\begin{array}{l}\text { Interactive Multimedia } \\
\text { Online, Internet based access } \\
\text { of www resources, Computer } \\
\text { Mediated Communication, } \\
\text { using automated response } \\
\text { systems, Campus Portal } \\
\text { access to Institutional } \\
\end{array}$ \\
& Process and Resources \\
\hline
\end{tabular}

Table 2.1: Distance Learning Generations

In countries such as Nigeria, governments have already tried out some procedures on distance learning related to nomadic groups [1] such as "Literacy by radio," mobile schools, which could be instantly assembled, and TV/radio education. It concludes that radios are way more affordable, accessible, and handier than televisions, but that education organizations in these countries should make the correct approach with mobile devices.

With that in mind, this section will focus on the two main areas directly related to mobile learning: Design and Education.

\subsubsection{Design Principles}

To design an app destinated to mobile learning, we first should address the fundamentals needed for the mindset required to create such solutions and the problems and opportunities raised.

There are eight principles related to distance education and the format and the design of educational materials on mobile devices [3]. The UID (User Interface Design) principles enumerated are:

1. Equitable use - the contents offered should be accessible for anyone anywhere, delivering content in a format as simple as possible;

2. Flexible use - The education content provided should give the student space to use it the way he wants;

3. Simple and intuitive - Avoid redundant complexity;

4. Perceptible information - use captions, descriptors, and transcriptions in the content offered;

5. Tolerance for error - minimize the risks and consequences of mistakes;

6. Low physical and technical effort - the tasks offered should be required to be solved with the minimal steps possible;

7. Community of learners and support - Associate learners, based on the preferences they prefer. 
8. Instructional climate - Push regular reminders

Even though the app design should make it easy to use for everyone, the education process's focus is better done when targetting the young groups. With that, the design should be ready for children's mindset. Research also conclude that:

- Children wanted to see in future computers more humanized capabilities: it should be able to talk to them, being intelligent, and having a personality [17].

- The criteria for the systems image was that it should be self explainable and instantly recognized by the user [17], distinguish the different activities and that the rest of the system components should share the same metaphor. The final interface image was a humanoid directly linked to the other system functionalities via different body parts .

When aiming for student retention, a study sought to ascertain students' attitudes and opinions on mobile learning effectiveness, shows us that students like receiving short information related to feedback on assignments [5], important dates, grades, and examination results.

\subsubsection{Education}

With the educational process evolving constantly, the learning activity stopped being only associated to specific locations, and people now learn continuously in daily situations. This process can be described as Contextual Lifelong Learning (COLL) [16] , and its characteristics are:

- Achieving knowledge is not restricted to pre-specified times or places. However, it happens whenever there is a break in the flow of the daily routine performance and the student reflects on the current situation, chooses to approach a problem, to share an idea, or to gain an understanding;

- Formal education cannot accommodate people with all the information and skills they need to earn throughout a lifetime. Therefore, people will regularly need to improve their skills to discuss immediate obstacles and participate in continuing vocational and professional development.

With these features' reconceptualization, the COLL environments are not pre-specified but created through the learning activity [17]. They also cannot be decomposed into elements independent of the learner and are constructed dynamically by learners interacting with their surroundings. Other essential conclusions with this research are:

- Children want to work in groups, but their work products should be kept private. Their preferences for seeking help with a problem were mostly from a friend.

- Children disliked using computers where the processing speed was slow, which cannot be considered a problem anymore, with the significant advance in processing speed in the last years. 
- The platform designed should support personal learning with projects that could include multiple contexts, including school, home, or even the outdoors, to capture and annotate everyday events.

Mobile phones are widely used in informal education since phones are not allowed during school hours [4] [2]. We use them to call colleagues and friends to see if they can help us or help them reciprocally, to see their problem-solving knowledge.

This idea of mutual help and mutual lifestyle support is popular in African traditional culture. The famous proverb "Umuntu ngmuntu ngabantu" translates to "you are who you are because of others". The research results concluded that:

- Mobile phones work pretty well as tools of the learning process's aid since while teachers could focus on the learning process, the learners were very open to using this kind of technology.

- A mobile audio encyclopedia is of immense interest in African learners' case since access to paper is limited, and there's a strong African oral tradition.

\subsection{Challenges, Issues and Opportunities}

\subsubsection{Challenges and Issues}

This list contains the following challenges when designing for mobile learning:

- The first challenge identified was the problems we could verify when using PDAs or even mobile phones with keyboards. The learning resources were scarce, and the media content formats were mostly only SMS texts and images [3]. The reality of this challenge changed years ago about device variability, being now the norm being a touch smartphone, without physical keypads and small screens. The mobile market has changed, and so does the nature of this challenge. The device variability now is based on the phone specifications related to the phone's performance, such as battery and processing power. Students generally want to learn on their own devices since those devices' features are already well known and used by their owners.

- As also identified in the list of challenges, slow download speed and limited internet access are some of the biggest challenges [3] of this thesis since we want the device to work mostly offline. With this, the interface design will be taking into account the autonomy of its user, and we will ensure that even if the user spends more time offline than he should, he won't lose his passion for learning through the app.

- Related to the challenges brought by small screen sizes and lacking color, resolution, and contrast [3], since the mobile market standards changed, as in the 1st challenge presented, there have been many studies related to designing responsive apps for different smartphone 
sizes and screen resolutions. Since the experience is one from one app and not from a website, we can use the screen's full size and not be cluttered by the web browser interface elements.

- Regardless of the challenge raised by awkward text input [3], this issue will not be a challenge anymore since smartphone keyboards use mostly the qwerty format. Now, keyboards have many functionalities related to the way the user type. The user can download different keyboard schemes and languages, which is not considered tedious and time-consuming.

- Memory consumption will be a fundamental challenge in the process [3] since the app is designed to work offline. We will also discuss the use of external memory as it appears as a possibility discovered by this paper's reading. Instead of using the internet to download content to be displayed offline, sharing a USB that connects to mobile devices might be an exciting solution in cases where there is no internet availability in a long-range.

Since the app design focuses on people in conditions where internet connection is scarce, nomadic populations should use it. The challenges of mobile education for migratory communities [1] are :

- The risk that nomad populations might not want to embrace such solutions. The solution recommended by the author was an awareness campaign, so the concept of mobile phone usage in daily life wasn't such confusing.

- The cost related to these kinds of solutions. Government action might be required to help in this field.

- The monitoring and evaluation of the educational program that would require non-governmental and community-based organizations to act.

The app should also instruct the user to be more autonomous, to avoid quitting education as long as possible. Research [5] shows that:

- Poor network conditions mostly restrict mobile learning.

- Withdrawals' major factors were mostly personal such as the absence of interaction with fellow students and lack of time due to job and family responsibilities. Non-personal factors were insufficient academic support and information.

\subsubsection{Opportunities}

When designing for mobile learning, the following opportunities listed are:

- The experience will be cost-free, as in the case of many m-learning opportunities, outside the mobile device's investment, being it a phone or a tablet [3]. The authors also refer to a critical point, that is the fact that laptops and PCs are more expensive. The size and portability of mobile devices is a plus. 
- The second opportunity refers to the various multimedia interactive content that can be offered via mobile devices [3]. The app should deliver different multimedia and content types to give the most immersive learning experience we can. The device capabilities such as images and sounds are essential components to what we want to offer and study.

- The last opportunity refers to continuous and situated learning support [3]. Mobile learning can offer ongoing learning support since the students can do the learning activities in multiple locations. With that, we can offer a more inclusive and higher quality education.

The benefits identified when we introduce nomadic populations to mobile learning [1] are :

- The possibility for nomadic people to acquire literacy without disruption of their lifestyles

- The need to only use one mobile learning system, without the need to change between different schools

- The acquisition of the interactional and transactional skills needed for people they meet

- The development of the sense that education is a basic need to survive in this modern world

A survey [5] done shows us that:

- Mobile learning can be helpful since it provides instant support.

- Mobile learning brings new learning opportunities.

- Mobile learning is flexible since students can learn anywhere, anytime, and improve communication between students and teachers.

Research [17] also concludes that:

- The mobile learning approach helps people manage their lives more efficiently to perform learning activities daily.

- The context of mobile learning more strongly mediates itself than classroom instruction. It includes time and location, the learner's trajectory, goals, motivation, the surrounding resources, co-learners, and other available conversants.

\subsection{Methodologies and Frameworks}

\subsubsection{Interaction Design and Human-Centered Design}

Everything artificial is designed, but not every design involves physical elements. Interaction design surges as the type of design that embodies the ways people interact with technology. It tries to achieve people's perceptions to these three questions: what's to be done, what's happening, and what happened. Working with these perceptions involves principles related to art, psychology, and design, to guarantee positive and enjoyable experiences [13]. 
As Interaction Design appears as a focus area, Human-Computer Design (HCD) corresponds to the philosophy and methods that assure that the designs match the people's demands and skills for those which the designs are meant [13].

\subsubsection{User-Centered Design}

User-Centered design has a slight difference from Human-centered design, as it changes the way technology is designed. It doesn't have a humanistic approach in terms of human interests and has a goal-oriented focus on predetermined technological problems, not concentrating so much on emotional maneuverings [6].

\subsubsection{Fundamental Principles of Interaction}

In the interaction between a person and a product, there is a need to explore how it works. That constitutes Discoverability, the way a user discovers the whats and hows related to a product's usability. Discoverability is based on six concepts:

1. Affordances - the relationship between an object's properties and how the user thinks they can use it

2. Signifiers - the indicators that communicate appropriate behaviors

3. Constraints - the clues that limit the set of possible actions

4. Mappings - the relation between elements of two sets of things

5. Feedback - the communication of the results of an action

6. Conceptual models - an uncomplicated explanation of how something works

\subsubsection{The Seven Stages of Action}

These principles are brought as insights into the seven stages of action as showm in figure 2.1 . The seven stages of action are a cycle of questions to ask, and each step demands a unique design strategy. The questions are:

1. What do I want to accomplish?

2. What are the alternative action sequences?

3. What action can I do now?

4. How do I do it?

5. What happened?

6. What does it mean? 
7. Is this okay? Have I accomplished my goal?

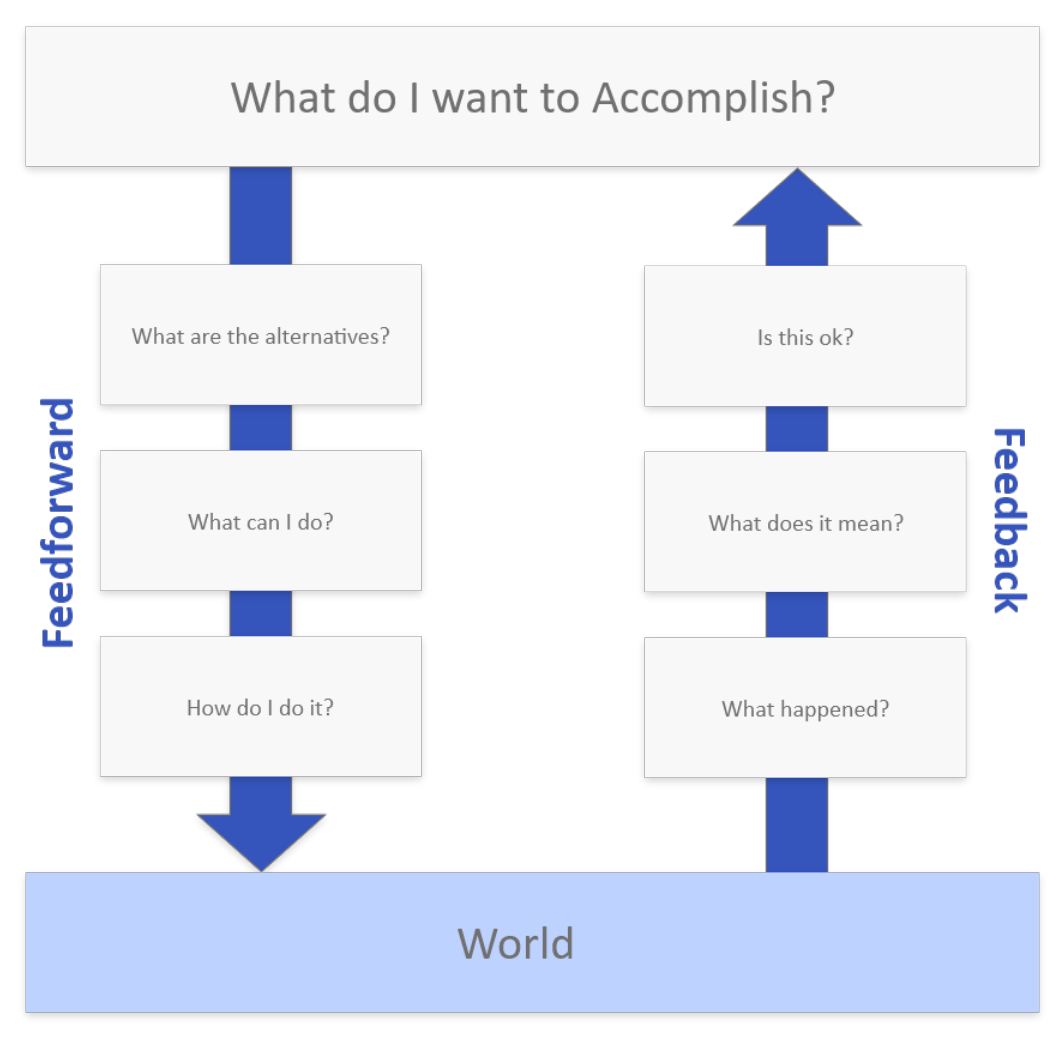

Figure 2.1: The Seven Stages of Action

Feedforward relies on the usage of signifiers, constraints, and mappings, informing the user when he questions the execution of a process. Feeback comes as the result of the consequence of an action, where the conceptual model is present. Ideally, these phases are presented to recognize the information that should match the user needs promptly.

\subsubsection{Lifecycle Models}

From the different lifecycle models used when managing the design process for a product, we can distinguish different lifecycles based on their usage:

- for software development - waterfall model, spiral model and many others

- for Human-Computer Interaction - mainly the star model and the Usability Engineering model.

Since this dissertation will focus primarily on Human-Computer interaction, we analyze the star lifecycle and the usability engineering lifecycle below. 


\subsubsection{Star Lifecycle}

Hix and Harston proposed model 2.2, which represents a star that has the evaluation step as the focal point. Evaluation is encouraged since it is the phase where usability data is gathered. This model allows the design to be started in any process of the lifecycle [7]. It also ensures that evaluation is not done only in the end, being relevant after any lifecycle stage [18].

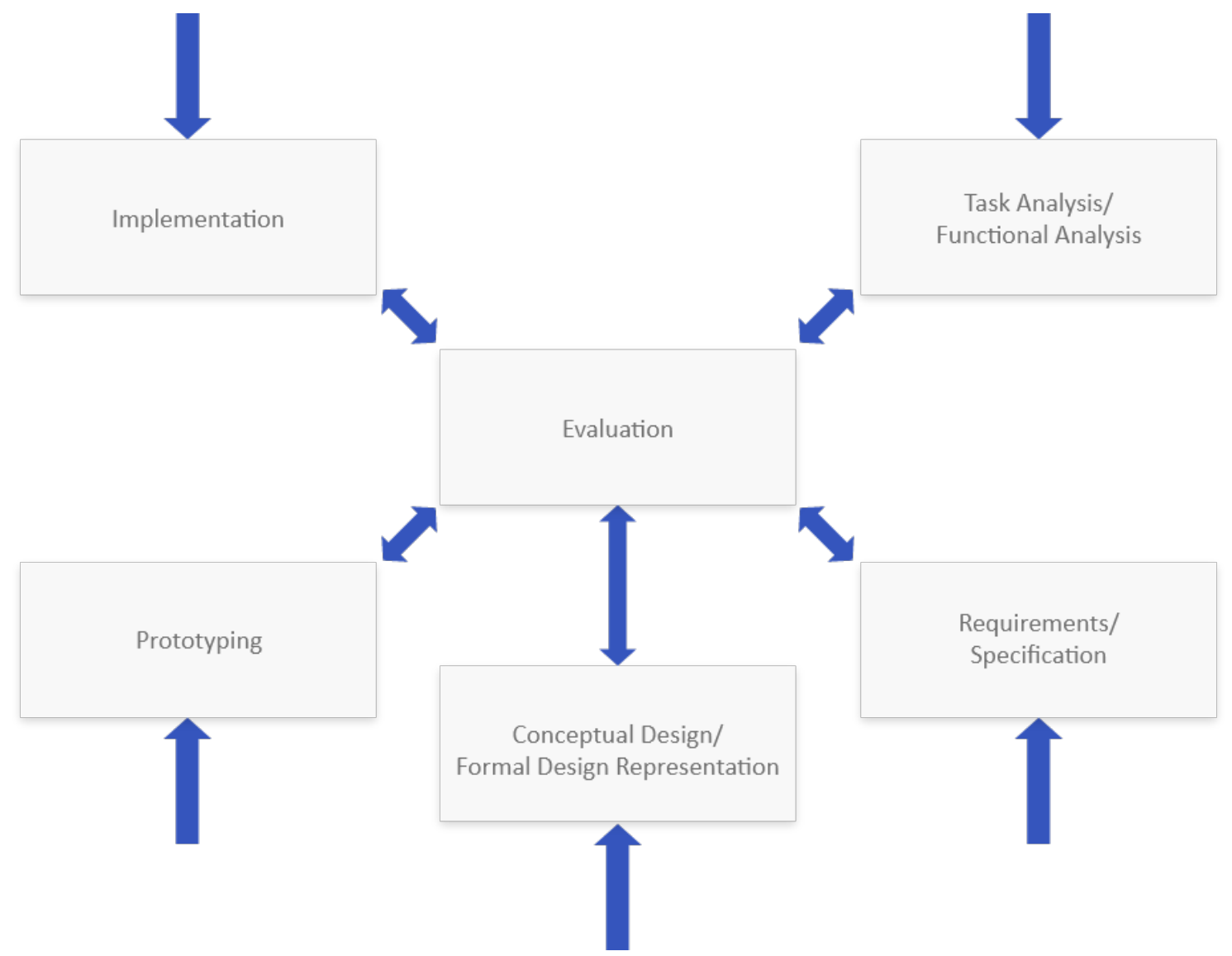

Figure 2.2: Star Lifecycle

\subsubsection{Usability Engineering Lifecycle}

Deborah Mayhew proposed model 2.3 in 1999. This lifecycle is concentrated on the user performance on tasks, so the design is prioritized based on their objectives. It introduces usability tasks to a traditional environment of software engineering[15].

There are three significant main phases:

\section{Requirement Analysis}

\section{Designing/Testing/Development}

\section{Installation}




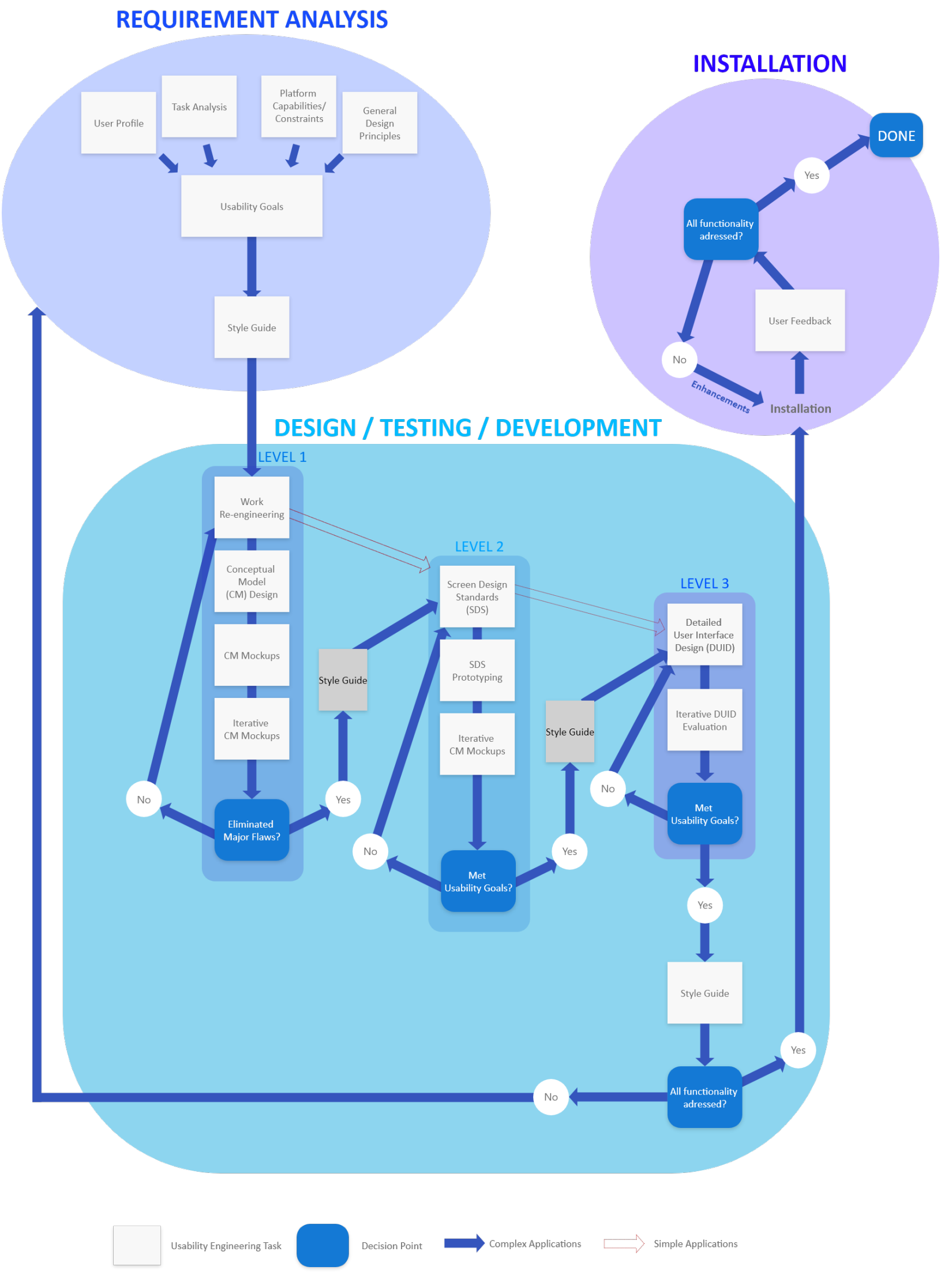

Figure 2.3: Usability Engineering Lifecycle 
Requirement Analysis includes:

- User Profiles - Set User characteristics

- Contextual Task Analysis - Get a user-centered model of work

- Usability Goal Setting - Specify the quantitative and qualitative usability goals

- Platform Capabilities and Constraints - Establish the capabilities and constraints to limit UI alternatives

- General Design Principles - Guideline the product under development

Design/ Testing / Development is divided into three different levels. In the first level, we have:

- Work Re-engineering - Re-engineer the prevailing user work model

- Conceptual Model Design - Set a high-level UI design framework

- Conceptual Model Mockups - Validation, support and refinement of the Conceptual Model Design

- Iterative Conceptual Model Evaluation - Evaluation of the Conceptual Model Design In the second level, we have:

- Screen Design Standards - Design Standards for UI Design

- Screen Design Standards Prototyping - Validation, support and refinement of the Screen Design Standards

- Iterative Screen Designs Standards Evaluation - Evaluation of the Screen Design Standards

- Style Guide Development - Document the conceptual model design and the screen design standards

In the third level, we have:

- Detailed User Interface Design - Design of the detailed user interface

- Iterative User Interface Evaluation - Validation, support and refinement of the Detailed User Interface Design

In the Installation phase, we have the user feedback, where we obtain the usability data after a product has been installed.

\subsubsection{Lifecycles Comparison}

Even though both of these lifecycles can be used in HCI contexts, they rely on different backgrounds. In table 2.2, we can see the major differences. 


\begin{tabular}{|l|l|l|}
\hline & Star & Usability Engineering \\
\hline Activity Order & Fixed & Free \\
\hline Recommended for & Big Projects & Flexible Projects \\
\hline Origin & Usability Engineering & Empirical work on designer's HCI approach \\
\hline
\end{tabular}

Table 2.2: Lifecycle Comparison

\subsubsection{FRAME Model}

Mobile learning offers learners the best practical way to access information. The FRAME model ( Framework for the Rational Analysis of Mobile Education) design [9] [2] takes full advantage of the features to implement when designing for these mobile learning experiences. It takes into consideration various aspects related to social and personal aspects of learning and psychological theories, as we can see in figure 2.4.

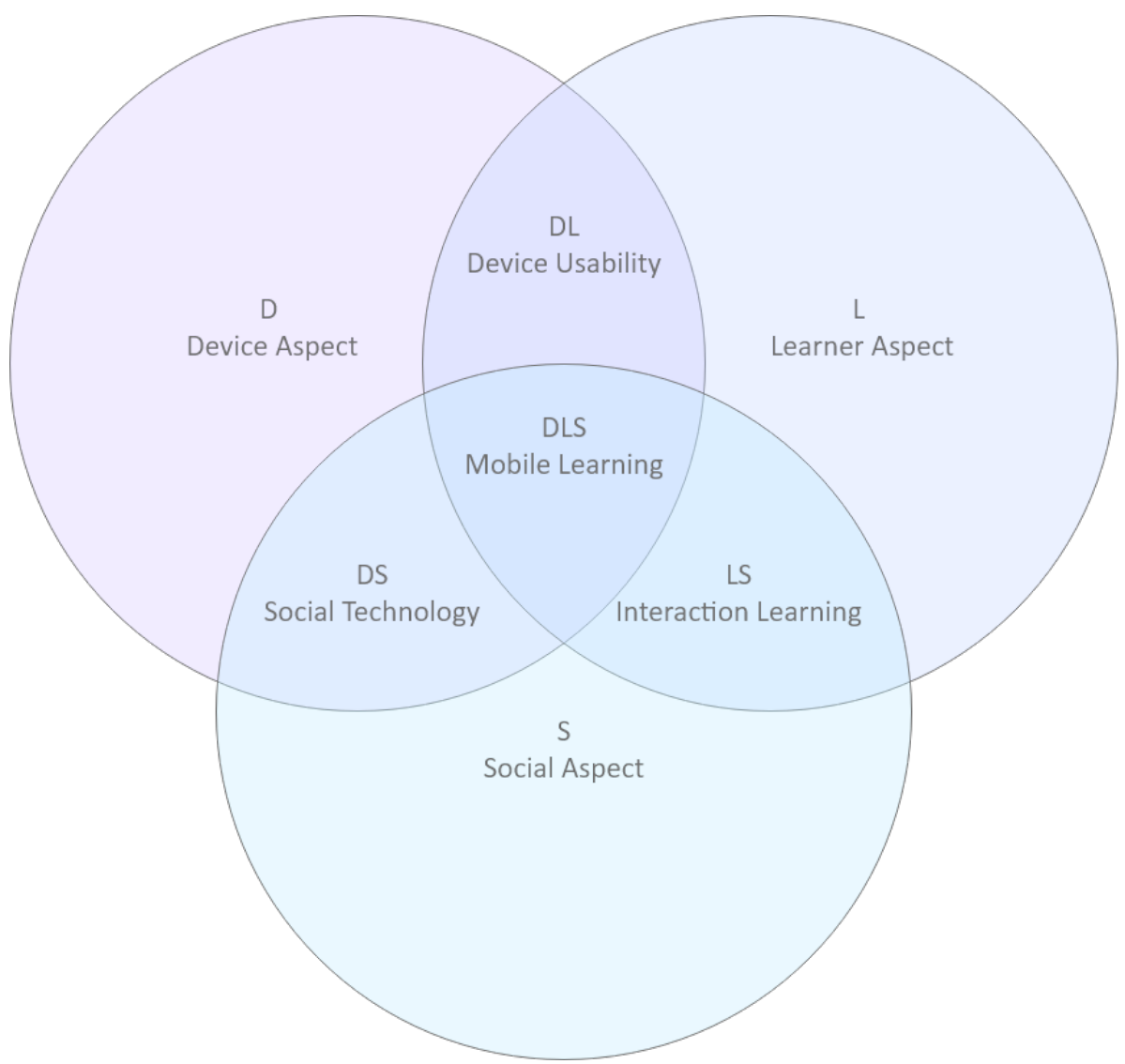

Figure 2.4: The FRAME Model

Mobile devices are considered as active components both to learn and other social processes in this model. FRAME also weighs the various benefits of mobile learning, such as the idea that learners should have access to the learning experiences anytime, anywhere. 
The FRAME model can be represented by a Venn diagram between three different circles, each one containing the diverse aspects related to mobile learning, such as the device aspect (D), the learner aspect (L), and the social aspect (S). The intersections consist of Device Usability (DL), Social Technology (DS), Interactional learning (LS), and in the center, they all converge in mobile learning (DLS).

In the Device aspect (D) as shown in table 2.3, we include as criteria the different software and hardware design of the mobile devices such as:

- Physical Characteristics: changes how the user handles the device and how he can move around with it;

- Input Capabilities: changes how the user selects and positions objects or data on the device;

- Output Capabilities: changes how the human body senses alterations in the device;

- File Storage and Retrieval: the standardization of storage and retrieval systems;

- Processor Speed: changes the response rates that may affect error rates with the user forgetting initial goals and task sequences; determined by the amount of RAM, file storage speed, user interface speed, and system configuration;

- Error Rates: changes the way users might be or not able to perform desired tasks and lose confidence in the device;

\begin{tabular}{|l|l|}
\hline Criteria & Concepts \\
\hline Physical Characteristics & $\begin{array}{l}\text { Size, weight, composition,placement of } \\
\text { buttons and keys, right/left handed } \\
\text { requirements, one or two-hand operability }\end{array}$ \\
\hline Input Capabilities & $\begin{array}{l}\text { Keyboard, mouse, light pen, pen/stylus, touch } \\
\text { screen, trackball, joystick, touchpad, } \\
\text { hand/foot control, voice recognition. }\end{array}$ \\
\hline Output Capabilities & $\begin{array}{l}\text { Monitors, speakers or any other visual, } \\
\text { auditory, and tactile output mechanisms. }\end{array}$ \\
\hline File Storage and Retrieval & $\begin{array}{l}\text { Storage on the device (RAM or ROM) or } \\
\text { detachable, portable mechanisms such as } \\
\text { USB drives, CDs, DVDs, and SD cards. }\end{array}$ \\
\hline Processor Speed & $\begin{array}{l}\text { Response rates; speed with which the device } \\
\text { reacts to human input. }\end{array}$ \\
\hline Error Rates & $\begin{array}{l}\text { Malfunctions resulting from flaws in } \\
\text { hardware, software, and/or interface design }\end{array}$ \\
\hline
\end{tabular}

Table 2.3: Device Aspects 
In the leaner aspect (L) as shown in table 2.4, we include as criteria how the learners use what they already know and how they manage information, such as:

- Prior Knowledge: changes how easily a learner can comprehend new concepts;

- Memory: changes how multimedia provides different stimuli, so learners retain and understand concepts more easily;

- Context and transfer: changes the active way learners use information to remember, understand, and transfer concepts

- Discovery Learning: changes the way it stimulates learners to develop skills to filter, choose and recognize relevant information in different situations;

- Emotions and Motivations: changes how the learner is willing to adopt new information due to the effects of their emotional state and desire to complete tasks;

\begin{tabular}{|l|l|}
\hline Criteria & Concepts \\
\hline Prior Knowledge & $\begin{array}{l}\text { Cognitive structures already in memory, } \\
\text { anchoring ideas1, schema theory, Gagne's } \\
\text { conditions for learning }\end{array}$ \\
\hline Memory & $\begin{array}{l}\text { Techniques for successful encoding with the } \\
\text { use of contextual cues: categorization, } \\
\text { mnemonics, self-questioning, semantic and } \\
\text { episodic memory, tactile, auditory, olfactory, } \\
\text { visual imagery, kinaesthetic imagery, dual } \\
\text { coding, and encoding specificity }\end{array}$ \\
\hline Context and transfer & \begin{tabular}{l} 
Inert vs. active knowledge. \\
\hline Discovery Learning
\end{tabular} \\
\hline Emotions and Motivations & $\begin{array}{l}\text { Feelings of the learner towards a task; } \\
\text { neasons or accomplishing a task and/or } \\
\text { interface design }\end{array}$ \\
\hline
\end{tabular}

Table 2.4: Learner Aspects

In the Social aspect (S) as shown in table 2.5, we include as criteria the social interaction and Cooperation processes such as:

- Conversation and Cooperation: changes the quality and quantity of communication;

- Social Interaction: Agreement on the meaning of signs and symbols may affect reinforcement of social and cultural beliefs and behaviors; 


\begin{tabular}{|l|l|}
\hline Criteria & Concepts \\
\hline Conversation and Cooperation & $\begin{array}{l}\text { Social constraints; } 4 \text { maxims (rules): } \\
\text { quantity, quality, relation, and manner }\end{array}$ \\
\hline Social Interaction & $\begin{array}{l}\text { Conversation as a cooperative activity, } \\
\text { sharing of signs and symbols. }\end{array}$ \\
\hline
\end{tabular}

Table 2.5: Social Aspects

Moving on to the intersections, we first start with the learner and the device aspects, known as the Device Usability intersection (DL) as shown in table 2.6. In this intersection, we include as criteria the relationship between the characteristics of mobile devices and cognitive tasks, such as:

- Portability: changes the way the user moves the device to different environments;

- Information Availability: changes how the user retrieves stored information when and where it's needed;

- Psychological comfort: changes the cognitive load and speed with which user can perform tasks;

- Satisfaction: changes the pleasure and the enjoyment related to the user, its personality, and culture

\begin{tabular}{|l|l|}
\hline Criteria & Concepts \\
\hline Portability & $\begin{array}{l}\text { Portability and durability (dependent on } \\
\text { physical characteristics, number of } \\
\text { components, and materials used to construct } \\
\text { the device). }\end{array}$ \\
\hline Information Availability & $\begin{array}{l}\text { Anytime, anywhere access to information } \\
\text { stored on a device. (This is a distinct from } \\
\text { information transfer, a characteristic of social } \\
\text { technology (DS).) }\end{array}$ \\
\hline Psychological comfort & $\begin{array}{l}\text { Learnability, comprehensibility, transparency, } \\
\text { intuitiveness, memorability, and metaphors }\end{array}$ \\
\hline Satisfaction & $\begin{array}{l}\text { Aesthetics of the interface, physical } \\
\text { appearance of the device, functionality, } \\
\text { preferred cognitive style }\end{array}$ \\
\hline
\end{tabular}

Table 2.6: Device Usability Intersection

The second intersection is the Social Technology intersection (DS) as shown in table 2.7, between the Device aspect and the social aspect. It focuses on how mobile devices enable communication and collaboration amongst multiple individuals and systems, including criteria such 
as:

- Device Networking: changes how the users connect to other users and networks;

- System Connectivity: changes how the users exchange information and documents within and across systems;

- Collaboration Tools: changes the way users cooperate;

\begin{tabular}{|l|l|}
\hline Criteria & Concepts \\
\hline Device Networking & $\begin{array}{l}\text { Portability and durability (dependent on } \\
\text { physical characteristics, number of } \\
\text { components, and materials used to construct } \\
\text { the device). }\end{array}$ \\
\hline System Connectivity & $\begin{array}{l}\text { Anytime, anywhere access to information } \\
\text { stored on a device. (This is a distinct from } \\
\text { information transfer, a characteristic of social } \\
\text { technology (DS).) }\end{array}$ \\
\hline Collaboration Tools & $\begin{array}{l}\text { Learnability, comprehensibility, transparency, } \\
\text { intuitiveness, memorability, and metaphors }\end{array}$ \\
\hline
\end{tabular}

Table 2.7: Social Technology Intersection

The third intersection is the Interaction Learning intersection (LS) between the learner and social aspects. It represents learning and instructional theories, as shown in table 2.8, including criteria such as:

- Interaction - changes the types of interaction that can stimulate learning with varied effectiveness;

- Situated Cognition - changes the purpose of a learning task to motivate the learners;

- Learning Community - changes the way learners work with others to achieve mutual goals;

\begin{tabular}{|l|l|}
\hline Criteria & Concepts \\
\hline Interaction & Learner-learner, learner instructor, \\
& learner-content; computer-based learning \\
& $(\mathrm{CBL})$; intelligent tutoring systems, zone of \\
& proximal development \\
\hline Situated Cognition & $\begin{array}{l}\text { Anytime, anywhere access to information } \\
\text { stored on a device. (This is a distinct from } \\
\text { information transfer, a characteristic of social } \\
\text { technology (DS). })\end{array}$ \\
\hline
\end{tabular}




\begin{tabular}{|l|l|}
\hline Criteria & Concepts \\
\hline Learning Community & $\begin{array}{l}\text { Learnability, comprehensibility, transparency, } \\
\text { intuitiveness, memorability, and metaphors }\end{array}$ \\
\hline
\end{tabular}

Table 2.8: Interaction Learning Intersection

The last intersection is the main one, in the center, consisting of the convergence of the three different aspects, the device, the learner, and the social aspect, in the Mobile learning process (DLS). Table 2.9 shows the different criteria applied in this intersection. It implements improved collaboration amidst learners, access to knowledge, and a more profound contextualization of learning, in criteria such as:

- Mediation: changes the nature of the interaction itself as learners interact with their environment, tools, and information;

- Information Access and Selection: changes the efforts related to the learner's recognition and evaluation of the accuracy of information;

- Knowledge Navigation: changes the learner's skills to appropriately select, manipulate and apply information for their unique situations and needs;

\begin{tabular}{|l|l|}
\hline Criteria & Concepts \\
\hline Mediation & Task artefact cycle, mediation \\
\hline Information Access and Selection & $\begin{array}{l}\text { Information noise, identification of patterns } \\
\text { and relationships, relevancy, and accuracy }\end{array}$ \\
\hline Knowledge Navigation & $\begin{array}{l}\text { Knowledge production vs. knowledge } \\
\text { navigation }\end{array}$ \\
\hline
\end{tabular}

Table 2.9: Mobile Learning Process

\subsubsection{Experimental Design}

To identify causal relationships and answer questions, we design experiments that aim to reveal significant scientific value results. There are three different types of studies as shown in figure 2.5: experiments, quasi-experiments, and non-experiments [10]. 


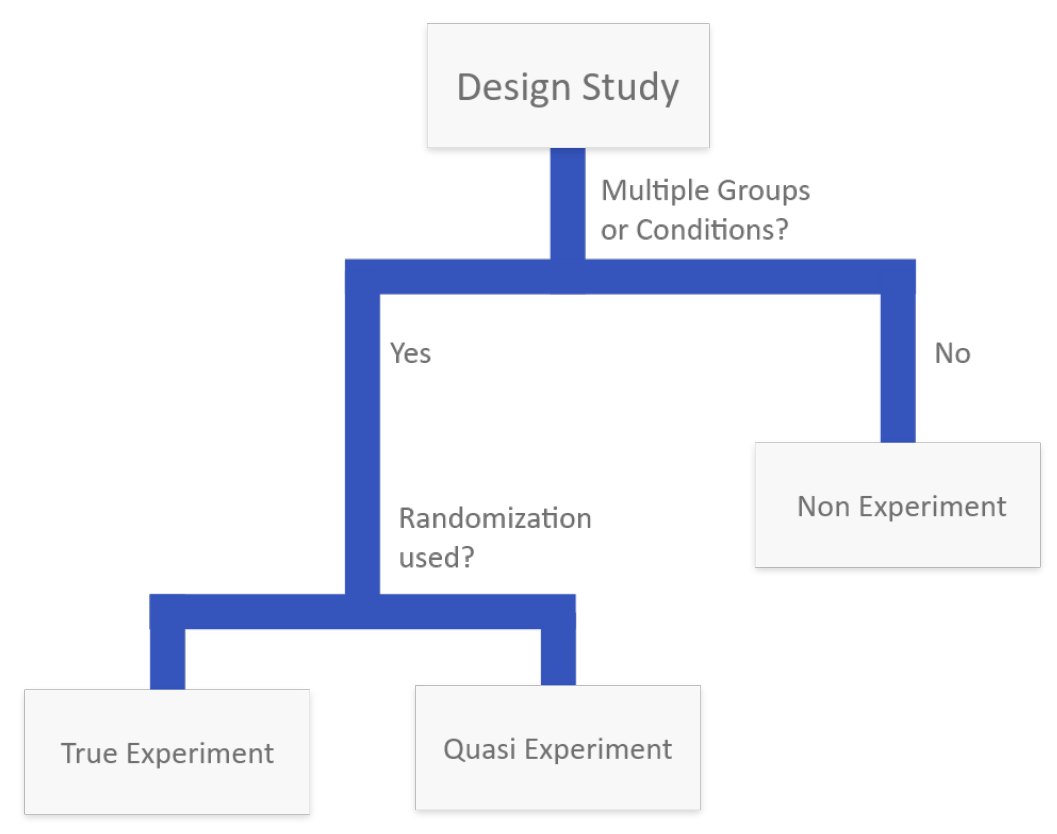

Figure 2.5: Defining true experiments

For this thesis, the aim is to produce true experiments, and for that, the following factors need to be verified:

- A true experiment is based on at least one testable research hypothesis and aims to validate it.

- There are usually at least two conditions (a treatment condition and a control condition) or groups (a treatment group and a control group).

- Quantitative measurements typically measure the dependent variables.

- Various statistical significance tests analyze the results.

- A true experiment should be designed and engineered to exclude possible biases.

- A true experiment should be replicable with different participant samples, times, locations, and experimenters.

To determine the basic structure of the design of an experiment, we have first to answer two questions:

- How many independent variables do we want to investigate?

- How many different values does each independent variable have?

If the number of independent values is more than one, it should be a factorial design, and if not, it should be a basic one-level design. The number of independent variables depends basically on the conditions of an experiment. With that in mind, the figure 2.6 was designed: 


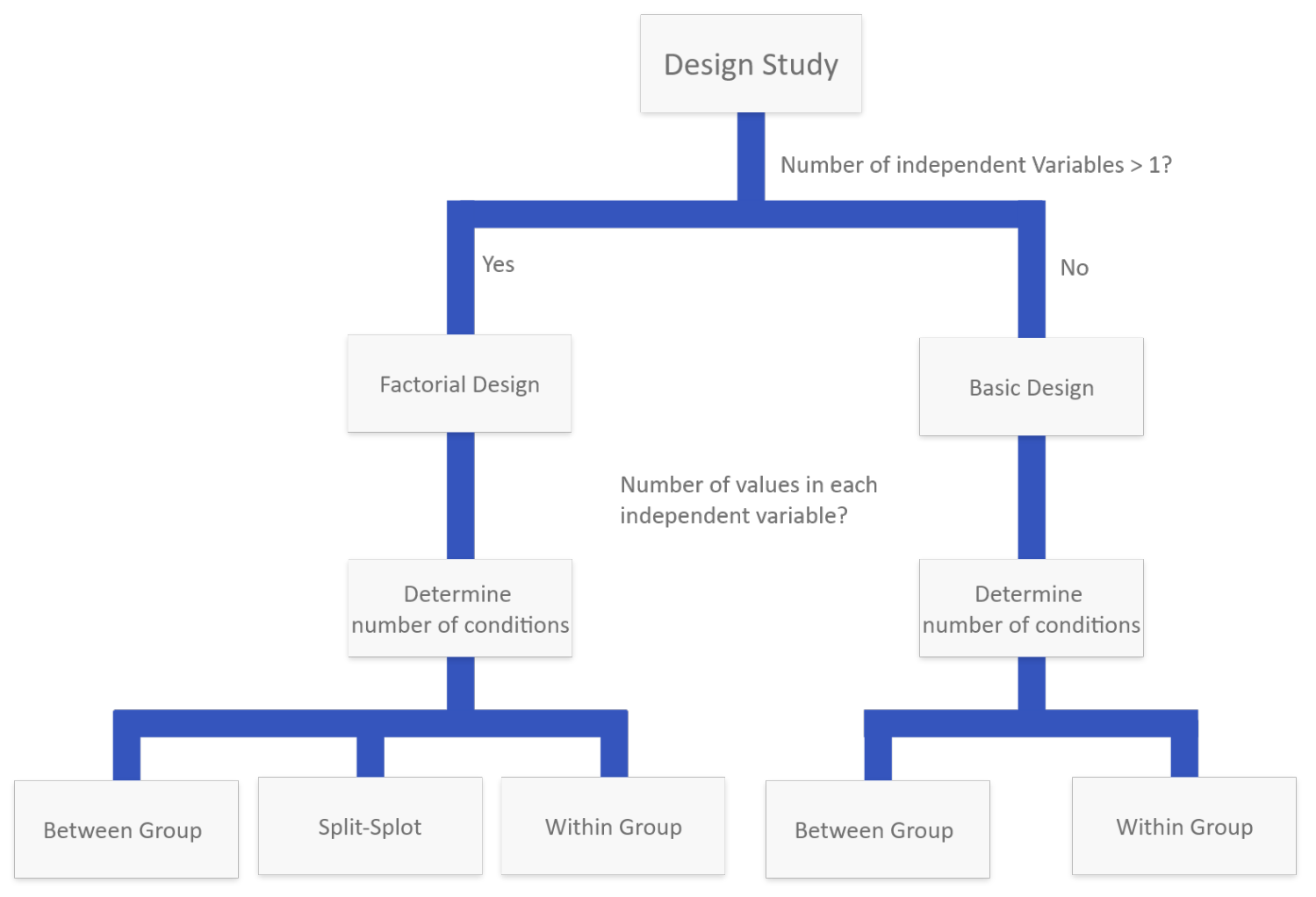

Figure 2.6: Experiment Structures

After determining the number of conditions, there are two possible main paths in both factorial and basic design. It can be between groups and within groups, and in the case of factorial design, it can also be a split-plot, which is a combination of both. In between-group design, the number of participant groups coincides with the number of experimental conditions. That is, each participant is exposed to only one experimental condition. In within-group design is exposed to multiple experimental conditions, and with that, only one group of participants is needed for an entire experiment. Table 2.10 compares this methods with more detail.

\begin{tabular}{|l|l|l|}
\hline & Between-Group Design & Within-Group Design \\
\hline Advantages & $\begin{array}{l}\text { Cleaner, Avoids learning } \\
\text { effect, Better control of } \\
\text { confounding factors, such as } \\
\text { fatigue }\end{array}$ & $\begin{array}{l}\text { Smaller sample size, } \\
\text { Effective isolation of } \\
\text { individual differences, More } \\
\text { powerful tests }\end{array}$ \\
\hline Disadvantages & $\begin{array}{l}\text { Larger sample size, Large } \\
\text { impact of individual } \\
\text { differences, Harder to get } \\
\text { statistically significant results }\end{array}$ & $\begin{array}{l}\text { Hard to control learning } \\
\text { effect, Large impact of } \\
\text { fatigue }\end{array}$ \\
\hline
\end{tabular}

Table 2.10: Type Of Experiment Designs 


\subsection{Related Work}

Mobile learning solutions as a form of education have been used by already quite some time, and on the app stores, we can find out a lot of different apps that allow learning any place at any time. Most of the solutions found are made for online learning, but we will focus on solutions made to work offline.

According to UNESCO, in the learning solutions for education response for Covid-19 [20], in the section of Systems with strong offline functionality, there are three different solutions:

\section{- Kolibri}

\section{- Rumie}

\section{- Ustad Mobile}

Bellow, there is a showcase and analysis of these three different apps since they aim to bring offline solutions like the app in this dissertation.

\subsubsection{Kolibri}

Kolibri aims to bring high-quality education technology to low-resource communities (rural schools, refugee camps, orphanages, non-formal school systems, prison systems). It relies on a peer-to-peer distribution, and the libraries are designed for formal and informal education materials as we can see in figure 2.7. It is designed to run on Windows, Linux, and OSX [8].

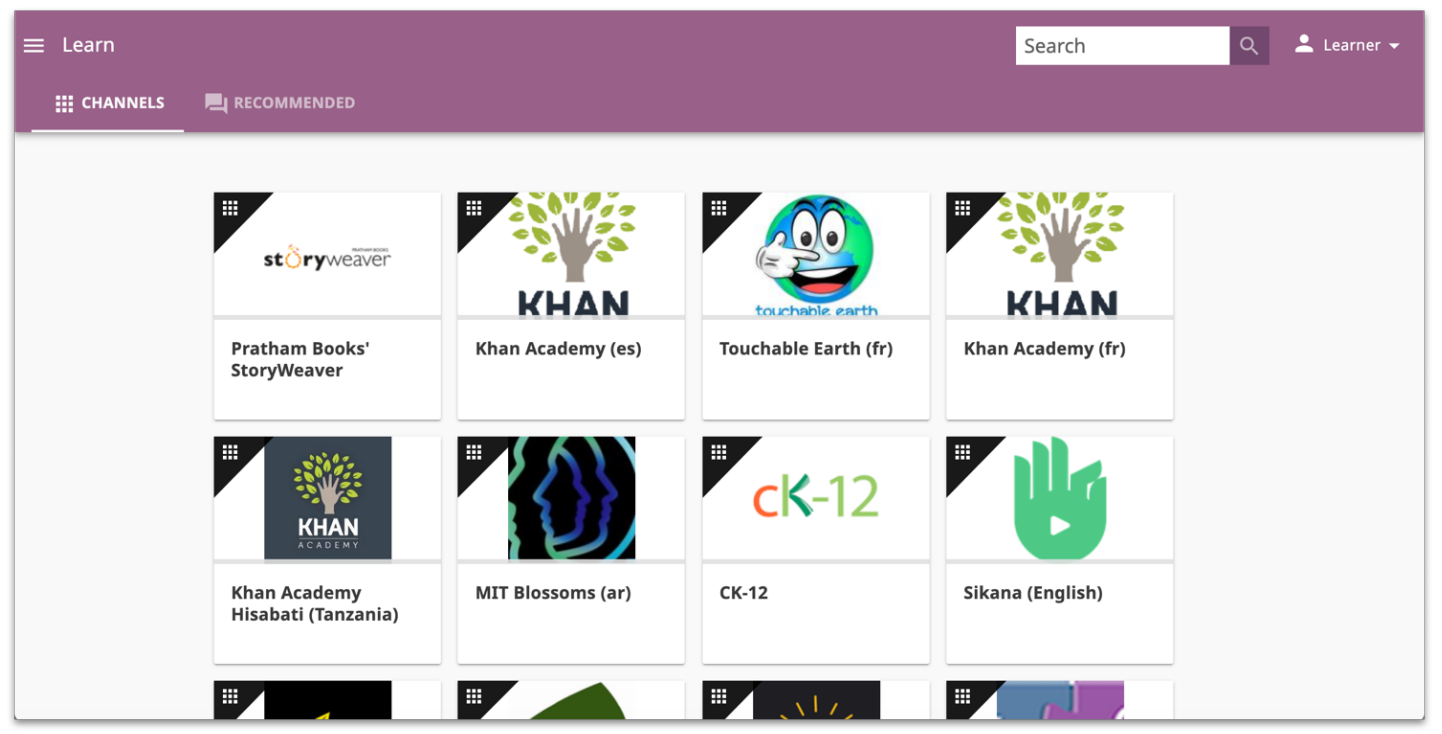

Figure 2.7: Kolibri Channels 


\subsubsection{Rumie}

Rumie brings free learning resources to learners wherever they are. Learners also have access to curated resources like instructional PDFs, MP3s, and videos, available for offline use. The goal was to make the learning experience as interactive and easy as social media. Rumie runs on supported browsers, as we can see in figure 2.8 and Android devices [14].

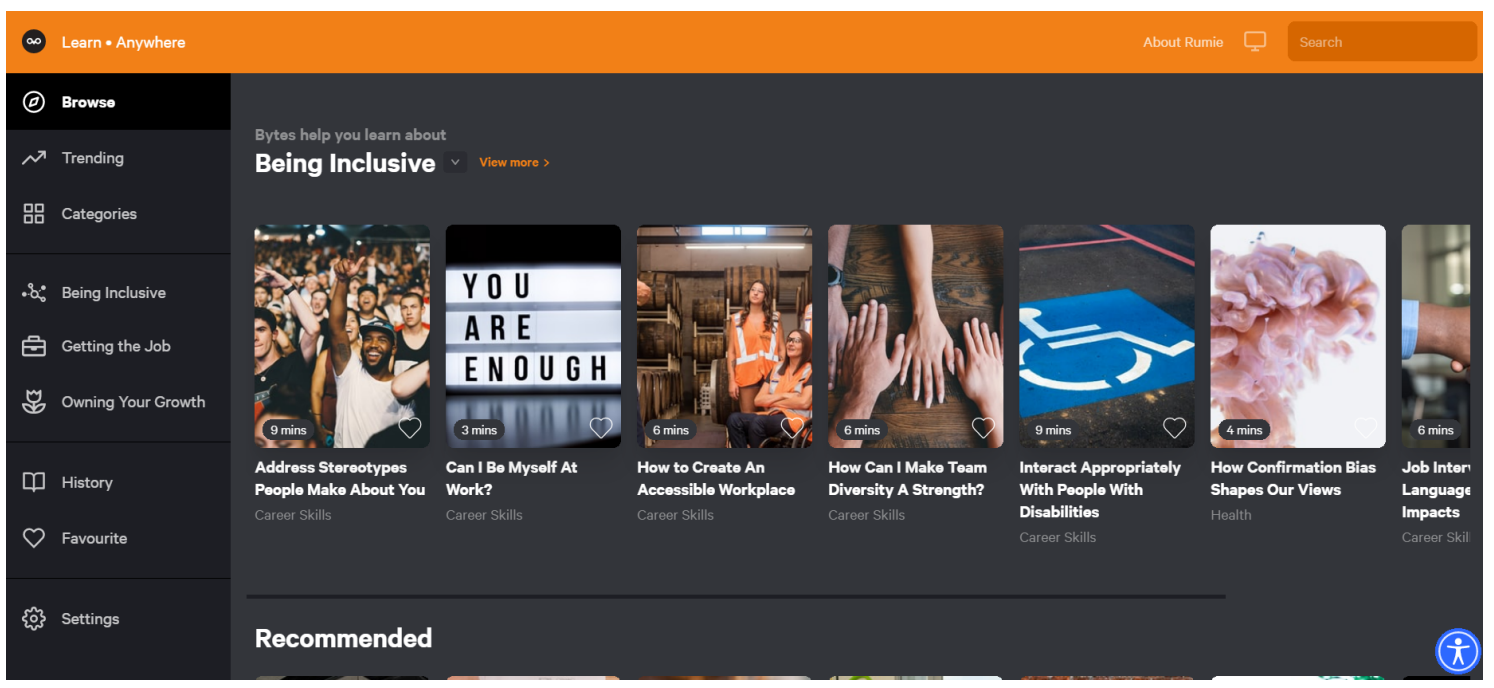

Figure 2.8: Rumie on Browser

\subsubsection{Ustad Mobile}

Ustad Mobile is an Android app that aims to bring online and offline gallery contents to learners and management tools for their educators and organizations. Upon downloading course content, it is possible to access offline ebooks, interactive exercises, and videos, as shown in 2.9 [12]. 

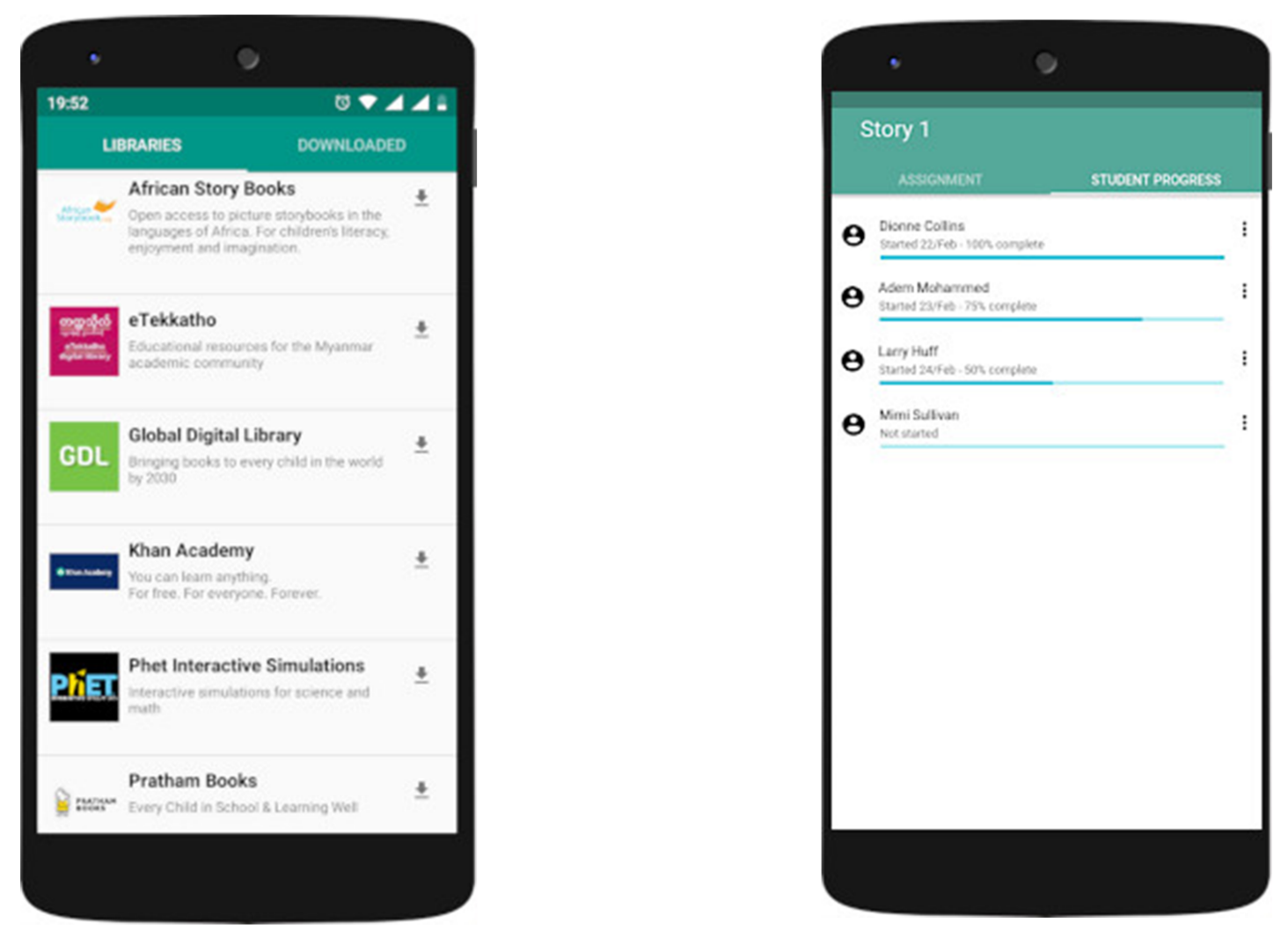

Figure 2.9: Ustad Mobile; On the left: Learner Screen; On the right: Educator Screen

\subsubsection{Summary and App Comparison}

These three mobile apps apply different technological approaches to solve education in places where internet access is scarce. In table 2.11, we differentiate the three apps based on their approaches:

\begin{tabular}{|l|l|l|l|}
\hline & Kolibri & Rumie & Ustad \\
\hline Work Offline & Yes & Yes & Yes \\
\hline Peer-to-Peer & Yes & No & No \\
\hline Android App & No & Yes & Yes \\
\hline
\end{tabular}

Table 2.11: Offline App Comparison

Even though the methods differ in terms of technologies, the content format is the same in all of these apps: a library that accesses content in different modules.

These applications' user experience relies on the content, not on creating a user routine or companion. This dissertation's biggest challenge will be to discover which ways we can display the learning content so students can be more comfortable with learning away from their educators. 


\section{Chapter 3}

\section{Problem and Proposed Solution}

Chapter 2 revealed that some efforts related to distance learning were already made, even in countries where there is a large community of nomadic populations, like Nigeria. It also revealed that there are now studies and methodologies ready to develop mobile learning solutions, having in mind the challenges and opportunities brought by them.

With the previous research analysis, we can identify some of the obstacles to have in mind and some expected results of experimental work done before. This chapter shows the problem we want to solve and how to solve it, based on the conclusions taken and the methodologies presented by previous research.

\subsection{Problem}

Typically, in the case of distance learning, the digital solutions that exist are mostly dependent on the mutual connection between the teacher and the students', made using resources such as platforms like Moodle, google classroom, and Microsoft teams, video-calling solutions, like Skype, Zoom or Google meets, and even in some cases via TV and radio. The problem is that learning, in this situation, requires that the students and the teachers establish contact in the same shared schedule, using the same tools, and, most importantly, imply that the students have a connection to those same tools. If students do not have access to the internet, the contact with the classroom is lost. In countries where school dropout happens in the early stages of life, lack of access to these instruments brings scalar educational problems in a population, making it harder for a society to develop if it wants to.

Most of the tools that already exist do not promote student retention and autonomy, making it harder for students who have little motivation and educational habits, especially when there is no real-time contact with their teachers. That makes the process of giving up and quitting studying a lot more simpler. 


\subsection{Proposed Solution}

In order to attempt to solve this problem, this thesis will focus on the learning experience, applying HCI methodologies to help create and design the interfaces of an app that aims to solve this problem while making the learners motivated and helping them to have a more self-sufficient lifestyle in the education field.

\subsubsection{Conceptual Model}

The concept relies on observations made in chapter 2, where we can see in countries like Nigeria and South Africa, the vocal sharing cultural tradition [1]. The best representation of the knowledge sharing is a peer-to-peer (P2P) solution as shown in figure 3.1.

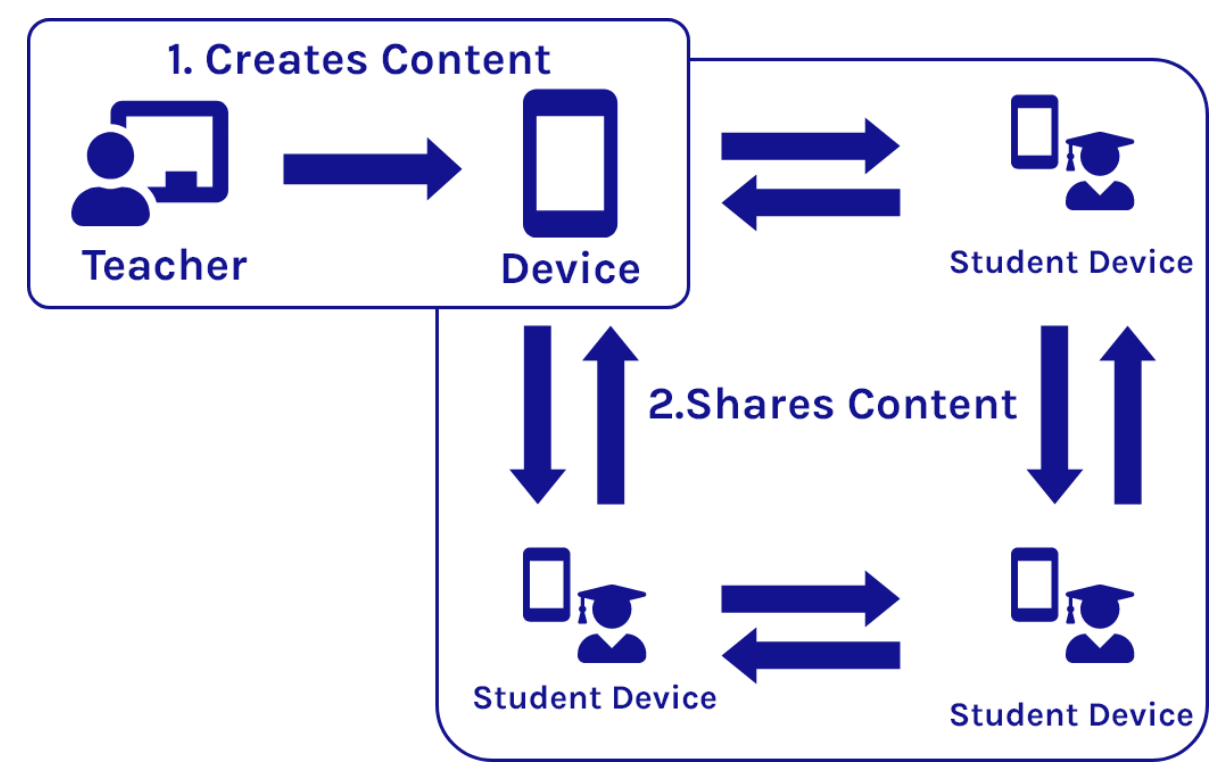

Figure 3.1: Conceptual Model

The conceptual model relies on two main factors, the creation of content and the sharing experience. The teacher, or educator, produces the educational content he wants in the formats available. After creating the content, the teacher can now share it with his students so they can learn at home or in any other place. The students themselves can also share the teacher's content, making a network of knowledge sharing. This concept also relies on the fact that lifelong contextual learning relies mainly on collaboration between individuals [16].

\subsubsection{System Architecture}

Even though this dissertation's focus is on the Human-Computer interaction side, this thesis's concept can be transcribed in a technical context. It relies on the dynamical construction of UI elements. The concept is shown in figure 3.2. 


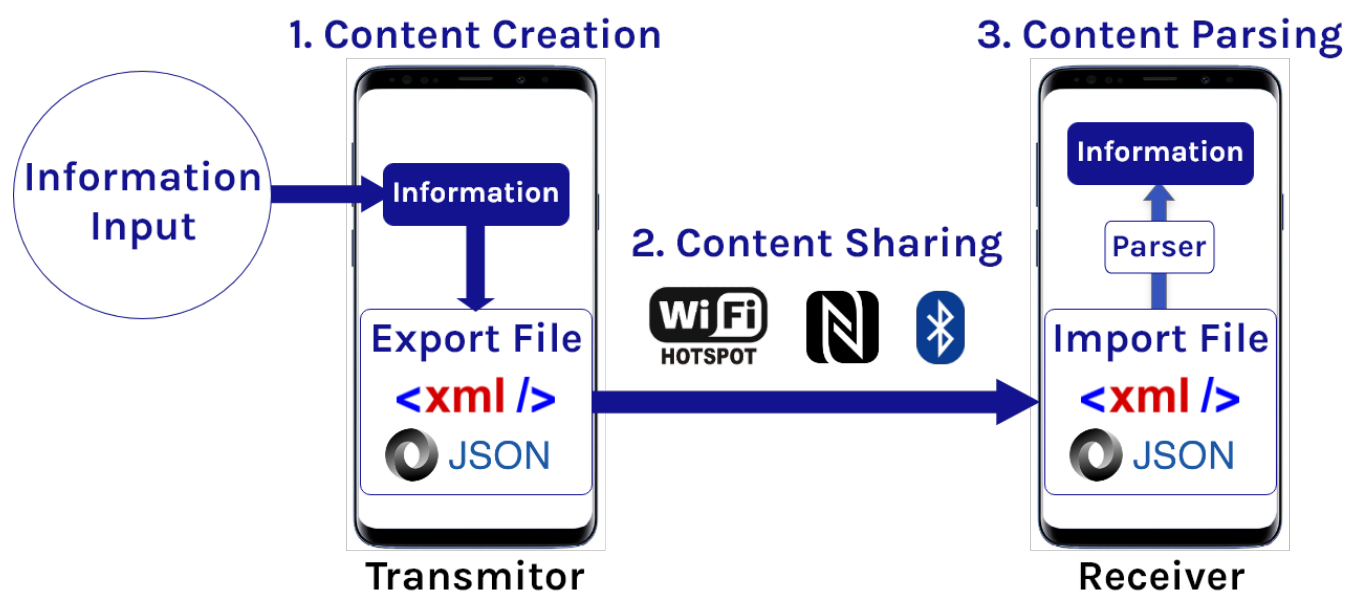

Figure 3.2: Architecture Model

The experience relies upon three fundamental events:

\section{Content Creation}

The teacher inputs on the app the information and content meant for his students to learn. The compilation of this information will result in an exported file that contains the learning content and informs the relationship between the content and the UI elements, for example, an XML or JSON file.

\section{Content Sharing}

After the first step, the teacher can now share the compiled file. In order to share between devices without needing mobile data, the files can be shared via NFC, Bluetooth, Wifi Hotspot, or even Android nearby share. This process can also be done between students, sharing the file with the teacher's content without being by his side.

\section{Content Parsing}

When the content reaches the destined device, it is now parsed to transform the received file in the correspondent UI elements with the teacher's content. The content shows in the order and format intended by the teacher.

\subsubsection{Methodologies}

Based on the Methodologies and frameworks presented in chapter two, we can point out essential procedures to implement experiences and test the students' interfaces:

- The FRAME model can evaluate the mobile learning experience in order for it to be as completed and fulfilling as possible for the app users.

- The experiments to be done should also follow the guidelines of Experimental Design in order to produce significant results. These experiences will take into account the various fundamental principles of interaction to make the design user-centered. 
- Based on the two different lifecycles showcased, it can be concluded that, for this dissertation, the most appropriate one is the Star lifecycle model since the project requires flexibility due to the nature of the evaluations to be made, and the focus will be on an HCI approach.

\subsubsection{Prototyping Tools}

There are a lot of various tools available that allow the development and testing of prototypes, but the ones that will be shown in table 3.1 are the main ones used in previous projects.

\begin{tabular}{|l|l|l|l|}
\hline & Adobe XD & Figma & Marvel \\
\hline Free & Yes & Yes & Yes \\
\hline Can animate objects & Yes & Yes & No \\
\hline Can Transition through different screens & Yes & Yes & Yes \\
\hline Can work with voice commands & Yes & With Plugins & With Plugins \\
\hline Easy Prototype Sharing & Yes & Yes & Yes \\
\hline
\end{tabular}

Table 3.1: Prototype Tools Comparison

With this in mind, the recommended prototype tool for this project relies on Adobe XD. Some exercise formats might require voice commands, and there is no need to install plugins in Adobe $\mathrm{XD}$ since it is a native functionality.

\subsubsection{Goals}

This dissertation will focus on the interface design of the students and teachers apps in order to:

- Discover the best way to organize and find information inside the app so the students can learn most efficiently;

- Find out which content format is ideal when learning in an app like this to minimize the app size and development effort;

- Incentive studying and learning autonomy inside the app and motivating the students to not quitting their studies;

- Make the sharing content feature as accessible as possible. 


\section{Chapter 4}

\section{Requirements}

Following the plan for realizing this dissertation, we start the first phase, the gathering of Requirements. Requirements refer to the needs to fulfill when designing a product, in this case, mobile applications.

Since the work is distributed into two different and separate apps, different procedures were applied to create the apps requirements lists, one for the teachers and one for the students. The procedures selected rely on the availability and possibility of contacting teachers and students remotely.

\subsection{Students App}

The app design, more than allowing different possibilities in each lesson's content provided by the teacher or educator, is by itself a learning environment since it should encourage the students to be more autonomous in the learning activity.

Since it was impossible to contact students directly or remotely due to the lack of contacts and communication channels, the student's app requirements rely on the FRAME model, which examines the design for mobile learning experiences such as this app.

\subsubsection{FRAME Model}

With that in mind, when planning and analyzing a mobile learning environment, applying the FRAME model presented before, the following questions should be answered.

\subsubsection{Device Aspect}

On the Device Aspect (D), have we considered :

\section{- Selecting a device with comfortable physical characteristics}

The devices the app is intended to be used are generally smartphones and tablets since they allow comfortable use in almost any situation. In addition, these devices are ideal for daily travel and are cheaper than laptop computers. 
- Allowing users to adjust input and output settings (i.e., font sizes, addition of peripherals) The app should come with accessibility settings that allow better display options and usability. The addition to peripherals, in this case, is not necessary since the controls rely mainly on touching the screen.

- Selecting devices with processing speeds and input and output capabilities that will best complement user tasks

On this topic, knowing that better processing comes with more expensive devices, the app functionalities should be resumed in tasks that can be handled using devices with slower processing speeds and input/output capabilities. This way, the app should be able to run on devices with slower capabilities and specifications.

\section{- Providing instructions for storing and retrieving files}

As explained in the conceptual model, file storing and retrieval are mainly related to the teacher's app, not the student app. On the other hand, the student app will focus on sharing class content, and that will come with an intuitive guide so that more students are easily reached.

- Taking measures to identify and limit perceived and real error rates of the mobile hardware and software

The app should store information related to some errors that can happen while using this system. The development team can then analyze the logged errors to improve the app once there is a possibility to report them.

\subsubsection{Learner Aspect}

On the Learner Aspect (L), in designing mobile learning activities, have we considered:

\section{- Assessing the learners' current level of knowledge (if possible)}

The user's teacher/educator will create the content, and for that, testing the user's current level of knowledge is up to the content creator.

- Using schemas, anchoring ideas, advance organizers, or other instructional techniques

Even though the content creators might not want to use the exact nature's instructional techniques, the app components should allow them.

- Using contextual cues and multimedia to provide a variety of stimuli to assist comprehension and memory

The app should support different multimedia formats to be more didactic and ludic. Some of those formats might be video, audio, and pictures. The app will use these components inside each lesson and in the main menus for a more enhanced experience.

- Structuring learning activities around authentic contexts and audiences 
The app flow and usability should focus on being the most relatable to student's context and lifestyle. In addition, the learning activities will be as simplified as possible, so supervision is not needed while using this app.

- Designing learning situations to stimulate active transfer of concepts and procedures to different contexts

Even though the teacher creates the learning content, the app should allow the conceptualization of many life situations. Those concepts and procedures are easier to explain using the multimedia formats the app should support.

- Allowing learners to explore, discover, select information relevant to their own unique problems

Students should be able to highlight the information they might want to use later and study. Various activities may allow students to approach problems they can personally relate to, to find some external support.

\subsubsection{Social Aspect}

On the Social Aspect (S), in terms of culture and society, have we considered:

- Clarifying definitions, cultural behaviors (etiquette), or Symbols that participants might require while interacting

Even though it is primarily up to the teachers to present cultural behaviors and definitions in the content they create, the app should use symbols that students can easily understand and encourage students to share content and knowledge.

- Providing methods or guidance for ensuring sufficient, accurate, and relevant communications among participants in the mobile media space

Even though the app is designed to work offline, making online conversations impossible, there is guidance when the student wants to share the content with other students.

\subsubsection{Device Usability Intersection}

In the Device Usability intersection (DL), while using mobile devices in learning activities, have we considered:

- The locations and climates in which the learner may wish to carry a device

The student should be able to learn entirely offline, as long as the device is charged and the student uses it for short moments throughout the day. The student can go through lessons already done 
before if it needs to, and in case it is not possible to learn on a specific day, the content will still be available for later.

- If the learner's device will permit access to information whenever and wherever needed (just-in-time learning)

Students should use this app whenever they need to, and for that, the information should be displayed in the best way possible and easy to access. There is no time restriction in terms of using the app, and so the user can choose when it is the right time to learn something for how much time is required.

- Reducing cognitive load by chunking content, reducing the number of required actions to complete tasks, using mnemonic devices, and simplifying displays

Displays will be simplified to the max to reduce the cognitive load required to start a lesson, and also the complexity of the tasks will also require a minimal amount of steps to solve.

- Making the device aesthetically pleasing and functional for learners by allowing them to choose themes and adjust preferences

The app should be able to allow some personalization in order to give a more personal experience, alongside the accessibility options. The student should have a personal area where those settings can be changed.

\subsubsection{Social Technology Intersection}

In the Social Technology Intersection (DS), in accessing or providing networks for interaction, have we considered:

- Selecting appropriate wireless standards in light of the amount of data, speed, and security with which the data must be transferred

Even though the app is designed to work offline, the students should be able to share class contents between them, and for that, the best methods to share data offline will be taken into consideration when developing the app.

- Selecting appropriate collaboration software to meet the needs of the learning or social tasks

The app itself should allow collaboration since it relies on sharing the class content offline. It should not require additional software to share class content, mainly since it is meant to work offline in a specific format readable by the teacher's and the student's app. 


\subsubsection{Interaction Learning Intersection}

In the Interaction Learning Intersection (LS) with regard to interaction, have we considered:

- The learner's relationships with other learners, experts, and systems

This system relies on sharing content between teachers and learners so that the goal of achieving a more well-built education environment can be accomplished in environments where it could not be done before.

- The learner's preferences for social interaction and for learning information and/or skills The app will work as a tool for easy learning and easy access to information. Social interaction can be achieved with a gamified avatar in the app, but not more than that since it makes the student interact socially outside the learning space.

- Providing mobile media spaces for the development of communities of practice, apprenticeships, and mentorship between learners and experts

Scores can be transferred when sharing class data in order to allow the students to acknowledge their colleague's state of familiarity with the exercises and learning material studied. Teachers should also receive that information to know how well their students are performing.

\subsubsection{Mobile Learning System}

In a Mobile Learning system (DLS), have we considered:

- How the use of mobile devices might change the process of interaction between learners, communities, and systems

The learning process should positively change since it balances learning at home with some social connection with the teachers and colleagues. While promoting the students' autonomy, the students should maintain a connection with their communities to exchange lesson materials.

- How learners may most effectively use mobile access to other learners, systems, and devices to recognize and evaluate information and processes to achieve their goals

Inside the app, the communications are resumed mostly to sharing class content, and with that, we ensure cooperation between the different users to achieving their educational goals.

- How learners can become more independent in navigating through and filtering information

The app UI will allow the learners to have quick and easy access to the learning material made for them while inciting them to learn autonomously. 


\section{- How the roles of teachers and learners will change, and how to prepare them for that change?}

Teachers are required for the content to be created. With this app's use, the learning activity will be simplified and more successful, allowing the students to learn whenever they want and consolidate better the learning material. The teacher's app should provide some guidance and troubleshoot information to prepare teachers for it.

\subsubsection{Requirements}

From the FRAME model, we can take several requirements. Table 4.1 contains the requirements regarding the student's app.

\begin{tabular}{|l|l|l|}
\hline KR & Key Requirements & Priority \\
\hline KR- & As a student I would like to & \\
\hline KR-1 & Create a Local Profile & High \\
\hline KR-2 & Edit a Local Profile & Medium \\
\hline KR-3 & View the different courses & High \\
\hline KR-4 & View the different lessons inside each course & High \\
\hline KR-5 & View Lessons Content & High \\
\hline KR-6 & Solve Lessons Exercises & High \\
\hline KR-7 & View Lesson's Progress & High \\
\hline KR-8 & Have access to past course's material & Medium \\
\hline KR-9 & Report doubtful or wrong lesson's exercises & Low \\
\hline KR-10 & Favorite/ Pin important class material & Low \\
\hline KR-11 & Overview General Progress & Medium \\
\hline KR-12 & See Achievements & High \\
\hline KR-13 & Share Course's content offline & High \\
\hline KR-14 & See Friends Profile & Low \\
\hline
\end{tabular}

\subsection{Teachers App}

In order to gather more detailed data about this problem, we need to think about the techniques we want to apply for that. With this in mind, we concluded that the best techniques are interviews, questionnaires, and studying documentation, since focus groups, workshops, and naturalistic observation require fieldwork that may not be possible due to the current pandemic situation and to the considerable time commitment that would be needed.

For this requirements phase, we also concluded that the best way to validate and formulate new requirements would be to contact the teachers via interviews. This way, we could understand how comfortable the teachers are using technology since they will create the content for it and communicate better their mental models than children due to their info literacy and speech ability. 


\subsubsection{Interviews}

The interview is divided into four parts based on the type of information we will share

\section{Introduction}

First, the interview should start with my self-presentation and the purpose of this interview. The instructions should be clarified and the motivation behind this dissertation too. The participants can leave at any time, and all the data registered will be treated with respect.

\section{Demographics}

After the self-introduction, we will then know better the teacher or educator we are interviewing. We want to know basic information, such as their location, age, gender, and most importantly, how they usually use their smartphone and if they have one. An essential question is if they have good access to the internet since it is the central focus of this dissertation.

\section{Pedagogy Experience}

At this time of the interview, the questions will be aimed to discover how these teachers give their classes: the school years they teach, for how long, where and what. Here we will be confronted with different possible scenarios that the app should be able to help. To finish this part of the interview, questions related to the exercises and content format they use to give in their classes. This question is key to this whole interview since it is the content format that we want to discover and that the app should support.

\section{App and Conclusion}

Before concluding the interview, some questions will be asked regarding the app to know if they agree with the idea and, if not, why. After, we can also ask what could be done to fix eventual problems the teachers might find out. With this, we can not just validate the previous requirements but also possibly find new requirements to fit other necessities that were not previously discovered. To conclude, we thank the participants for their availability and their disponibility for these interviews.

\subsubsection{Results}

\subsubsection{Demographics}

Based on the questions made, the following demographical information was recorded on the sixteen interviews executed in the requirements phase:

- Fifteen participants were from Guinea Bissau, and the other participant was from Cape Verde

- The average age is 42 years old, and the participants were born from 1956 to 1993. Figure 4.1 represents the participant's age distribution. 
- Eleven participants were male, and five female as figure 4.1 shows.

- Ten participants owned a smartphone, and five did not as shown in figure 4.2.

- Eight participants had internet access, and seven did not. Important to point out that from the ten smartphone owners, only three did not have internet access. There was one exceptional case of a teacher that had internet access but did not own a smartphone. Figure 4.2 also refers to this reality.
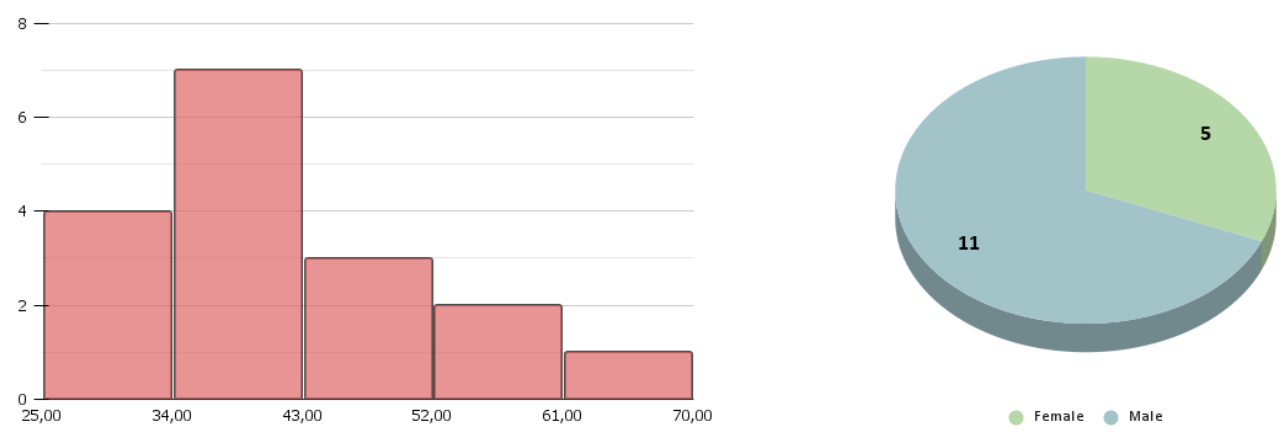

Figure 4.1: Age and Gender Distribution

Do you own a Smartphone?

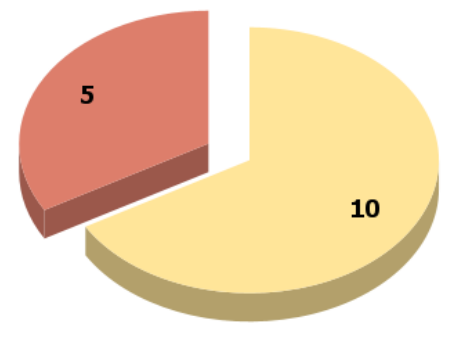

Yes No
Do you have internet access?

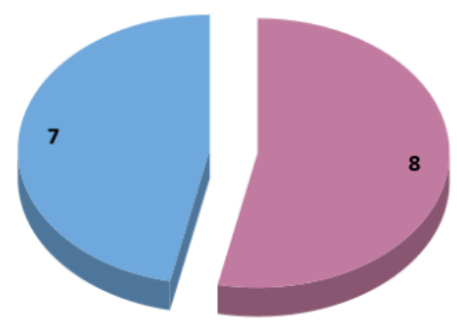

- Yes No

Figure 4.2: Smartphone and Internet Access

\subsubsection{Pedagogy Experience}

After the demographical questions, the following questions relied on the pedagogical experience. From those, the results were:

- On average, teachers had twelve career years as figure 4.3 shows.

- Regarding the educational levels, it is essential to note that study cycles in these countries are the same as in Portugal. With that in mind, there are four distinct study cycles: first cycle 
(that corresponds to primary school), second cycle (fifth and sixth grade), third cycle (from seventh to nine grade), and then finally, secondary school (that corresponds to high school). Thus, four interviewees were primary school teachers, four were second cycle teachers, seven were third cycle teachers, and only one worked in high school as we can see in figure 4.3 .

- About the usage of technology at work, as shown in figure 4.4 ten teachers reported not using technology in their job, even though four of them said they had used it before in other contexts besides work. Of the positive replies, the programs used were Microsoft Word, PowerPoint, and Excel. One interviewee also stated web searching.

- All the teachers affirmed that they usually scheduled homework for their students.

- None of the teachers interviewed had internet in their workplace.

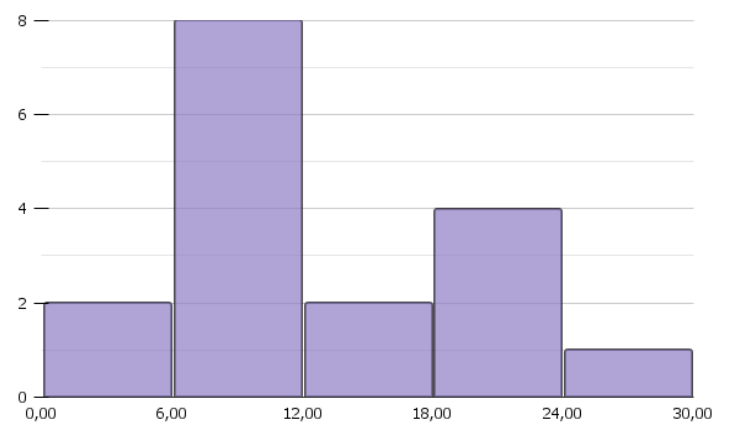

Education Levels

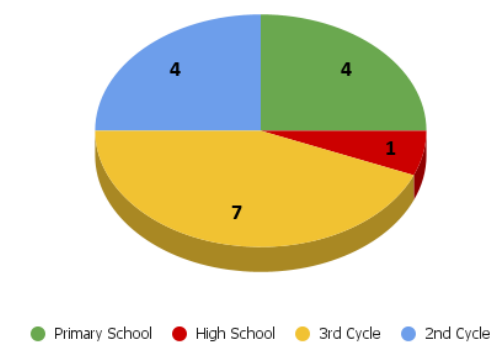

Figure 4.3: Carreer years distribution and Education Levels

Have you ever used any technology at work?

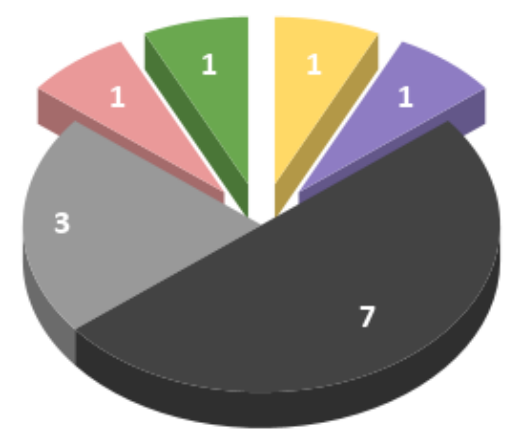

Figure 4.4: Technology Usage in the workplace 


\subsubsection{Open Ended Questions}

In the last questions of the interview, after introducing the concepts behind the app, teachers were asked about what they thought about this app and what they would like to see in it. Overall, the answers were very positive, describing this idea as very beneficial. Some teachers also pointed out that even though students sometimes do not possess the economic conditions to purchase a phone, this solution would help surpass the need to have a data plan to have internet access for education.

Their suggestions relied primarily on the types of content they would like to see working in the app: video, audio, read and write exercises, orality training, oral comprehension, and in the field of geography, access to didactic maps. Other suggestions relied on app functionalities, like watching the lesson's progress and a troubleshooting guide to help the teachers use the app.

\subsubsection{Requirements}

The interviews demonstrated overall very positive reception from the teacher's side of the app's idea, and with the suggestions and ideas that surged during the open questions and based on the requirements of the student's app, the teacher's app requirements to evaluate can be found in table 4.2.

\begin{tabular}{|l|l|l|}
\hline KR & Key Requirements & Priority \\
\hline KR- & As a Teacher I would like to & \\
\hline KR-1 & Create lessons & High \\
\hline KR-2 & Create lesson content & High \\
\hline KR-3 & Create Local Profile & High \\
\hline KR-4 & Edit local profile & High \\
\hline KR-5 & Edit Lesson & High \\
\hline KR-6 & Edit Content & High \\
\hline KR-7 & Delete Lesson & High \\
\hline KR-8 & Delete Content & High \\
\hline KR-9 & See Students Progress & Low \\
\hline KR-10 & See Statistics of Lessons Shared & Medium \\
\hline KR-11 & Share Course's content offline & High \\
\hline
\end{tabular}

Table 4.2: Teachers App Key Requirements

\subsection{Use Cases Diagram}

Use Cases diagram 4.5 was also designed, keeping in mind the different requirements observed before. The two different possible users are teachers and students. They share almost all use cases (identified in the ellipses), except for two since only teachers are meant to create class content, and only students should use it. 


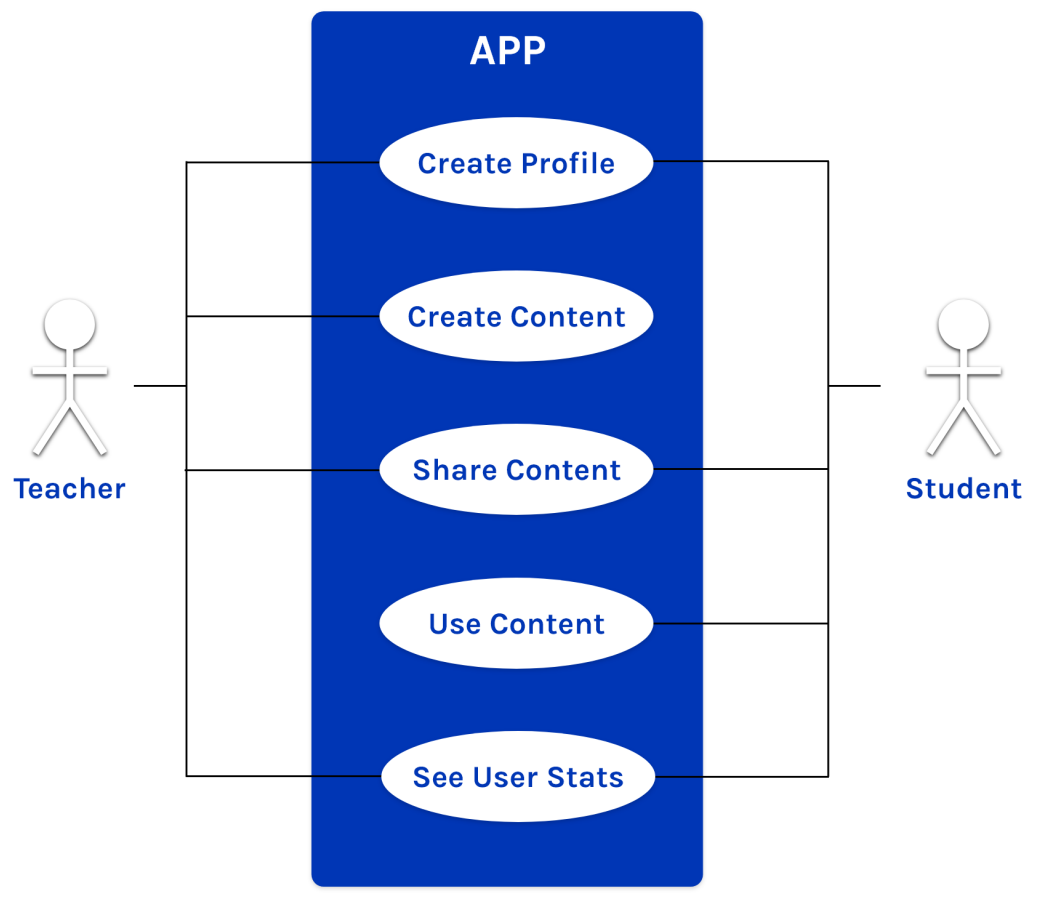

Figure 4.5: Use Cases Diagram 


\section{Chapter 5}

\section{Design}

Right after the requirements phase, with the interviews done and the FRAME model applied, the Design phase begins with creating personas that were fundamental for the later stages of this phase: the wireframing and the prototyping.

\subsection{Personas}

Based on the interviews and other observations made, the personas were designed on the different needs behind the usage of this system. For that, we created three distinct personas: two students from different study cycles and one teacher. Below we have a brief shortened version of the three personas:

\subsubsection{Márcio}

Age: 11

Gender: Male

Job: 5th Grade Student

Goals:

- Dreams of being a firefighter or an engineer

- Wants to play soccer or basketball in a regional team

- Have a pet dog

\section{Frustrations:}

- Lacks the motivation to study sometimes

- Doesn't like some of his teachers

- Has a short attention span

- Has dyslexia 


\section{Bio:}

Márcio was born in Piaui, Brazil. He is the only son of a loving couple. Márcio prefers playing outside with his friends to being inside the classroom. He usually gets decent grades, but sometimes he fails in some school subjects like maths and history. He usually studies with support from his father at home, which helps him do homework and prepare for evaluations. When his father doesn't have time to supervise him due to a more busy schedule at work, Márcio tends to skip homework.

\subsubsection{Luzia}

Age: 13

Gender: Female

Job: 7th Grade Student

Goals:

- Go to High School to study Sciences

- Sees herself as a doctor or nurse in the future

- Have Good Grades

- Spend more time with her little brother

\section{Frustrations:}

- Lacks extra study material

- Doesn't have a study companion

- Is slightly color blinded

Bio:

Born in Benguela, Angola, Luzia is the daughter of a couple of farmers. She loves the time she spends at school with her friends and is one of the best students in class. She has a little brother and spends part of her time at home helping her mother raising him. Even though she has excellent grades usually, she would love to have some company to study with her at home, like when she is in class.

\subsubsection{Adesh}

Age: 32

Gender: Male

Job: English Teacher

Goals:

- Be a good professional 
- Be a good father to his children

- Experiment giving classes to different school years

\section{Frustration:}

- Have a better salary

- Doesn't have a lot of time to have a hobby

- Has an elbow problem from a bike accident

Bio:

Adesh is from Patna, India. Even though he spent all his childhood in Bengaluru, after meeting his wife, Amita, he decided to go live in Patna. He moved with her to Patna to create a family and establish his career. Adesh teaches English at high school, giving extra classes to students who need more school support. Having three kids at home, he barely has spare time for himself. The time he wanted to spend doing some sport or hobby is spent planning and preparing all his classes.

A more detailed version of the personas can be found in appendix A, containing more information such as Quotes and personality traits.

\subsection{Wireframes}

Based on the different requirements and with the different personas in mind, wireframes were created using Balsamiq, an intuitive tool that focuses primarily on wireframe creation, using simple controls. The wireframes were created in five different boards:

1. Students Main Screens

2. Settings Screen

3. Lesson Screens

4. Teachers Main Screens

5. Content Creation Screens

\subsubsection{Student Main Screens}

The Student's options for navigation would rely upon three different main pages: the homepage, later called Library, the personal page, later called Notes, and the share page. Both Library and Notes pages are accessed through the navbar and the share page on the upper right corner in the Library. 


\subsubsection{Homepage}

As figure 5.1 shows the homepage starts with a greeting at the top of the screen that welcomes the student, depending on the time of the day the app is open. This way, the introductory approach sounds more friendly and comfortable to new users. The share button appears on the right side of the screen to help the students easily access the share page to send or receive educational content with their teachers and their colleagues. Bellow the top section of this page, highlighted, are the lessons listed for that day and also the different disciplines with archived lessons, already done before. Since the app is meant to work as a companion, if students decide to click the current date, their schedules expand on the screen.
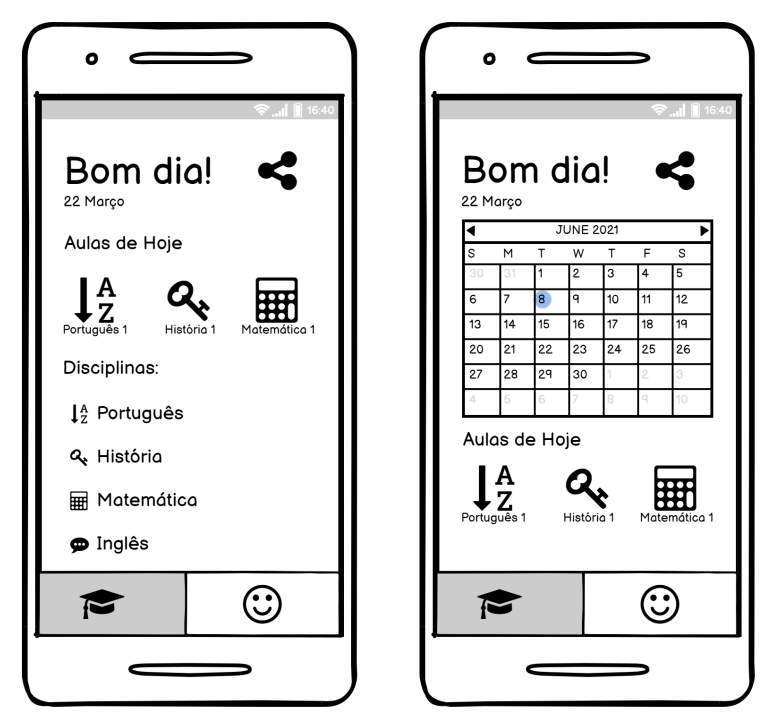

Figure 5.1: Students Homepage

\subsubsection{Personal Page}

The students can access their page on the navbar as figure 5.2 shows. It includes access to the content they marked as essential and medals due to achievements done while using the app as a gamified concept. On the top of the screen, the students can see their profile photos and the settings shortcut. The setting shortcut appears on this screen since it is something meant to be used infrequently. 

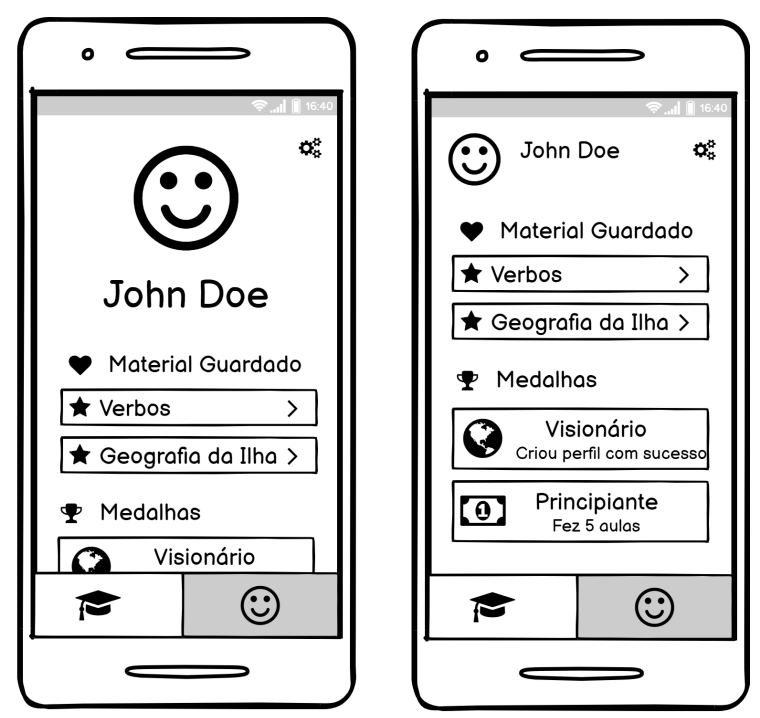

Figure 5.2: Students Personal Page

\subsubsection{Sharing Page}

This page can be accessed on the homepage and is straightforward in terms of what's supposed to do there. Figure 5.3 There are only three buttons: one meant to send content, one to receive content, and the back button, to go back to the main page. This way, the sharing process is simplified into the actions available.

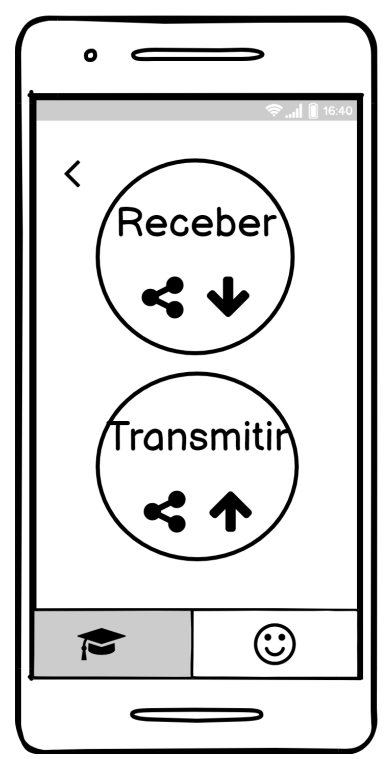

Figure 5.3: Students Sharing Page 


\subsubsection{Settings Screens}

As a continuation of the profile page, the settings introduce the different toggles and app capabilities regarding the app's usability. In addition, the settings regarded different accessibility needs such as Dark Mode, Bigger Fonts for the visually impaired, and subtitles for the audio impaired. Students can also change their information and profile picture and, to establish a lifestyle change, they can set daily reminders to use the app. Figure 5.4 shows the different screens found in the app's settings.
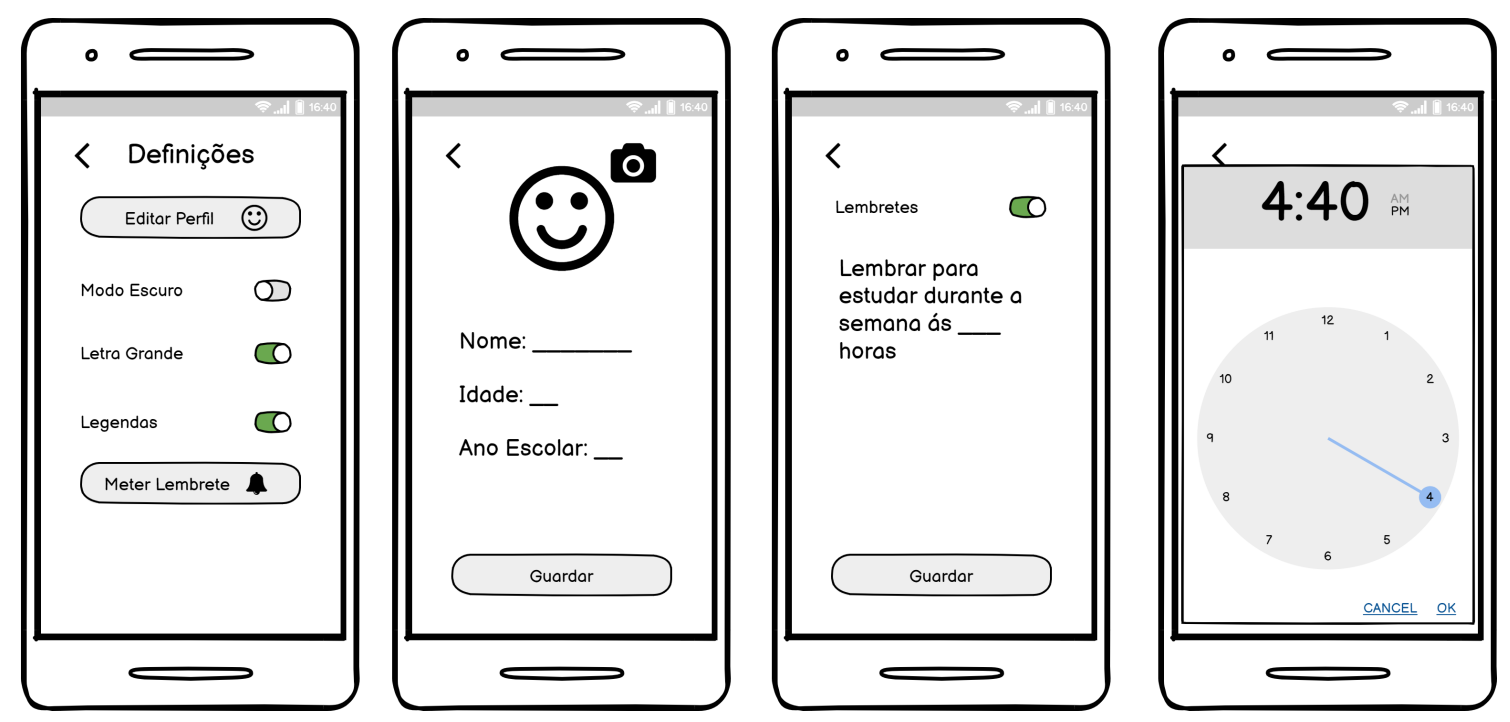

Figure 5.4: Settings Page

\subsubsection{Lessons Screens}

When a student decides to start a lesson, on the home screen, after selecting it, the lesson opens. Before clicking start, the student can read a brief description of the content explored in that lesson, and, after pressing start, the different tasks show up. As shown in figure 5.5, on the task screen, the screen is divided principally into three distinct parts:

1. the status bar, displaying how much of the lesson was completed by the student

2. the task itself

3. the confirmation button that validates a task solution 


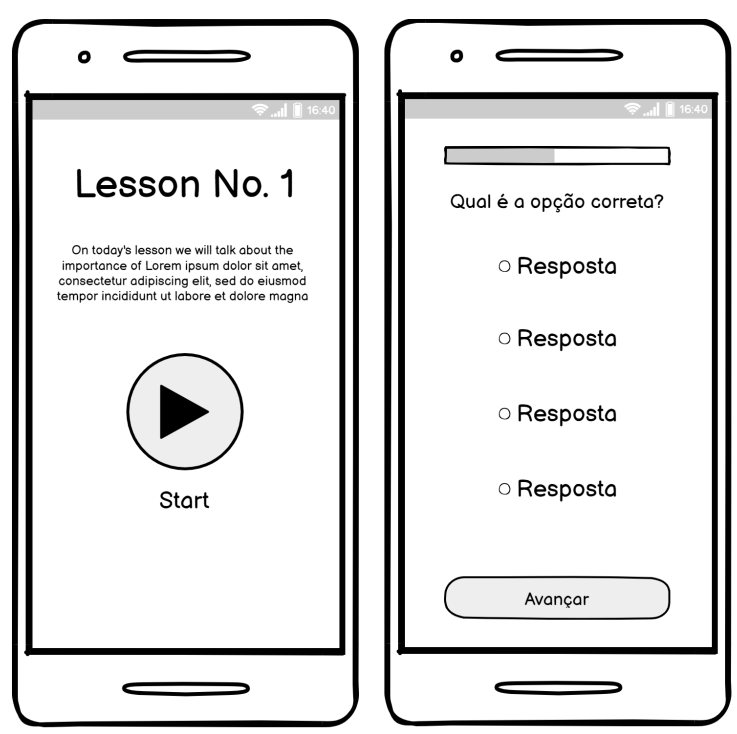

Figure 5.5: Students Lesson Screens

The tasks can take multiple formats, depending on what is being asked. This task is a multiplechoice question. Other formats can be found in the appendix C.

\subsubsection{Teachers Main Screens}

On the teacher's app, the paradigm was different: instead of displaying educational content, this app should enable the creation of that same content. With that in mind, this app experience should be similar to one of document creation. So, below the search and profile icon at the top of the app, a create lesson button allows teachers to generate lesson documents. A lesson contains the different tasks and educational content for one session. Underneath the button, previously created lessons can be found with some quick controls. When clicking on the profile icon, the teachers can see their profiles, displaying personal information and stats related to classes already shared with their students. There is also a settings button presented in the same position as in the student's profile screen as we can see in figure 5.6. 


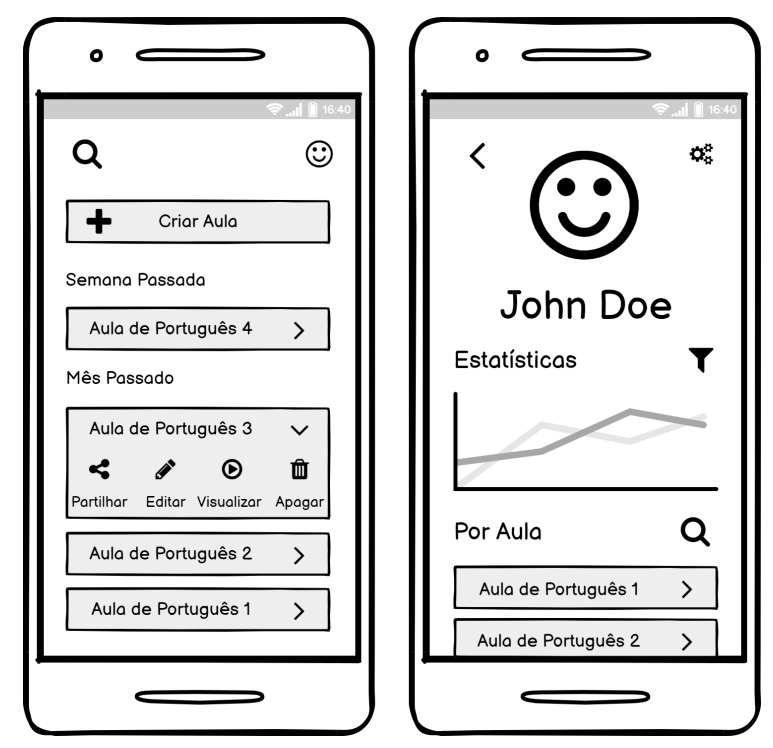

Figure 5.6: Teacher Main Screens

\subsubsection{Content Creation Screens}

After creating a lesson, or when editing one, teachers have to fill a class with content, such as questions, text, audio, video, and other contents. Similar to creating a lesson, a button to create content, and content already created with shortcuts, is displayed when inside a lesson's menu. However, distinct from the teacher's homepage, this time, the top of the screen allows the user to change the lesson's name and the content name. When creating content, a dropdown menu can be found below the name to select the type of content or its format. Based on the type of content, the content menu alters. Figure 5.7 shows the content creation screens.
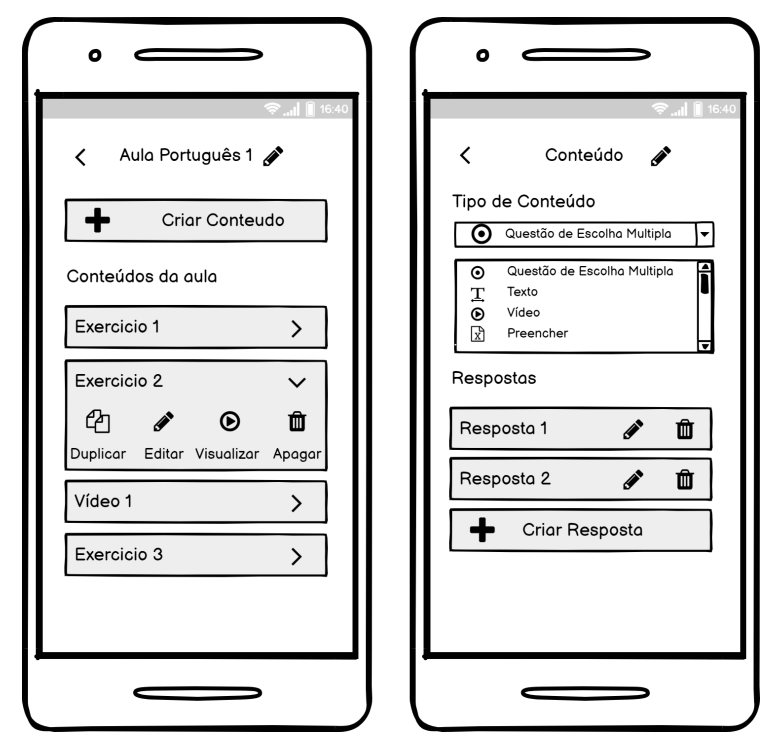

Figure 5.7: Content Creation Screens 


\subsection{Prototyping}

There was a necessity to make the prototypes as closer to a finished product as possible to test how the students and teachers would interact with the different interfaces. With that in mind, a highresolution prototype was conceived using Adobe XD. Dissimilar to Balsamiq, using Adobe XD allowed to personalize the prototype's components with more complexity, and more importantly, create a user flow using transitions with actions and triggers.

\subsubsection{Teachers App}

The teacher's app design was relatively minimal, using line icons and buttons with contrasting colors. Another design choice was putting an instructional text with what to do in case the pages were empty as we can see in figure 5.8.

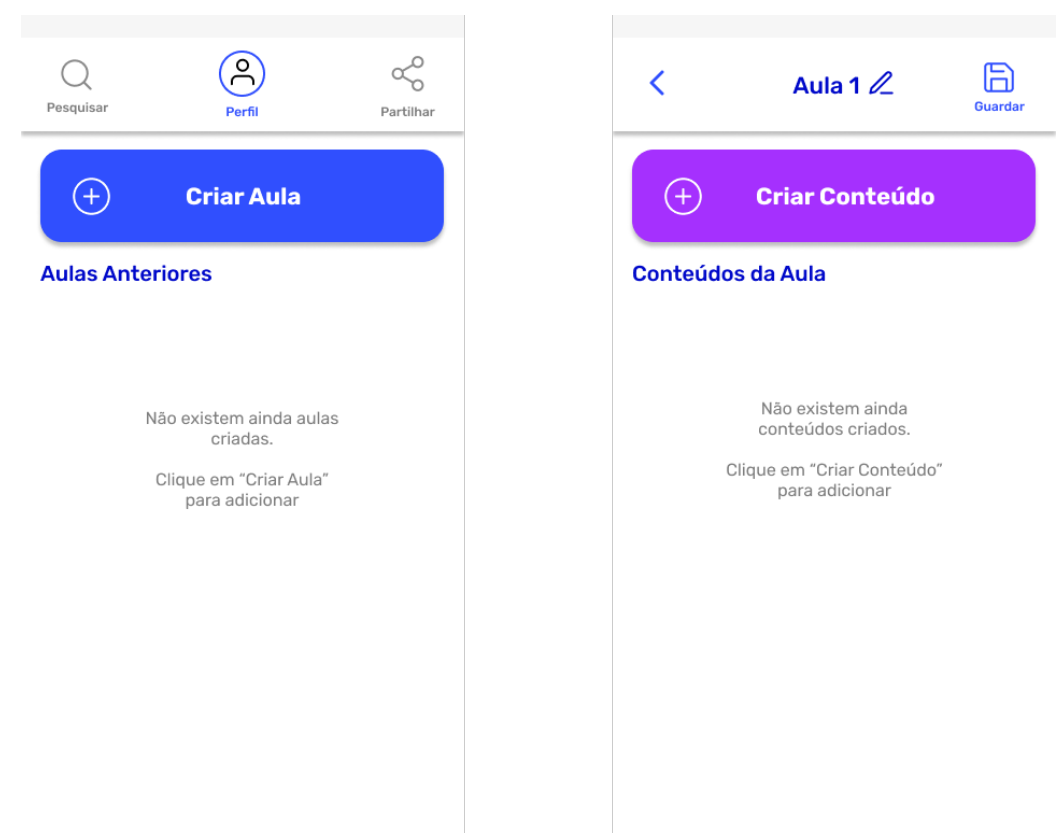

Figure 5.8: Teachers Screens with instructions

More screens related to the teacher's app can be found in appendix D.

\subsubsection{Students App}

In this case, the design was more ludic and dynamic, using colored icons with drawings and more colors. Regarding accessibility, to help Dyslexic students, the font used was OpenDyslexic, which is designed to be easier to read for people with dyslexia. The symbols used relly on classroom material, especially books since they are ways to transmit knowledge without requiring the internet. Figure 5.9 shows this design choices. 


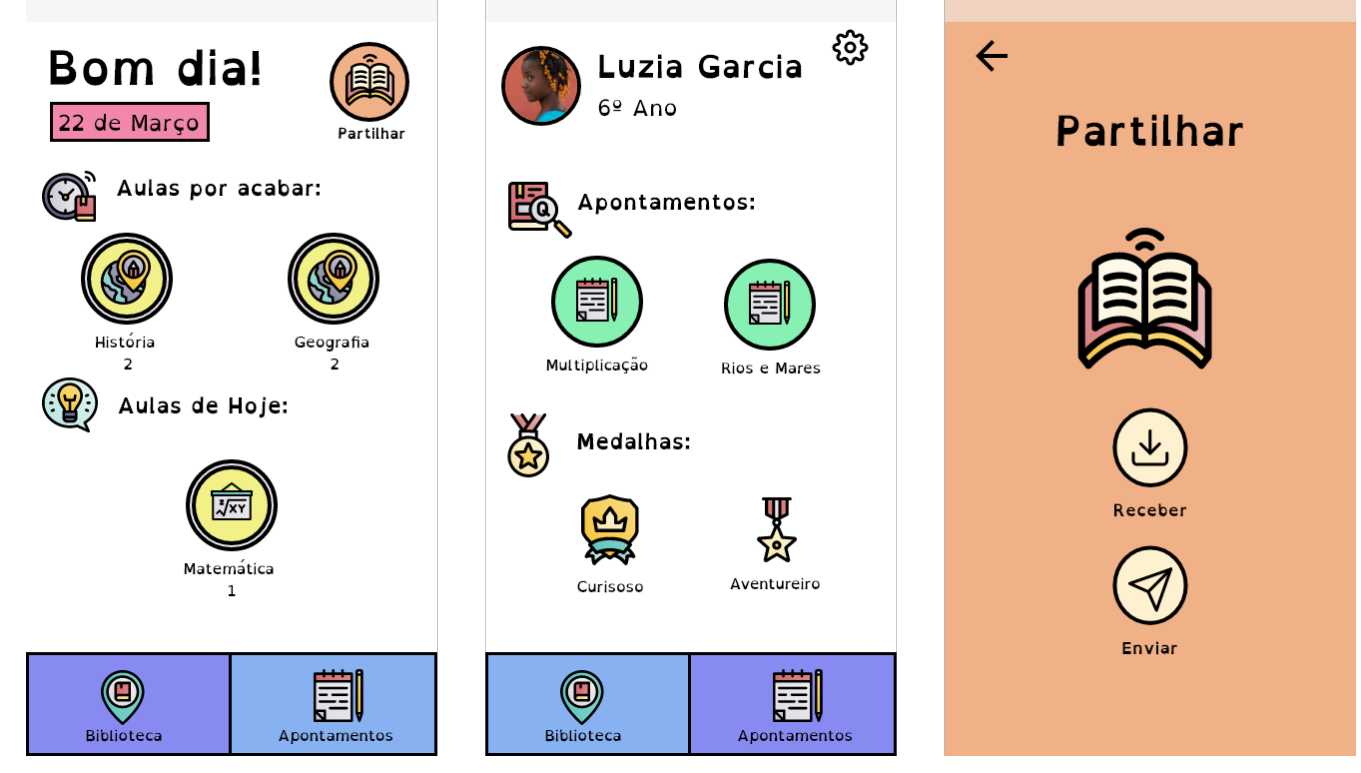

Figure 5.9: Students Main Screens

More screens related to the students app can be found in appendix E. 


\section{Chapter 6}

\section{Evaluation}

After the design phase was completed, the next big challenge in this dissertation was evaluating the prototypes since the communication was difficult and the ways to communicate were limited and unrelenting. With that in mind, there was a need to be very efficient since there were only a few short opportunities to contact the teachers reached before.

\subsection{Teacher's App}

Even though the initial focus of the requirements was the student's app, the first contact made was with the teachers. In order for them to be able to test with their students, the best way to introduce these apps relied on examining if they had an enjoyable experience using the app where they had to create the class's content. Furthermore, it was crucial to test the teachers first just in case the class format tested with the students needed considerable modifications based on the ease of using and creating class content.

\subsubsection{Methodology}

Since the ways to communicate with the teachers were very limited, the evaluation had to consider the different possible scenarios that we could encounter.

During the interviews, near the end, the teachers were invited to keep in contact via email or WhatsApp. These ways to contact do not rely on making costly phone calls and are a more carefree approach to build bridges and communicate. Of all sixteen teachers interviewed, only one provided their email, and five of them provided their WhatsApp contact as figure 6.1 shows. 


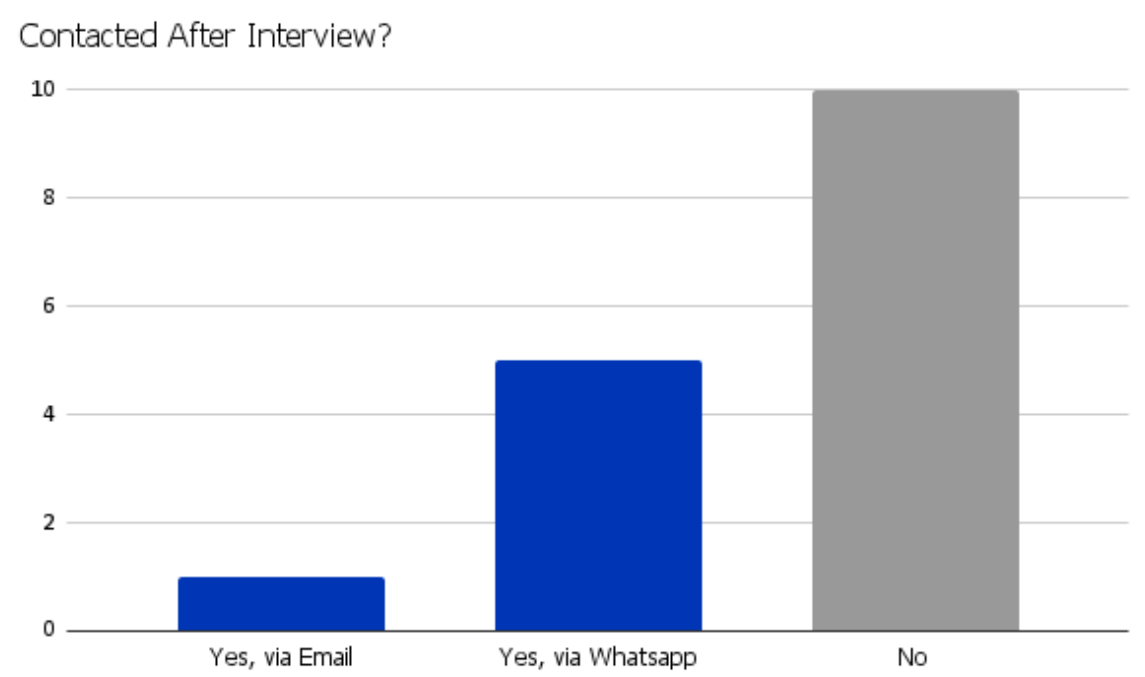

Figure 6.1: Contacts Shared

After the prototypes were completed, at the end of the design phase, the teachers who provided their contact were then invited to participate in their evaluation. Out of the six contacts available, four showed availability to participate, one did not answer, and another one informed us that the usability test couldn't be done since his internet data plan was about to cease.

One of the teachers talked about the experience with some of her co-workers and shared their contacts since they showed interest in also participating in using the prototypes. The new teachers were asked only the closed questions of the interview to obtain more information related to their demographics, technology knowledge, and ease of access to it, instead of making the full interview questions since the requirements phase was over. With that, in the end, seven teachers participated in the evaluation phase.

After scheduling the sessions, a call was made via WhatsApp to check in what format the test would be done. The test format would depend on the conditions present in the time of the call, following the methodology shown in figure 6.2. A Direct test occurs when the participants performed the tasks directly in their own devices, interacting with the prototypes. The teacher who contacted via email also had a Whatsapp contact, so the starting point to each test was a WhatsApp call. The first method to try was the direct one. At the beginning of each call, it would be settled if the participants were available at the moment to test, and a link to perform the test directly would be sent in a message.

The first attempt to test had to be rescheduled since the prototype had a big loading time on the users' phone, and a smaller-sized version (with every screen and functionality) was tested again in the same afternoon. This happened since Maze was not importing the teacher's prototype correctly from adobe XD, so the first solution implied to export it as screenshots and use them in Figma directly with transparent squares to trigger the screen animations and transitions. The 
loading times were high due to the rendering of the screenshot images. Due to this issue, the prototype had to be redone totally on Figma, but exactly in the same format.

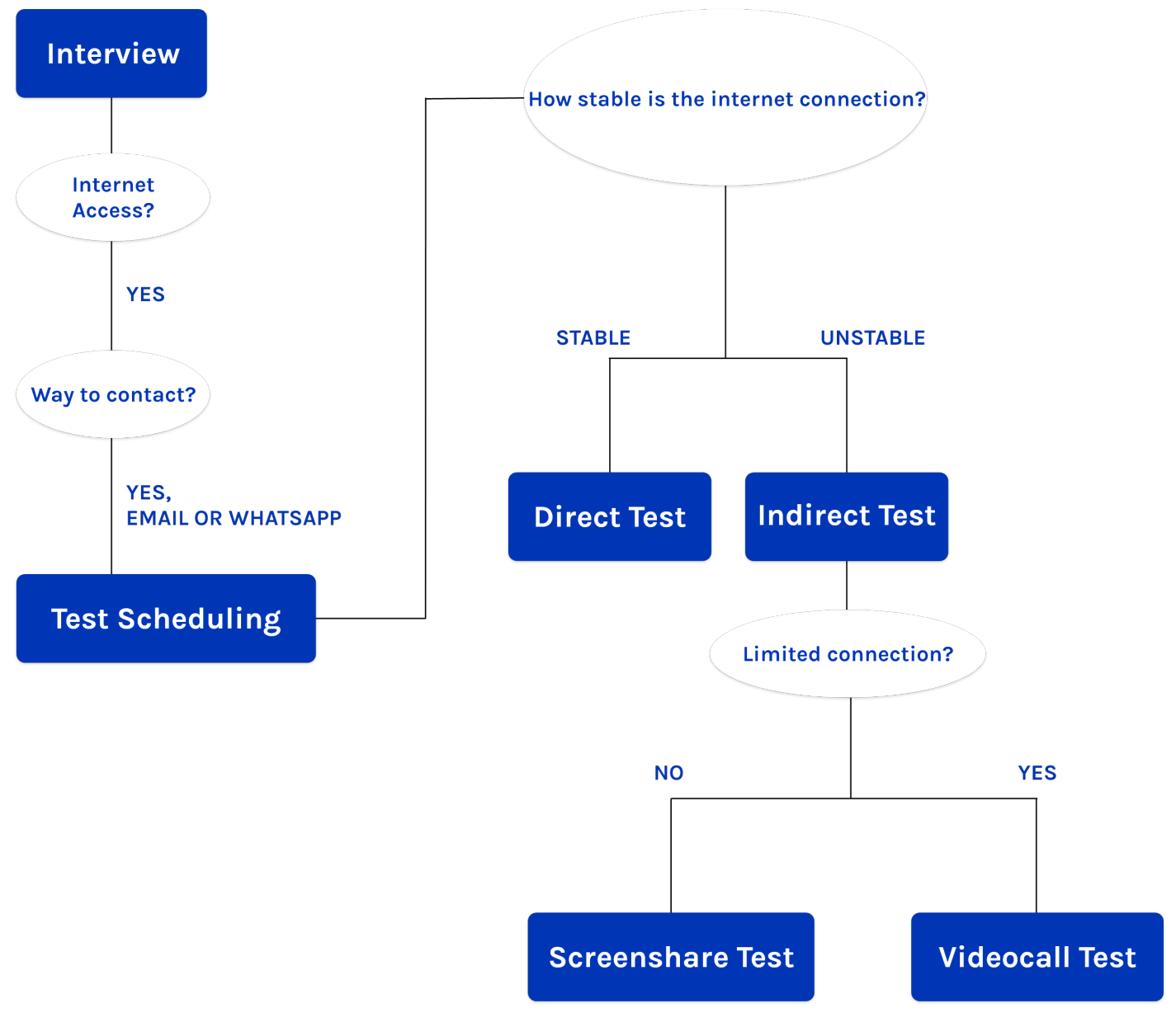

Figure 6.2: Methodology Scheme

During the call, the participants would be asked to open the link and tell what they saw on the screen in order to troubleshoot if necessary. This way, the loading times would show how good was the connection, and if the connection or the mobile device wasn't suitable enough to load the project, the test would have to be made indirectly since the user wouldn't be able to interact directly with the prototype. In case it would have to be an indirect test due to an unstable connection, the participants would be asked if the connection was limited and also if they could perform the test in Facebook Messenger. Indirect test implied that the interaction would be done in the facilitator's device. The question related to Facebook messenger was important since, on the video calls option, there is a functionality that allows screen sharing, making the test more comfortable and reliable. Screenshare test required the facilitator to share the screen directly through the communication app used to call the participant. If the participants had a limited data plan and did not have Facebook messenger, the test would be a Videocall test, where the phone 
back camera would display what was on the computer screen, in portrait mode to show the content on the same proportion as on the video call screen. From the teachers that shared their contacts, the types of test performed occured as shown in figure 6.3.
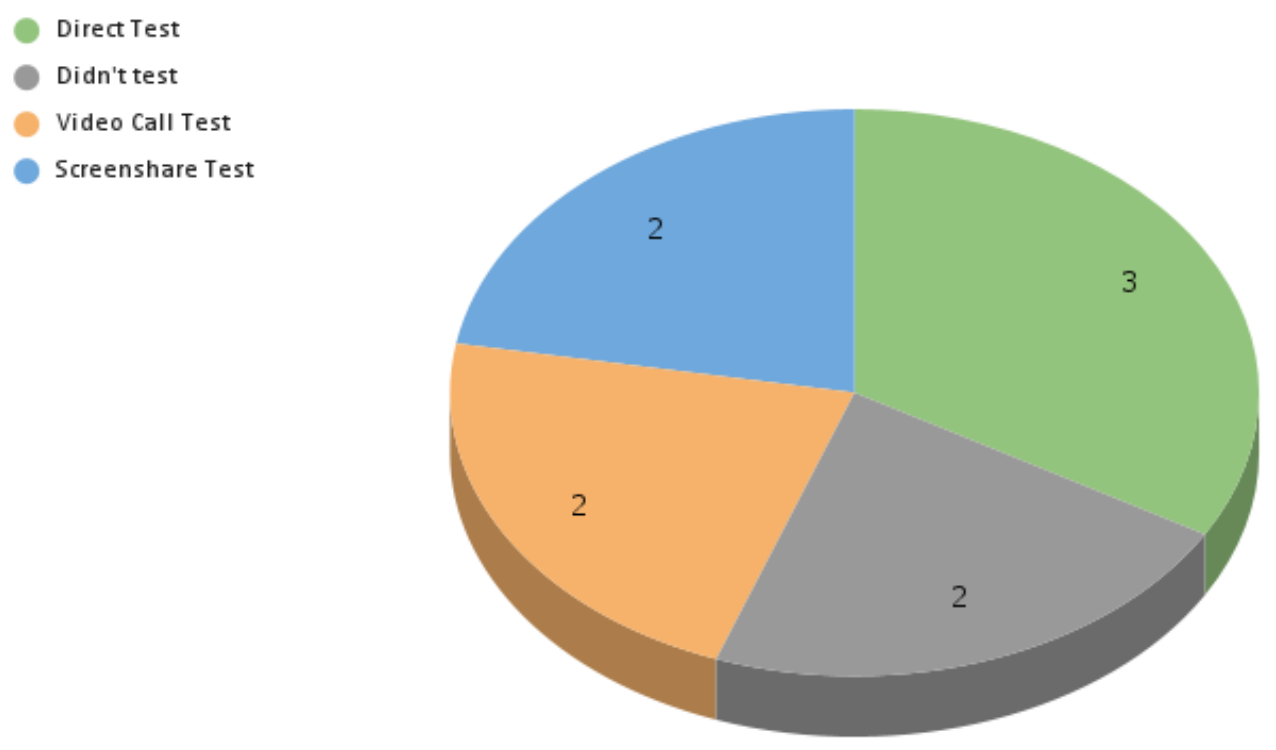

Figure 6.3: Interaction with the contacts

\subsubsection{Direct Test}

In the direct test, participants would be invited to open the link with the prototype in maze on their browsers and think aloud what they were thinking and seeing. During the test, a call was made with a facilitator via Whatsapp in case troubleshoot was needed.

In this method, the role of a facilitator is limited since what happens on the other side of the call cannot be directly supervised or interacted. The facilitator's approach has to be done with more perception in case the participant had any doubt.

\section{Advantages}

- The participants interacted directly and experienced by themselves the prototype.

- Using maze, we can visualize easily where the participant clicked and how they interacted with the prototype.

- The facilitator role needs less involvement in the process, making the results more realistic in terms of real-time usage by the users on the first time.

- The participants tested the prototype on their own devices, being more manageable to know the device's controls and limitations. 


\section{Drawbacks}

- Require a stable and proper connection to the internet to test. Out of seven participants, only three were able to open the link and load the prototype.

- Loading times while using the prototype might have slight changes due to the internet usage to make the call. Moreover, the exact opposite correlation happened since the internet usage on the prototype affected the call quality.

- Not possible to watch the facial and body expressions of the participants.

\subsubsection{Screen Share Test}

If the network conditions were not good enough or unstable, the evaluations proceeded with the indirect methods, which means that the user would not interact directly with the interfaces, but rather give guidance regardless of where to interact to achieve specific objectives. In order to screen share, the participants would be asked if they had a video call app that allowed screen sharing. The app used in this case turned out to be Facebook Messenger. While on call, the participant would be asked what paths and where to click to perform. Of the seven participants, two realized the test using this system.

\section{Advantages}

- Shorter loading times since opening the experience relied on the facilitator device

- Less usage of participants' device multitasking since only one app was needed to view the interfaces, which also affects the internet usage on the device, being possible to have better streaming resolution and quality.

- Partial scaling of the screen proportions, so the image on the participant's side was slightly adapted to the proportions on the facilitator's device.

- The facial and body expressions could be noticed if the participants decided to enable their cameras.

\section{Drawbacks}

- Harder to record possible misclicks

- The facilitator is more involved than in the direct test method by clicking on the interface instead of watching the participant's performance.

- Less immersive experience compared to direct testing since the performance depended on the ability to talk comfortably with the facilitator due to possible impostor syndrome. 


\subsubsection{Video Call Test}

If the network conditions were limited due to limitations on the data plans or lack of other ways to communicate that allowed screen share, the users were asked if they could do a direct video call with the facilitator, where the facilitator's back camera would be showing the screens in another screen (ex: tablet, laptop computer, desktop computer) The prototype would be recorded in portrait mode, and again the facilitator would interact with the screen that was being recorded directly. While on call, the participant would be asked what paths and where to click to perform. Of the seven participants, two realized the test using this mode.

\section{Advantages}

- It needs even fewer resources on the facilitator's device than the screen sharing method since the device that's being recorded is the one that needs to open the experience.

- The capability of zooming in on the elements, in case of poor readability, is possible and helpful in case the internet signal is weak, and the image quality on the participant's device is not the best.

- The facial and body expressions could be noticed if the participants decided to enable their cameras.

- It is the most straightforward method since it only relies upon using the same app for the initial call.

\section{Drawbacks}

- It might be challenging to record steadily in case a tripod is not used on the facilitator's side

- Bad screen scaling, since it depends on the facilitator's camera proportion

- The facilitator is even more involved in the experience since there is a need to know if the interfaces display correctly on the participant's side.

- The least immersive experience of the methods, since the display of the interfaces is the least closed to the prototype look on the participant's device.

\subsubsection{Tools}

\subsubsection{Maze with Figma}

For the prototype evaluation, the teachers who shared their Whatsapp personal contacts were invited to experiment with the teacher's app using Maze, a platform to perform usability tests based in a task-oriented environment, where the user is asked to perform different missions. This tool was chosen since it registers the users' paths and where the clicks and misclicks happened. The tool works with prototypes from different apps, such as Figma, Adobe XD and Invision. 
However, on the first attempt to use the tool with Adobe XD, the import had some issues because the prototype had many screens, and some elements were missing. Due to that, the prototype had to be redone in Figma, after a first attempt of moving the screenshots directly from Adobe XD to Figma. The loading times were too big, and after the first attempt to test with the first teacher, the experience would not open due to the screenshots' big resolution. After redoing only the essential screens in Figma, the loading times performance were much better.

The platform has many advantages regardless of testing in a remote environment since it can record the participants' performance when interacting with the interfaces with their hands. The tool has two different stages, the draft maze, and the live Maze. The draft stages enable the test creator to edit and create different tasks according to the objective it wants to evaluate. The live stage is irreversible, which means it does not allow edits on the tasks done after the draft stage since the results are recorded, and the participant's performance is stored.

\subsubsection{Messaging Apps}

In order to maintain contact, schedule, and share links and other information, the participants were contacted using messaging apps to skip the expensive costs regarding international calls, as done in the first contact during the requirements phase. For the facilitator job in remote regimes, the participants needed contact on the other side of the line to troubleshoot problems they might have, opinions they wanted to share, and thoughts concerning the prototype they were testing. The scheduling was done using Whatsapp and Gmail to pick a date the participants would be available, and the call apps using the testing were once again WhatsApp and, in case the connections were not limited, and the participants had Facebook, Facebook Messenger since it allowed screen sharing inside the app on mobile devices.

\subsubsection{Participants}

The participants for these experiments were expected to be from the target group of teachers and educators. The recruitment job was simplified since the initial contact for most of them was done during the interviews on the requirements phase. The other teachers that participated came from a direct referral from a teacher that had done the experience and recommended it to her colleagues.

Of the seven participants:

- Four participants worked with students from 1 st to 4 th grade, and the other three worked with students from the 7th to 9th grade.

- Five participants already used before programs like Word, Powerpoint, and Excel in the teaching activity. Two never used technology on their job.

- As required to perform the tests, all of them had a smartphone and internet access.

- Four participants were from Cape Verde, and the other three were from Guinea Bissau. Most of the teachers involved were women, in this case, five participants. 


\subsubsection{Tasks}

The participants tested the teacher's app to see how they could create content inside the app and navigate through it. Since the participants already previously used their mobile devices and could comfortably express what they were thinking, they were invited to perform seven different tasks in the prototype:

- Task 1 - Create and Save Lesson

- Task 2 - Create a Multiple Choice Question and Save

- Task 3 - Edit Solution from Exercise 1 to Answer 2

- Task 4 - Duplicate Exercise 1

- Task 5 - Delete Copy of Exercise 1

- Task 6 - Edit Profile Information

- Task 7 - Send Lesson 1

At the end of the seven tasks, the teachers were also asked how much they liked the experience using a smiley scale. All of these tasks were performed while on call, with a facilitator troubleshooting and helping the participants.

\subsubsection{Results}

\subsubsection{Task 1}

For the first task, the participants were requested to create a class from the main menu and then save it. This task was already an interesting question since the approach regarding this tool should be similar to programs meant to create documents. The class document had to be created and could be saved immediately as a blank document. From all the participants, five saved the document blank. The other two participants, instead of saving the class empty, decided to create an exercise first. The average duration for this task was around 2 minutes. The participant's heatmap corresponding to the user journey that required fewer screens to navigate and solve the task 1 is represented in figure 6.4 with the clicks done by participants. 

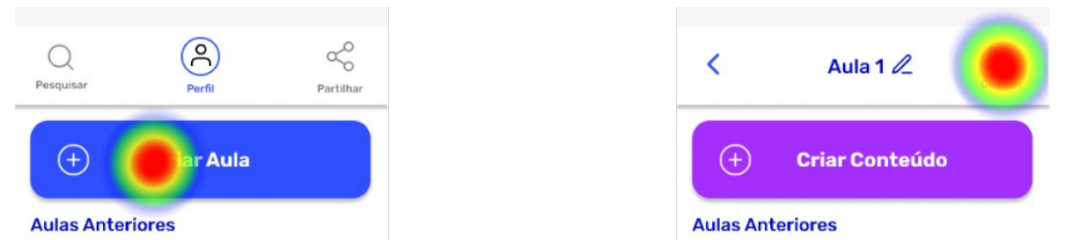

Aulas Anteriores
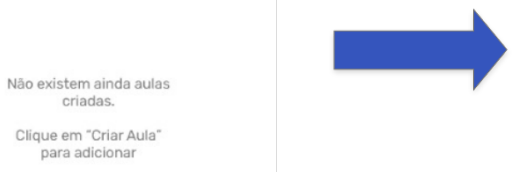

Nåo existem ainda
conteúdos criados.

Clique em "Criar Conteúdo"

Figure 6.4: Task 1 Direct Path Heatmap

\subsubsection{Task 2}

The participants had to create a multiple choice question directly inside the class menu on the second task. All of the participants were able to create it since the controls were very similar to creating a class, and two already reproduced this task in task 1 . To create a multiple-choice question, the participants had to expand the content type button and select the suitable option. With that done, they only needed to save after. The average duration for this task is about 1 min and 34 seconds. The participant's heatmap corresponding to the user journey that required fewer screens to navigate and solve the task 2 is represented in figure 6.5 with the clicks done by participants.

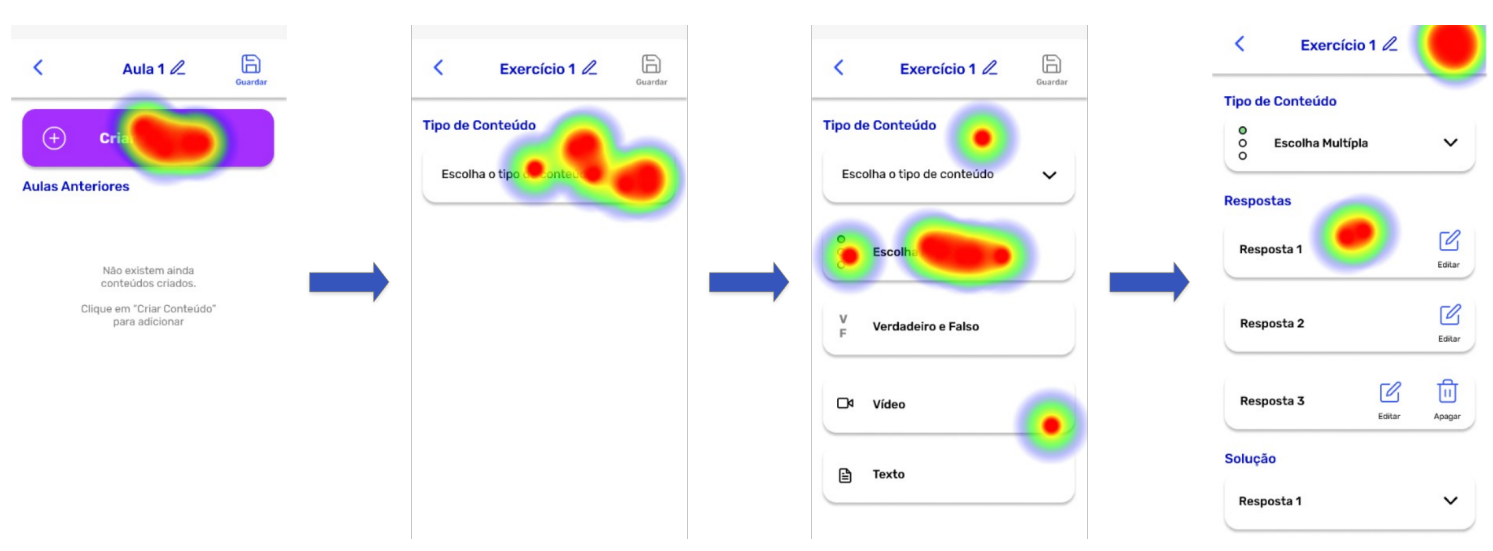

Figure 6.5: Task 2 Direct Path Heatmap 


\subsubsection{Task 3}

On the third task, the participants had to edit the solution of the exercise they had just created. Using the controls when clicking in the exercise, they could find the edit button to open the question menu. Inside the question menu, participants had to swipe down to reach the solution section. Clicking on the solution button expanded the solutions menu, and participants had to select the second answer. All the participants concluded this task, and except one participant, who misclicked on the duplicate button, every other participant did it directly. Since this was a more complex task, the average duration of this task is around $3 \mathrm{~min}$ and 10 seconds. The participant's heatmap corresponding to the user journey that required fewer screens to navigate and solve the task 3 is represented in figure 6.6 with the clicks done by participants.

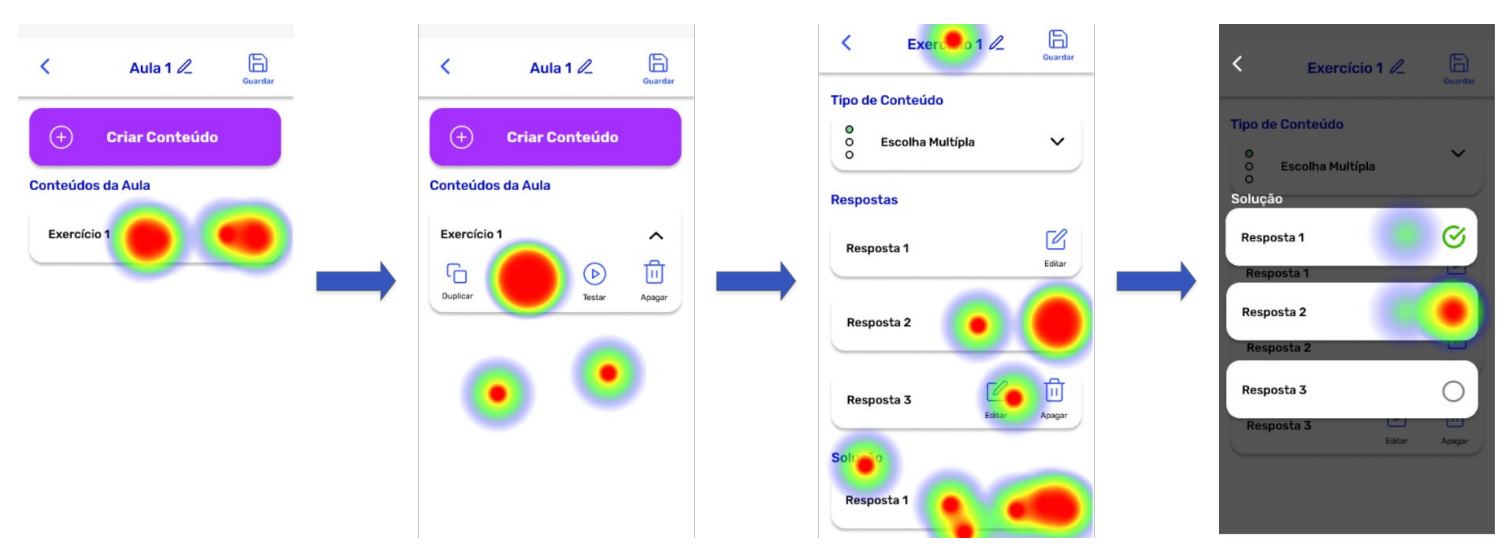

Figure 6.6: Task 3 Direct Path Heatmap

\subsubsection{Task 4}

Task number 4 required the participants to duplicate exercise one. For that, they only needed to click on the duplicate button when expanding the exercise one, like on the last task, to reach the quick controls. All of the participants concluded the task, but one initially thought that the button to duplicate was inside the edit question menu. With that, the average duration of this task is around 1 minute. The participant's heatmap corresponding to the user journey that required fewer screens to navigate and solve the task 4 is represented in figure 6.7 with the clicks done by participants. 


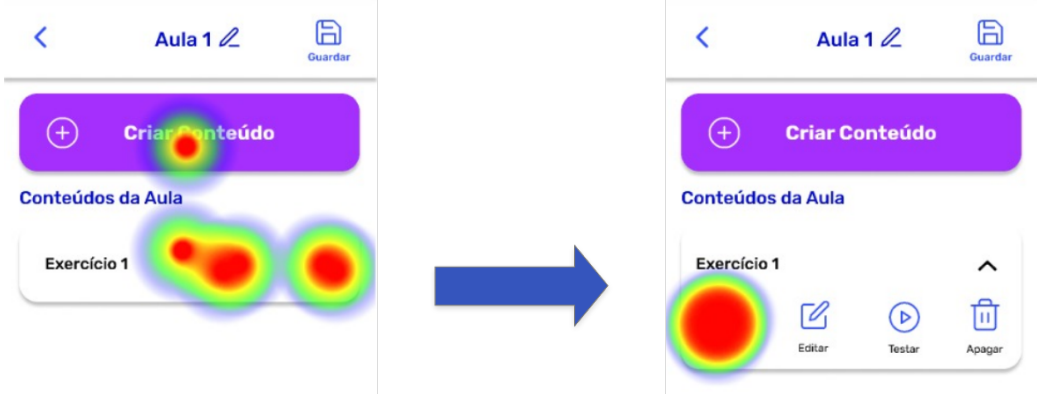

Figure 6.7: Task 4 Direct Path Heatmap

\subsubsection{Task 5}

Like on task number 4, task number 5 relied on the same controls, but in this case, the participant had to delete the copy of the exercise one done in the last question. Familiar with the controls, all participants concluded the task quickly, spending half the time they did in the task before: 30 seconds. The participant's heatmap corresponding to the user journey that required fewer screens to navigate and solve the task 5 is represented in figure 6.8 with the clicks done by participants.

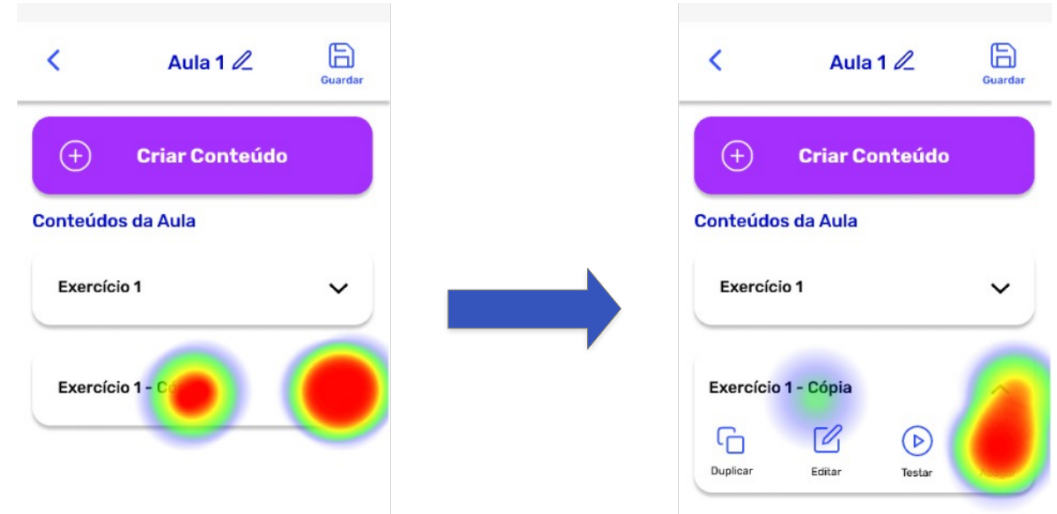

Figure 6.8: Task 5 Direct Path Heatmap 


\subsubsection{Task 6}

In order to test other sections inside the app, task number 6 had in mind the teacher's profile inside the app. In this section, we can see the personal information related to the teacher and the content already shared by that account. For that, in the main menu, the participants had to click on the avatar icon above to reach the profile section and then click on the edit button. This task had an average duration of 1 minute and 17 seconds and was done accurately and right by all participants. The participant's heatmap corresponding to the user journey that required fewer screens to navigate and solve the task 6 is represented in figure 6.9 with the clicks done by participants.

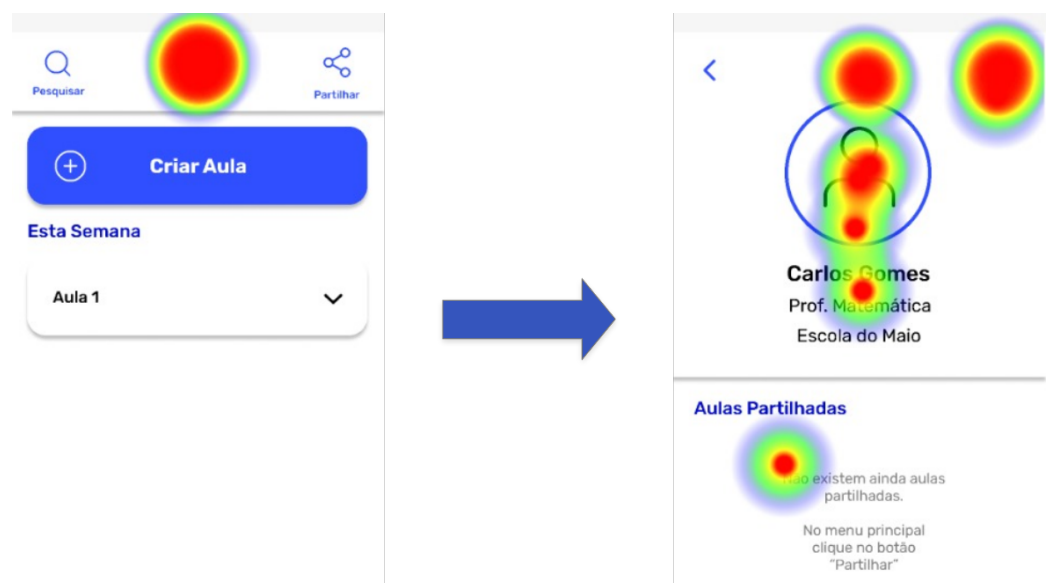

Figure 6.9: Task 6 Direct Path Heatmap

\subsubsection{Task 7}

To finish, task 7 had in mind one of the fundamental parts of this app: sending lessons to students. So, to test this, the participants had to access the share menu and select and send the lesson created before. There were two ways to reach the share menu: one was through the share button on the top of the page, visibly direct, and the other one by clicking and expanding the lesson menu, similar to the controls used before in tasks 3,4 , and 5. Interestingly only one of the seven teachers used the button located at the top of the screen that goes directly to the share menu. The rest of the participants chose to expand the lesson button to share it. This task was done correctly by all participants in an average time of 1 minute and 12 seconds. The participant's heatmap corresponding to the user journey that required fewer screens to navigate and solve the task 7 is represented in figure 6.10 with the clicks done by participants. 


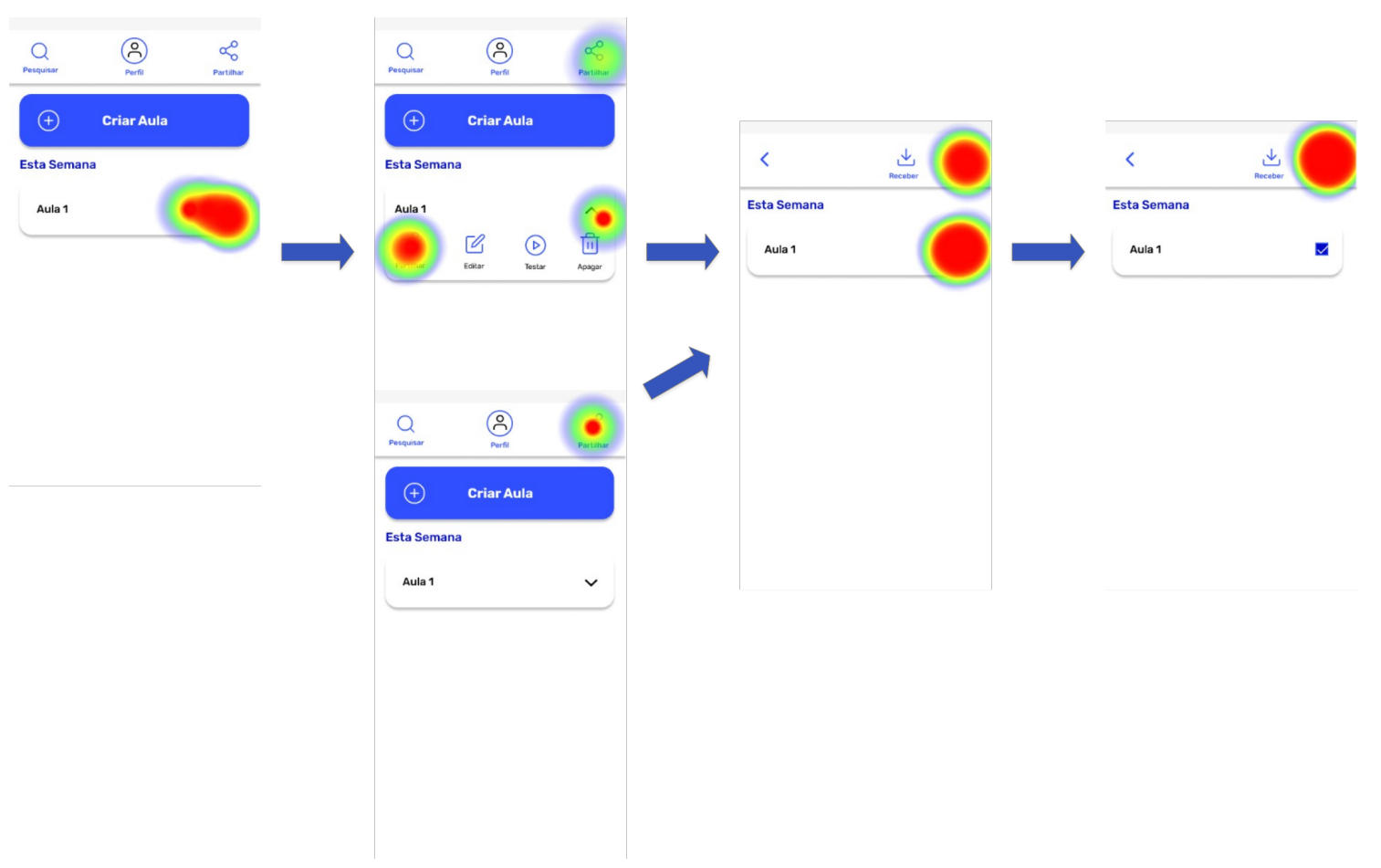

Figure 6.10: Task 7 Direct Path Heatmap

\subsubsection{Feedback}

At the end of the seven tasks, the teachers were asked how much they liked the experience using a smiley scale with five different faces. Every participant reported the sessions as an overall very positive experience. One of the participants rated the experience very positive during the call but selected the grumpy face because she did not distinguish the feedback question from a task.

\subsubsection{Conclusions}

The table 6.1 shows the teacher's average time to complete the test based on the types of tests done. As expected, the most complex task was the one where participants took more time, task 3. It can also be observed in the table that the test type that took more time to complete all tasks was the videocall. This result is primarily due to the considerable delay in the call since the most severe network conditions. However, independent of the network conditions and test types, all teachers had a positive experience. 


\begin{tabular}{|l|l|l|l|}
\hline Test Type & Direct Test & Screenhare Test & Videocall Test \\
\hline Number of Participants & 3 & 2 & 2 \\
\hline Task 1 Average Time (s) & 134.8 & 51,1 & 181.9 \\
\hline Task 2 Average Time (s) & 68.4 & 72.5 & 153.9 \\
\hline Task 3 Average Time (s) & 262.5 & 151.4 & 122.8 \\
\hline Task 4 Average Time (s) & 48.2 & 72.3 & 71.3 \\
\hline Task 5 Average Time (s) & 25.5 & 28.4 & 40.3 \\
\hline Task 6 Average Time (s) & 61.8 & 33.7 & 145.4 \\
\hline Task 7 Average Time (s) & 77.3 & 69.1 & 66.4 \\
\hline Total Average Time (s) & 653,2 & 450.4 & 741.8 \\
\hline Average Feedback Score & 5.0 & 5.0 & 5.0 \\
\hline
\end{tabular}

Table 6.1: Teachers App Results Overview

\subsection{Student's App}

The student's app turned out to be the biggest challenge to test since it would require:

- stable connection to perform the test in Maze directly

- a device to test all the students

- teachers availability to troubleshoot eventual problems and be a possible facilitator

Two teachers who performed the direct test showed steady internet connection and were invited to perform the activity with their students in class. The two teachers showed interest in this activity, but only one performed the tests in the end since the other one had calendar issues that would not make the experience possible.

\subsubsection{Methodology}

Similar to the direct test, as written above, this test would have to be done using Maze to record the students' interactions with the interfaces. This time though, the supervision was minimal, with the teacher handing her device to her students, one by one, to perform the tests.

\subsubsection{Tools}

\subsubsection{Maze with Adobe XD}

Once again, Maze was used for the participants to interact with the prototypes. The message with the mission to accomplish was fundamental since it covered the lack of supervision. This time, on the opposite of the teacher's app, the prototypes were correctly imported from Adobe XD since 
the number of assets to load was lower than on the teacher's app, not requiring extra time to copy the prototype in Figma due to importing errors.

\subsubsection{Participants}

This time the participants had more specific requirements since being a student was not enough to perform the tests in this remote mode: the students were required to know how to read, so they could read the instructions that existed in Maze. The participants turned out to be ten students, from a primary school in Cape Verde, in the third and fourth grades taught by a teacher that already participated in the teachers test.

These participants were the best target audience to experiment with the prototypes since the ability to read is not yet totally endured, but the app should meet their needs undeviatingly, not requiring advanced knowledge to navigate in the app. It also is the best target audience since the best way to combat illiteracy comes from an early age, and so the app should encourage these students to study more by giving them a more comfortable learning experience.

\subsubsection{Tasks}

For the student's app, the number of tasks and complexity had to be as short and straightforward as possible, since the network conditions inside schools would be impossible to control, it should not count with much supervision, and info literacy from the side of the students was unknown. With that in mind, the number of tasks considered was half of the max supported by Maze: five tasks. The five tasks evaluated navigation, controls, and functionalities:

- Task 1 - Begin Math Class

- Task 2 - Start class, Answer Question and Continue

- Task 3 - Open the Notes

- Task 4 - See the History Classes that are in the Library

- Task 5 - Share and Send Classes

Students were also asked how much they liked the experience at the end of the five tasks, using a smiley scale.

\subsubsection{Results}

\subsubsection{Task 1}

The first task required the student to click on the math class after identifying the correct button. The task difficulty was elementary, and the student only needed one click to perform it. Out of the ten students, only one deviated from the usual pattern by not identifying the Math class and moving to the other tab before clicking on the right button. With this in mind, the average duration 
for this task rounded to 16.3 seconds. The students heatmap corresponding to the user journey that required fewer screens to navigate and solve the task 1 is represented in figure 6.11 with the clicks done by participants.

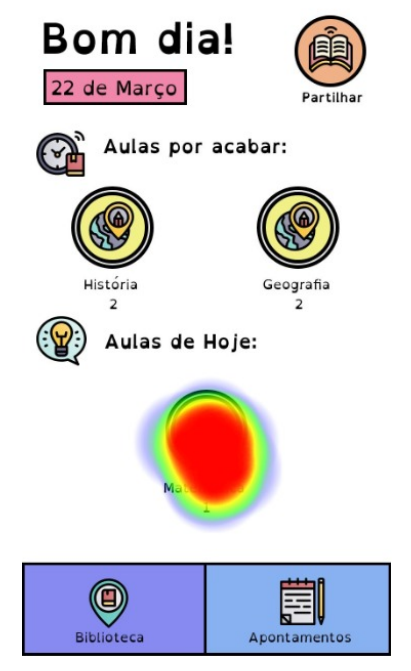

Figure 6.11: Task 1 Direct Path Heatmap

\subsubsection{Task 2}

Task two comes as a continuation of the first task that corresponds to the continuation after opening the math class: can a student use the controls correctly to start a class, select the correct option of a multiple choice question and submit the result? The answer is yes. Accompanied by a simple sum question, the students had to begin the class, select the correct option, and submit the answer. Every student performed the task correctly, without misclicks, in an average duration of 8.7 seconds. The students heatmap corresponding to the user journey that required fewer screens to navigate and solve the task 2 is represented in figure 6.12 with the clicks done by participants. 

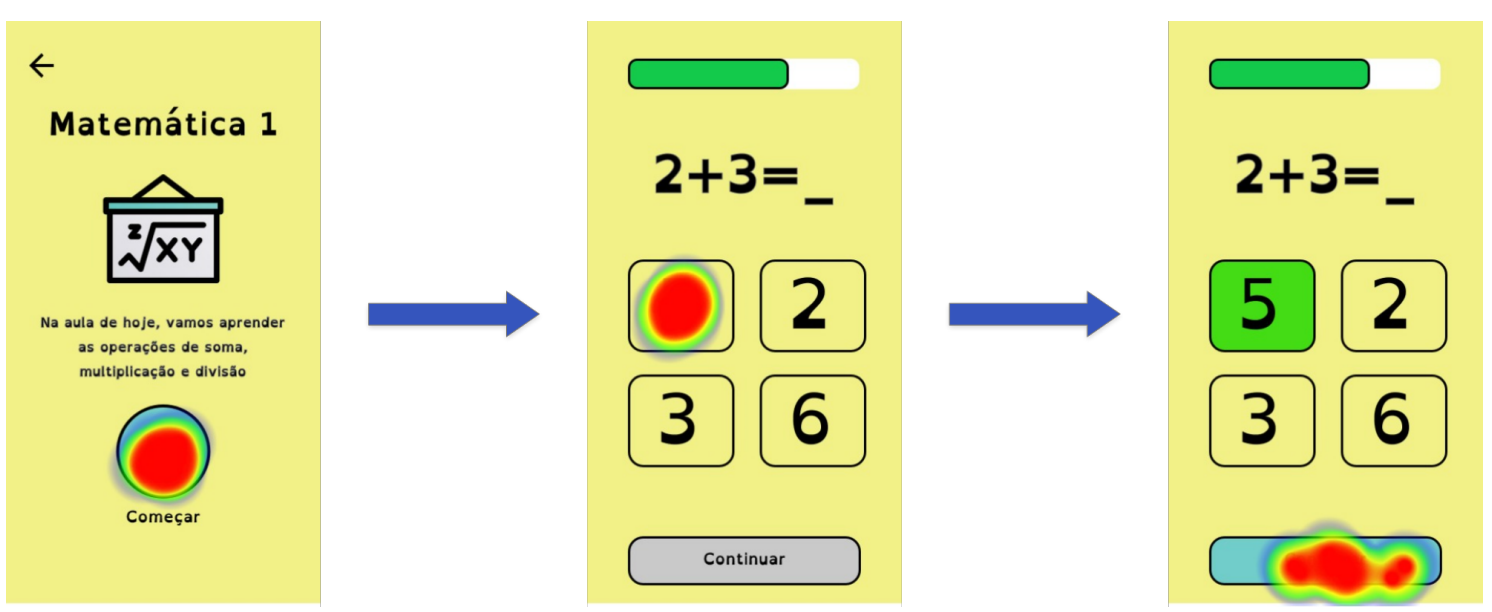

Figure 6.12: Task 2 Direct Path Heatmap

\subsubsection{Task 3}

This task only required the student to navigate to the notes tab, located on the navbar in the main menu. Unfamiliarly, only half the students got it correctly done without misclicking. The other half of the students got disoriented and repeated the same activity performed in the last task before clicking on the notes tab. Even though some students did not achieve the task directly, all completed it in the end, in an average duration of 12.5 seconds. The students heatmap corresponding to the user journey that required fewer screens to navigate and solve the task 3 is represented in figure 6.13 with the clicks done by participants.

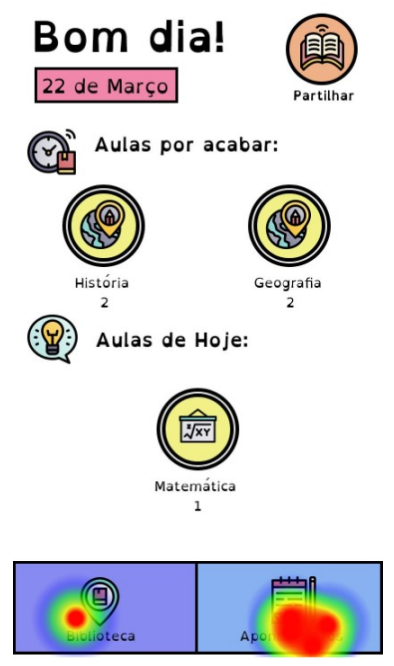

Figure 6.13: Task 3 Direct Path Heatmap 


\subsubsection{Task 4}

Task 4 also only requires one click, but it is essential to test if the students can click in the UI text element to expand. If some classes are completed, and students wanted to revisit them, clicking on a particular theme shows the theme's classes underneath it. Every participant got it right without misclicks and in an average time duration of 6 seconds. The students heatmap corresponding to the user journey that required fewer screens to navigate and solve the task 4 is represented in figure 6.14 with the clicks done by participants.
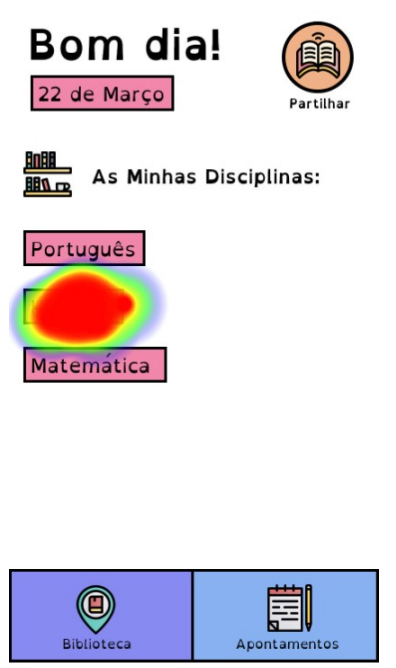

Figure 6.14: Task 4 Direct Path Heatmap

\subsubsection{Task 5}

The last task tests one of the principal components of this work: the ability to share classes inside the app. This task required the participants to click on the share button, and then in the share menu, click on the send button. Unfortunately, on Maze, the last screen programmed to show up in this task was the same as the second task, and two students could not complete the task correctly due to this inconvenience, even though Maze marked the task as completed. With that in mind, the eight valid tests were completed without misclicks in a time average of 7.2 seconds. The students heatmap corresponding to the user journey that required fewer screens to navigate and solve the task 5 is represented in figure 6.15 with the clicks done by participants. 


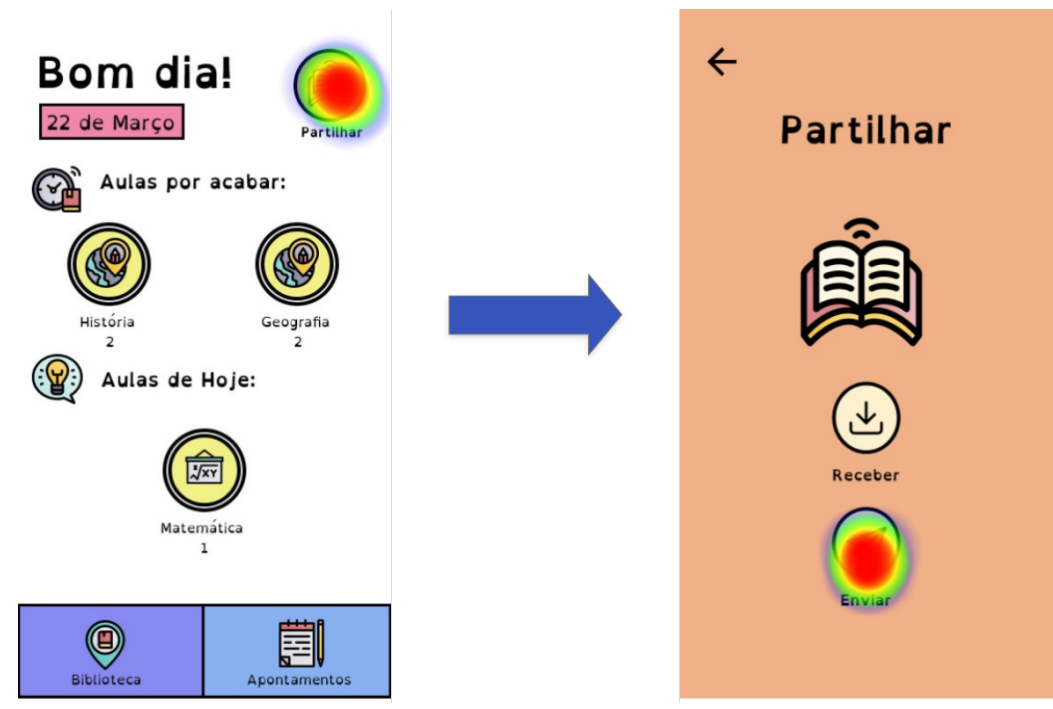

Figure 6.15: Task 5 Direct Path Heatmap

\subsubsection{Feedback}

At the end of the five tasks, the participants were asked how much they liked the experience on a smiley scale with five different faces. All of the students gave 5 out of 5 to this experience. Even though there was no direct contact with the students, their teacher expressed that they liked it a lot and even wanted to repeat the experiment.

\subsubsection{Conclusions}

Table 6.2 shows the student's average time to complete each task. Overall, the tasks where students spent most time were not the ones that needed more clicks but those involving navigational items, like the navbar. The short times can be verified due to the most succinct nature of the tasks and not having any delay due to being a direct test. In addition, all the tasks were performed on the same device and in the same location, the classroom. All the tests were direct since the network conditions were stable. 


\begin{tabular}{|l|l|}
\hline Test Type & Direct Test \\
\hline Number of Participants & 10 \\
\hline Task 1 Average Time (s) & 16.3 \\
\hline Task 2 Average Time (s) & 8.7 \\
\hline Task 3 Average Time (s) & 12.5 \\
\hline Task 4 Average Time (s) & 6 \\
\hline Task 5 Average Time (s) & 7.2 \\
\hline Total Average Time (s) & 60.7 \\
\hline Average Feedback Score & 5.0 \\
\hline
\end{tabular}

Table 6.2: Students App Results Overview 


\section{Chapter 7}

\section{Conclusions and Future Work}

Education will continuously evolve, accompanied by the digital and technological advancement that occurs every day. Students can learn through almost any digital device with access to multiple educative resources with just some simple clicks. Technology evolved to the point where people can learn where they want and when they want. Even though this statement is true, one crucial factor makes a heavy difference: to access that educational content, students and teachers require regular access to the internet.

Unfortunately, the current digital and technological services used in education are not ready for scenarios where the learners and instructors don't have sufficient internet conditions. In locations where this happens, when there is no possibility to have presential education, the connection between students and teachers is lost. Suppose the connection is lost for a continued time. In that case, students can lose interest in their studies and quit them more quickly, having a negative impact on their future and communities. Even though the internet makes the learning experience more complete, mobile devices and technologies can also make learning possible in places with no internet access.

\subsection{Main Results}

In this dissertation, the proposal done relied on a digital solution that does not depend on internet access to bring the learning experience to student's devices and homes. There was a need to contact and empathize with people from countries where the lack of internet access made the educational process impossible during the Covid 19 pandemic. Various contact attempts resulted in interesting conclusions and opinions regarding this solution. With that in mind, the prototypes were planned and developed to test with those same teachers and students using the suitable methodology. The results concluded that there is a need for a solution of this nature and that the solution evaluated was easy to use and provided a pleasurable experience.

The principal contributions summed are:

- Proposal of the Teachers and Students app ecosystem that is designed to bring education to places where internet access is minimal 
- Communication made with teachers from locations most affected by this issue to understand their needs, opinions, and suggestions for this solution.

- Application of the requirements lifted in a solution designed having in mind some accessibility needs

- Validation of the resulting prototype using a methodology that allowed the tests to occur in different scenarios based on the existing challenging conditions.

\subsection{Future Goals}

Future work relies primarily on testing what task formats work better, not only regarding the process behind their creation, since the inputs should be accessible for the teachers to use the tool, but also regarding what format students prefer and why. This work would require to schedule and experiment with the students and teachers involved and more. The methodology applied to approach and contact the test participants might also be improved regarding the tools used. With this study done then, the apps can be developed based on the conclusions taken so that the project can go live. 
Appendix A

\section{Personas}




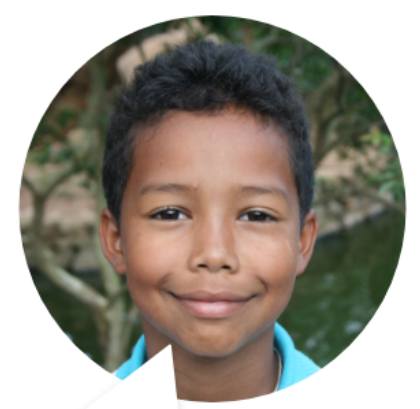

"I love my parents. When I grow up I want to be like them"

NAME: Márcio

JOB: 5th Grade Student

AGE: 11

FAMILY: Only Child

GENDER: MALE

LOCATION: Brazil

PERSONALITY
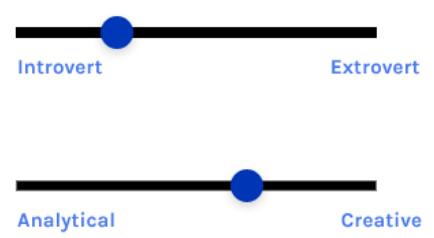

GOALS

- Dreams of being a firefighter or an engineer

- Wants to play soccer

or basketball in a

regional team

- Have a pet dog
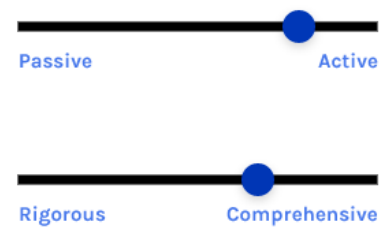

FRUSTRATIONS

- Lacks the motivation to study sometimes

- Doesn't like some of his teachers

- Has a short attention span

-Has dyslexia

\section{BIO}

Márcio was born in Piaui, Brazil. He is the only son of a loving couple. Márcio prefers playing outside with his friends to being inside the classroom. He usually gets decent grades, but sometimes he fails in some school subjects like maths and history. He usually studies with support from his father at home, which helps him do homework and prepare for evaluations. When his father doesn't have time to supervise him due to a more busy schedule at work, Márcio tends to skip homework. 


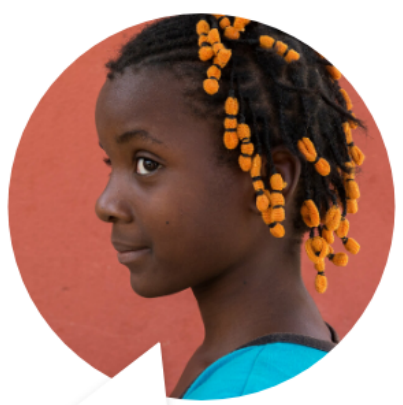

"When I grow up I want to heal people."

\section{PERSONALITY}
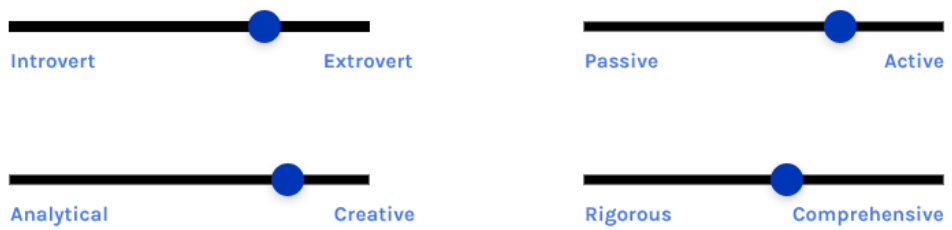

\section{GOALS}

FRUSTRATIONS

- Go to High School to study Sciences

- Sees herself as a

doctor or nurse in the

future

- Have Good Grades

- Spend more time with her little brother

- Lacks extra study material

- Doesn't have a study companion

- Is slightly color blinded

\section{BIO}

Born in Benguela, Angola, Luzia is the daughter of a couple of farmers. She loves the time she spends at school with her friends and is one of the best students in class. She has a little brother and spends part of her time at home helping her mother raising him. Even though she has excellent grades usually, she would love to have some company to study with her at home, like when she is in class. 


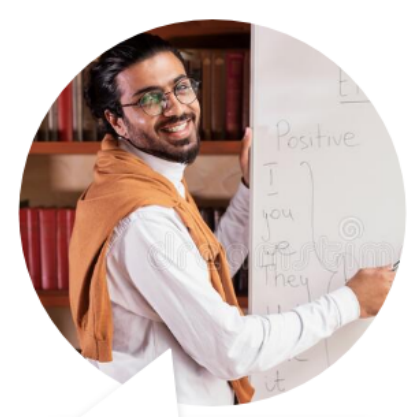

"I want to help each and every student to reach their dreams"

NAME: Adesh

PERSONALITY
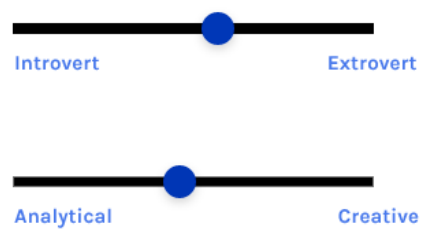

GOALS

-Be a good

professional

-Be a good father to his children

-Experiment giving classes to different school years
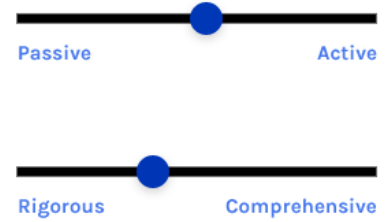

FRUSTRATIONS

-Have a better salary

-Doesn't have a lot of time to have a hobby

-Has an elbow

problem from a bike accident

\section{BIO}

Adesh is from Patna, India. Even though he spent all his childhood in Bengaluru, after meeting his wife, Amita, he decided to go live in Patna. He with her to Patna to create a family and establish his career. Adesh teaches English at high school, giving extra classes to students who need more school support. Having three kids at home, he barely has spare time for himself. The time he wanted to spend doing some sport or hobby is spent planning and preparing all his classes. 


\section{Appendix B}

\section{Intreview Script}

\section{B.1 English Version}

\section{Good afternoon!}

My name is Antero, and I'm preparing the interface of a teaching application that works offline. I'm doing this interview to understand better the reality of teaching in areas where internet access is more complicated and see how this application can improve this situation. All data from the interview will be handled with the greatest security and clarity, and if you see that it is necessary, you can leave the interview at any time. Would it be possible to record the interview?

First, I would like to get to know you better, especially where you are from and what your age group is.

Do you own a smartphone? And internet access?

What levels of education do you usually teach? What age groups do you teach, and what subjects do you teach? How long have you been teaching?

Do you use technology at work? And what kind of technologies do you usually use? Any technology you would like to use?

Is there internet access at the school where you teach?

What is the format you use to teach classes? What kind of exercises do you usually provide students with? Do you usually schedule homework?

We are studying an application that works in locations where internet access is limited. This way, students can learn at home even when they don't have an internet connection. Students can solve exercises and learn the material taught by their teachers by sharing the content with colleagues. They can also see their path to stay motivated to learn autonomously.

What do you think about the idea of this application? Why?

What do you think could be interesting to include in the application? What could be done about this?

Any questions you have, please feel free! Thanks for participating in the interview! If you remember any more questions, you can contact us via email or by phone. 


\section{B.2 Portuguese Version}

\section{Boa Tarde!}

Chamo-me Antero e estou a preparar o interface de uma aplicação de ensino que funciona offline. Estou a fazer esta entrevista de modo a perceber melhor a realidade do ensino em zonas onde o acesso á internet é mais complicado e ver de que maneira esta aplicação pode vir a melhor essa situação. Todos os dados da entrevista serão lidados com a maior segurança e clareza e se vir que é necessário pode abandonar a entrevista a qualquer momento. Seria possivel gravar a entrevista? Para começar, primeiro gostaria de o/a conhecer melhor, especialmente de onde é e qual é a sua faixa etária.

Possui um smartphone? E acesso á internet?

Quais são os niveis de ensino que costuma ensinar? A que faixas etárias costuma ensinar e que disciplinas? Há quanto tempo leciona?

Costuma usar tecnologia no trabalho? E que tipo de tecnologias costuma usar? Alguma tecnologia que gostaria de usar?

Existe acesso a internet na escola onde leciona?

Qual é o formato com que costuma dar as aulas? Que tipo de exercicios costuma fornecer aos alunos? Costuma marcar trabalho de casa?

Estamos a estudar uma aplicação que funciona em localizações onde o acesso a internet é limitado.

Desta maneira os alunos podem aprender em casa mesmo quando não possuem conexão á internet. Os alunos podem resolver exercicios e aprender a materia lecionada pelos seus professores partilhando o conteudo entre colegas. Podem também ver o seu percurso, de modo a maneterem-se motivados a aprender autonomamente.

O que é que acha da ideia desta aplicação? Porquê?

O que é que acha que podia ser intersessante incluir na aplicação? O que é que podia ser feito para isso?

Quaisquer questões que queira colocar por favor esteja a vontade! Obrigado por participar na entrevista! Se entretanto se lembrar de mais alguma questão pode contactar-nos através do email ou por telefone. 


\section{Appendix C}

\section{Lesson Content Wireframes}
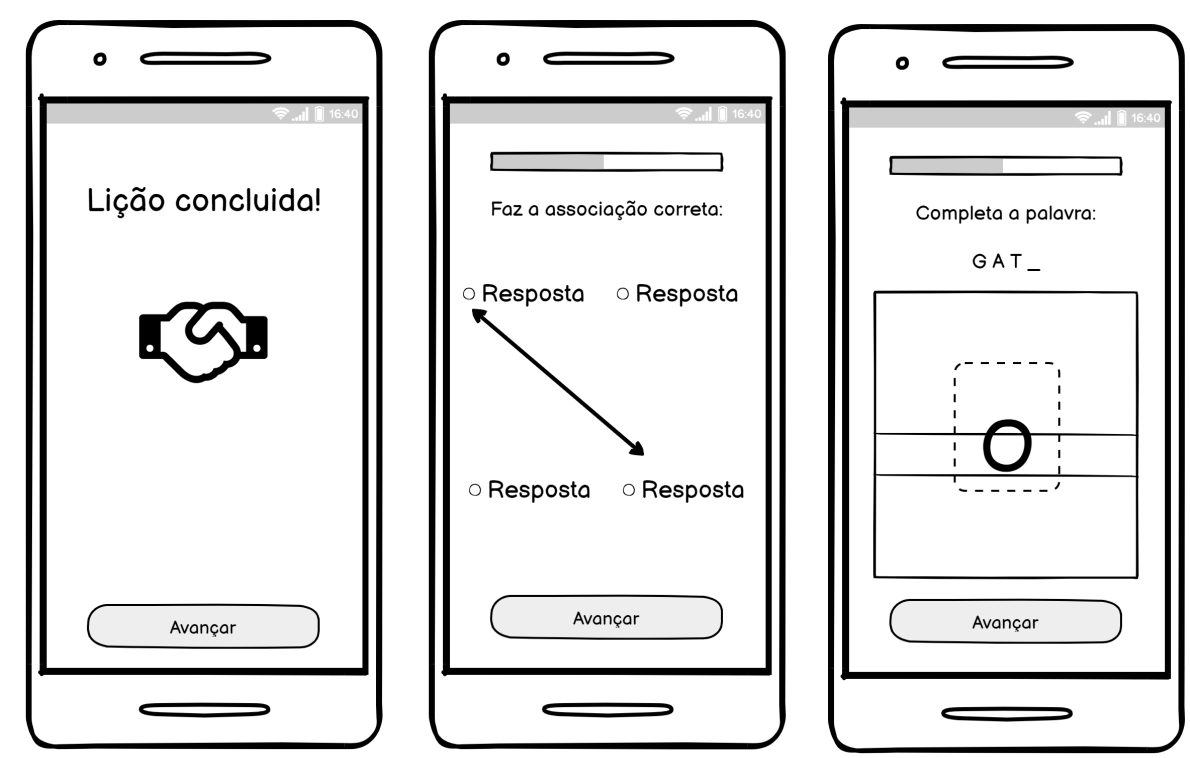

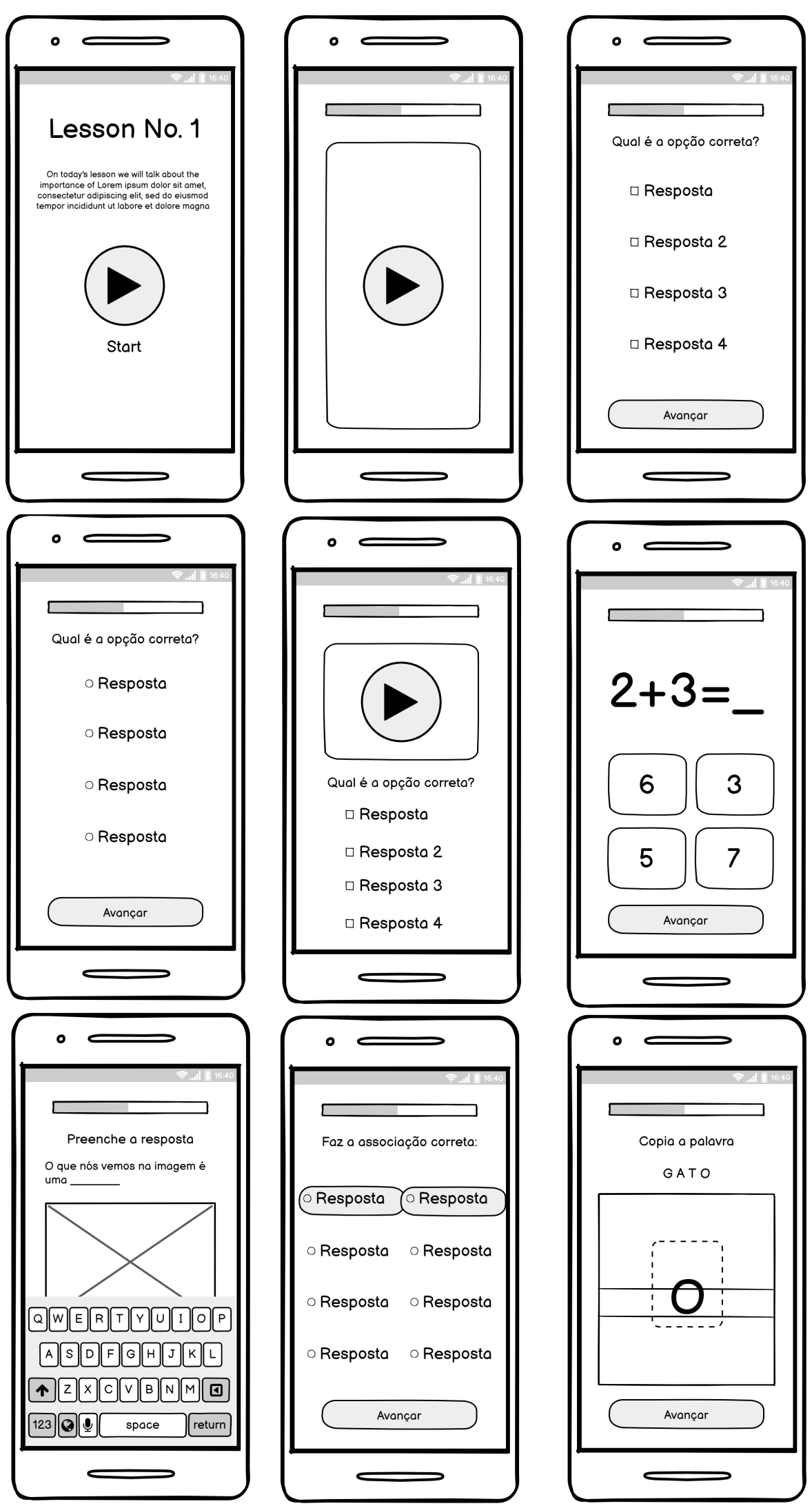


\title{
Appendix D
}

\section{Teachers App Designs}

\author{
D.1 Homepage
}

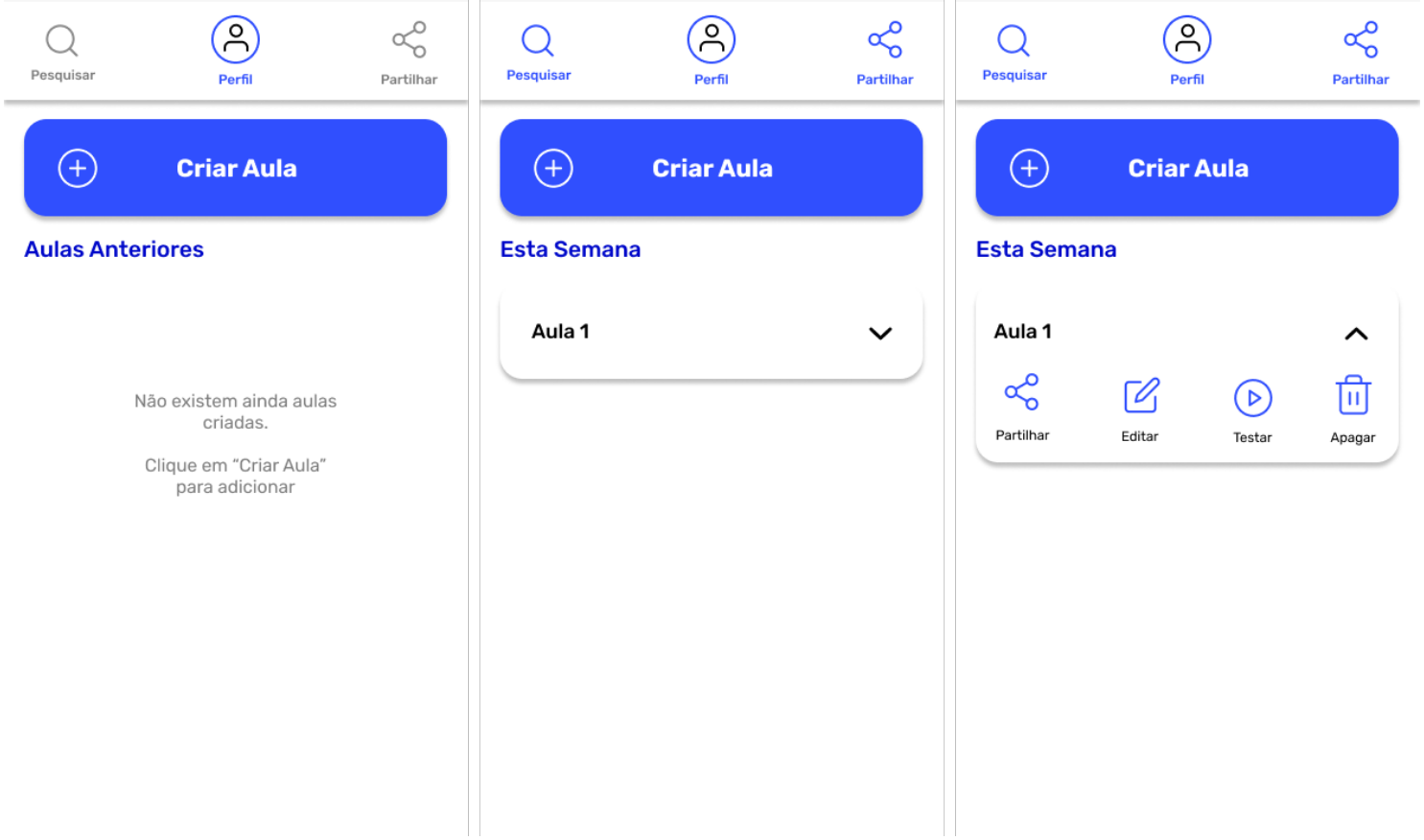




\section{D.2 Lesson Screens}

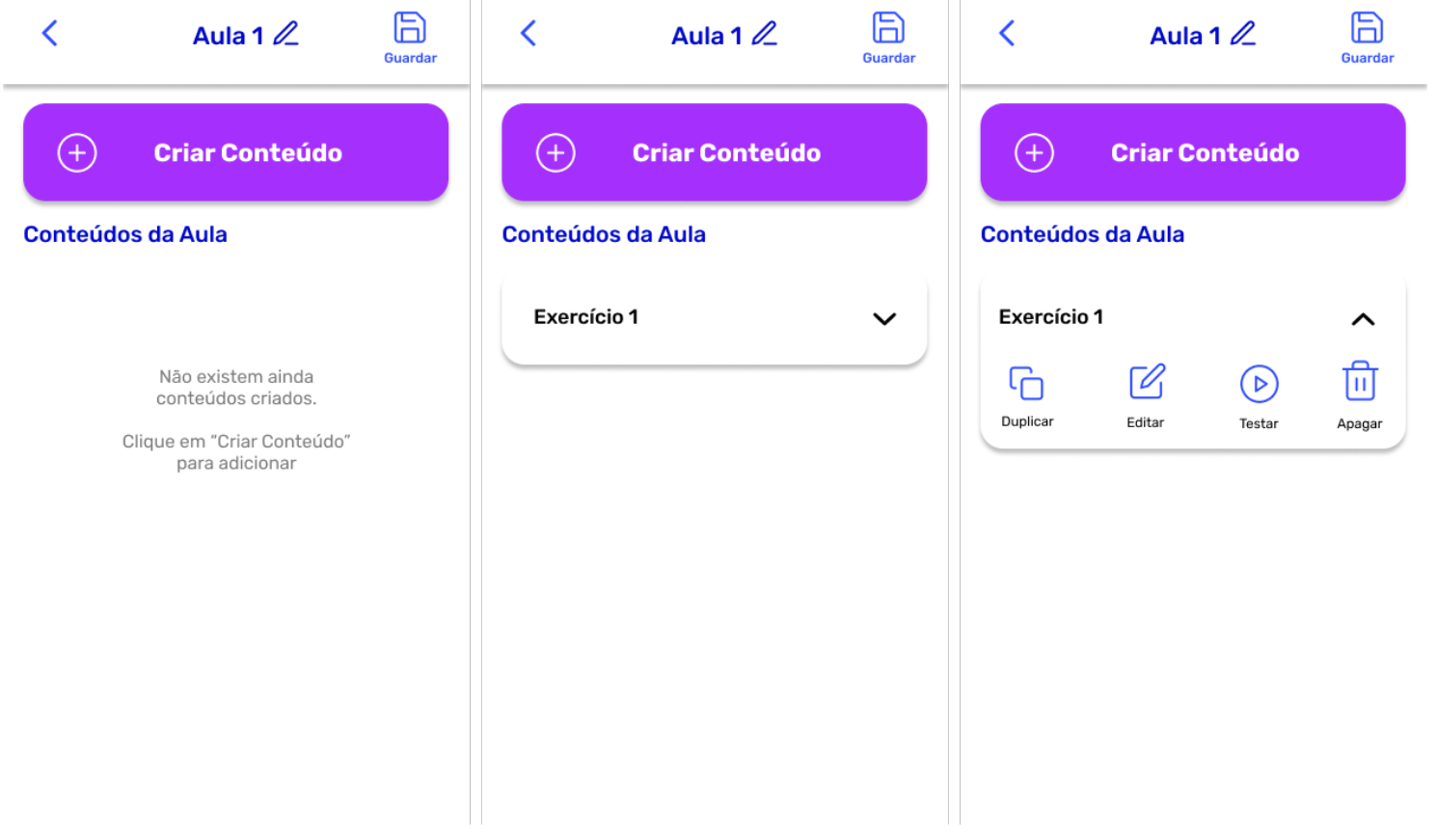

\section{D.3 Profile Screens}

$$
<
$$

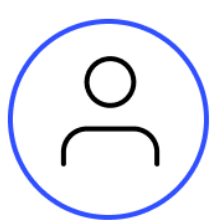

Carlos Gomes

Prof. Matemática

Escola do Maio

Aulas Partilhadas

Não existem ainda aulas partilhadas.

No menu principal

clique no botăo

Partilhar a

Editar

$<$

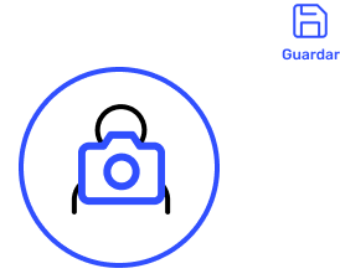

Nome

Carlos Gomes

Disciplina

Matemática

Escola

Escola do Maio 


\section{D.4 Share Screens}

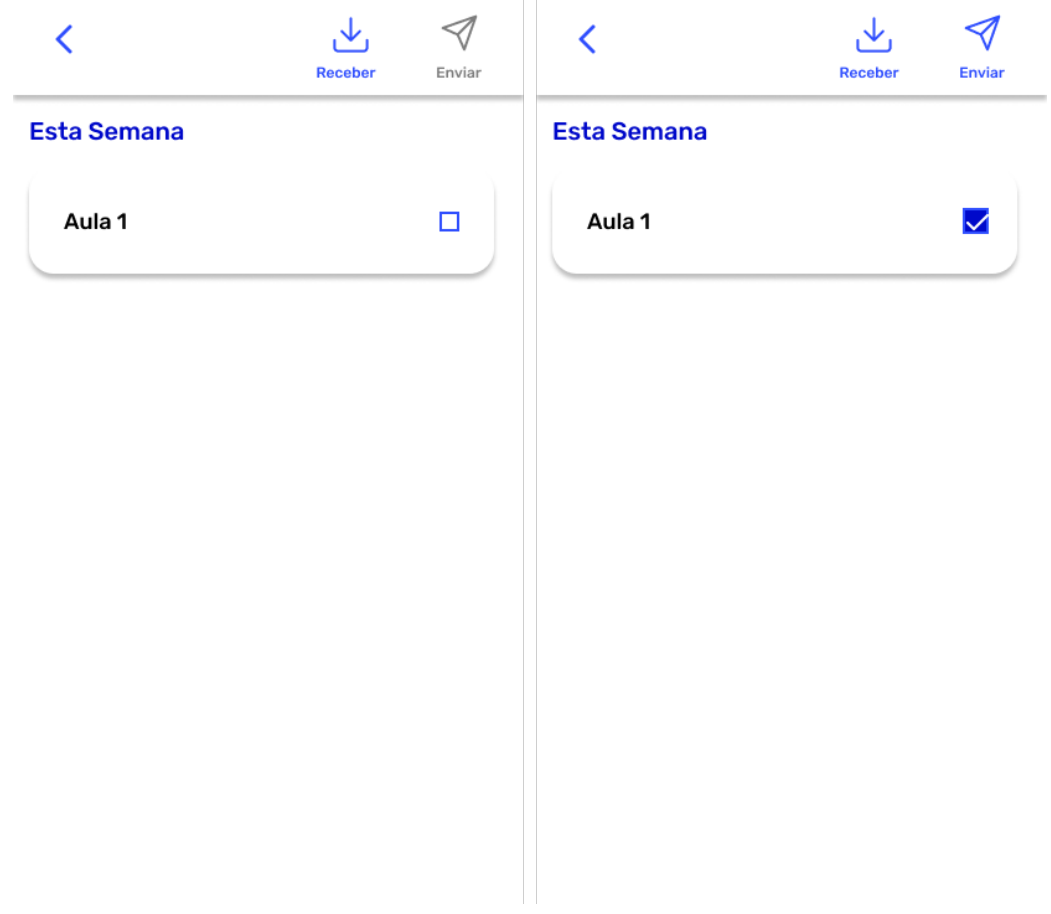

\section{D.5 Exercise Screens}

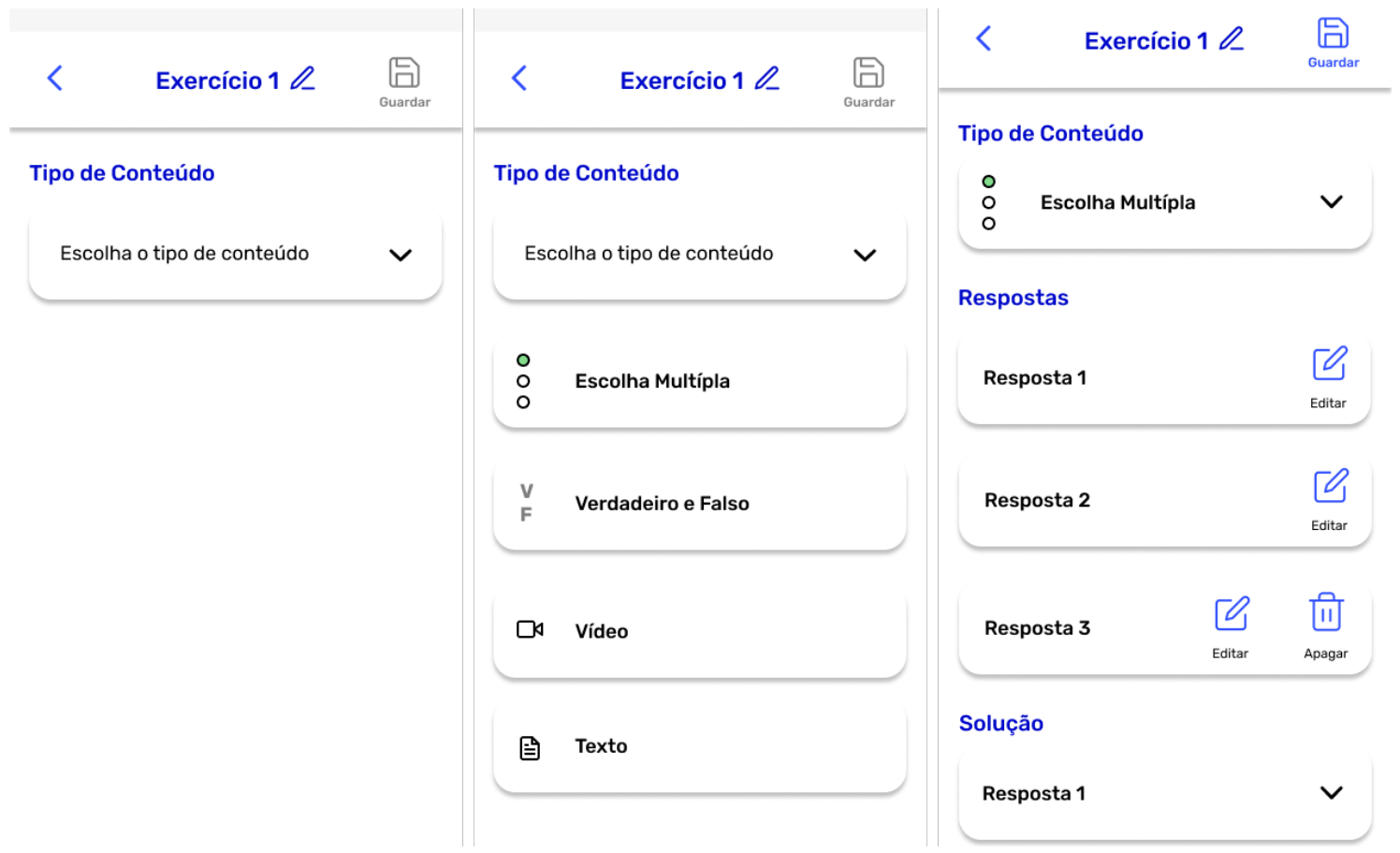




\section{D.6 Solution Selection Screens}

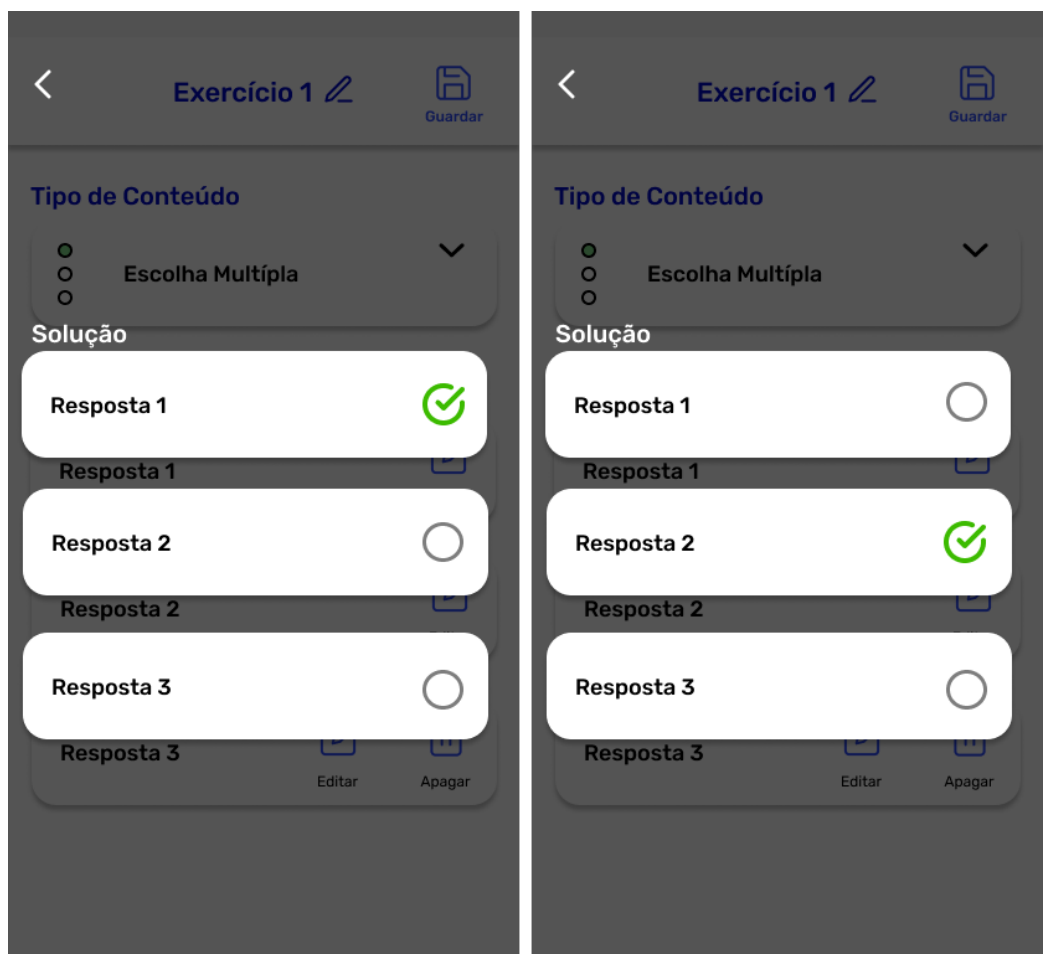




\title{
Appendix E
}

\section{Students App Designs}

\author{
E.1 Main Screens
}

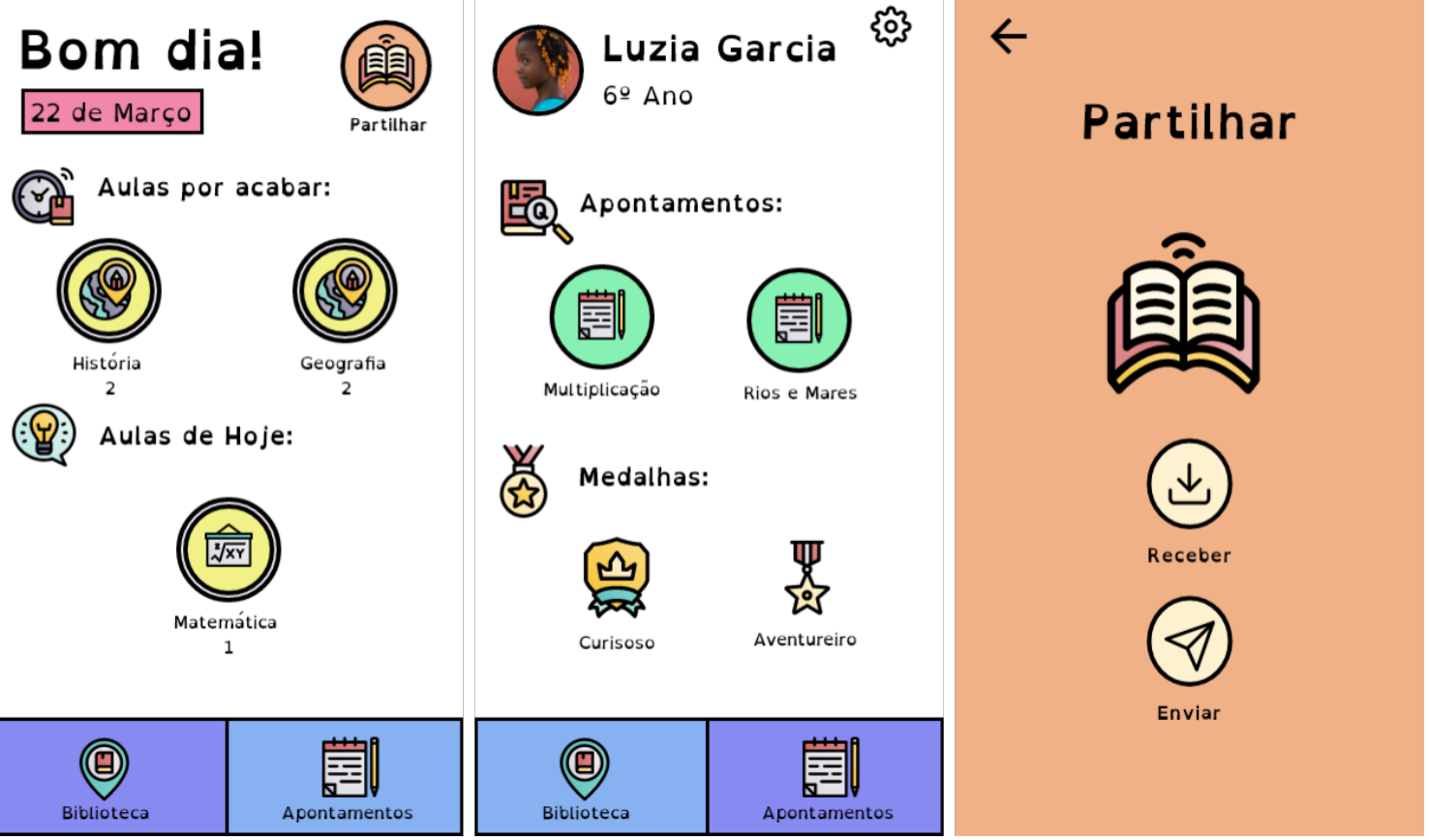




\section{E.2 Library Screens}

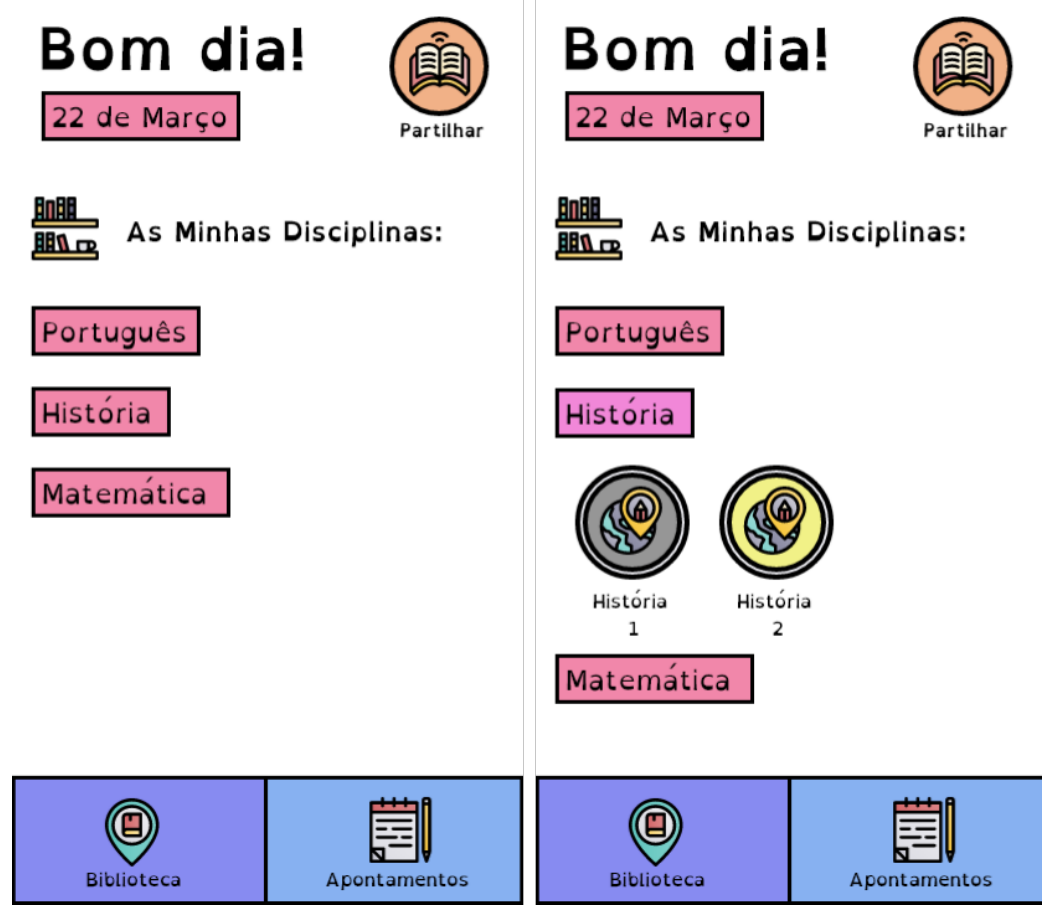

\section{E.3 Lesson Screens}

$$
\leftarrow
$$

Matemática 1

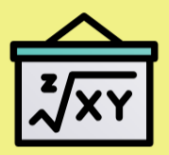

$\mathrm{Na}$ aula de hoje, vamos aprender as operaçőes de soma, multiplicação e divisăo

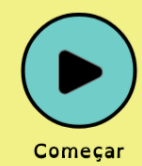

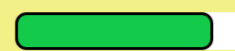

$2+3=$
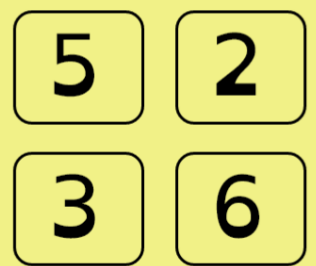

Continuar

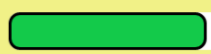

$2+3=$
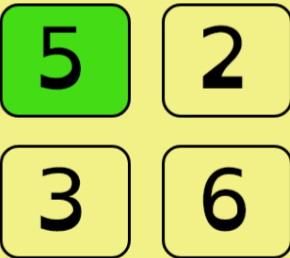

Continuar 


\section{References}

[1] Rashid Aderinoye, K. Ojokheta, and A. Olojede. Integrating mobile learning into nomadic education programme in nigeria: Issues and perspectives. International Review of Research in Open and Distance Learning, 8, 062007.

[2] Mohamed Ally. Mobile learning: Transforming the delivery of education and training. Athabasca University Press, 2009.

[3] Tanya Elias. Universal instructional design principles for mobile learning. International Review of Research in Open and Distance Learning, 12, 022011.

[4] Merryl Ford and Teemu Leinonen. Mobiled-mobile tools and services platform for formal and informal learning. Mobile learning: Transforming the delivery of education and training, pages 195-214, 2009.

[5] Bharat Fozdar and Lalita S Kumar. Mobile learning and student retention. International Review of Research in Open and Distance Learning, 8, 062007.

[6] Susan Gasson. Human-centered vs. user-centered approaches to information system design. Journal of Information Technology Theory and Application (JITTA), 5(2):5, 2003.

[7] Deborah Hix and H Rex Hartson. Developing user interfaces: ensuring usability through product \& process. John Wiley \& Sons, Inc., 1993.

[8] Kolibri. About kolibri. https://learningequality.org/kolibri/, 2020.

[9] Marguerite Koole. A Model for Framing Mobile Learning. 032009.

[10] Jonathan Lazar, Jinjuan Heidi Feng, and Harry Hochheiser. Research methods in humancomputer interaction. Morgan Kaufmann, 2017.

[11] Cynthia B Lloyd, Monica Grant, and Amanda Ritchie. Gender differences in time use among adolescents in developing countries: Implications of rising school enrollment rates. Journal of Research on Adolescence, 18(1):99-120, 2008.

[12] Ustad Mobile. About ustad mobile. https://www.ustadmobile.com/lms/, 2020.

[13] Don Norman. The design of everyday things: Revised and expanded edition. Basic books, 2013.

[14] Rumie. About rumie. https://learn.rumie.org/jR, 2020.

[15] Helen Sharp, Yvonne Rogers, and Jennifer Preece. Interaction Design. Beyond HumanComputer Interaction. 012007. 
[16] Mike Sharples. The design of personal mobile technologies for lifelong learning. Computers Education, 34:177-193, 042000.

[17] Mike Sharples, Dan Corlett, and Oliver Westmancott. The design and implementation of a mobile learning resource. Personal and Ubiquitous Computing, 6:220-234, 052002.

[18] Debbie Stone, Caroline Jarrett, Mark Woodroffe, and Shailey Minocha. User interface design and evaluation. Elsevier, 2005.

[19] John Traxler. Defining mobile learning. In IADIS International Conference Mobile Learning, pages 261-266, 2005.

[20] UNESCO. Distance learning solutions. https://en.unesco.org/covid19/ educationresponse/solutions, 2020.

[21] Niall Winters. What is mobile learning. Big issues in mobile learning, pages 7-11, 2007. 